
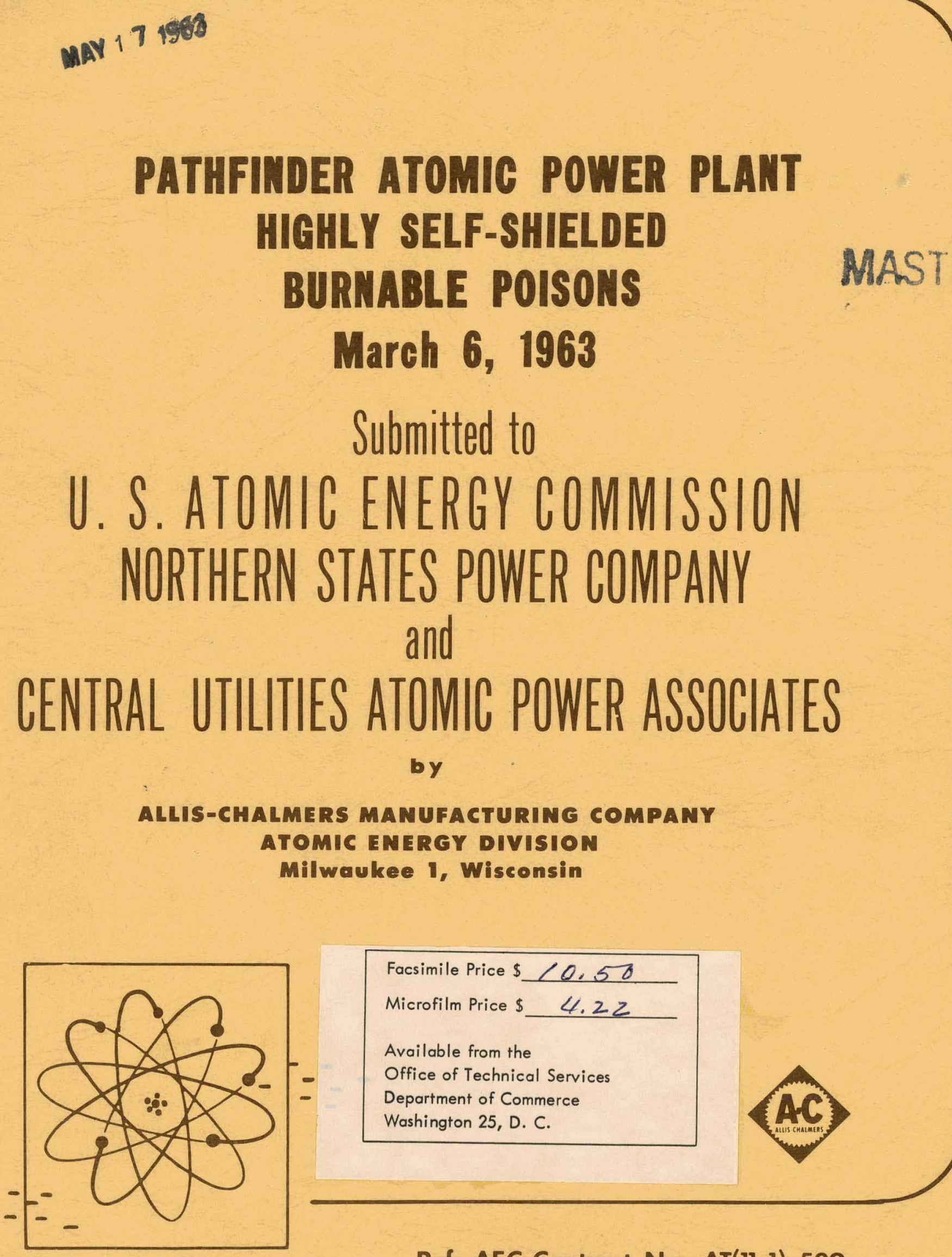

Facsimile Price $\$<0,50$

Microfilm Price $\$ 4.22$

Available from the

Office of Technical Services

Department of Commerce

Washington 25, D. C. 


\section{DISCLAIMER}

This report was prepared as an account of work sponsored by an agency of the United States Government. Neither the United States Government nor any agency Thereof, nor any of their employees, makes any warranty, express or implied, or assumes any legal liability or responsibility for the accuracy, completeness, or usefulness of any information, apparatus, product, or process disclosed, or represents that its use would not infringe privately owned rights. Reference herein to any specific commercial product, process, or service by trade name, trademark, manufacturer, or otherwise does not necessarily constitute or imply its endorsement, recommendation, or favoring by the United States Government or any agency thereof. The views and opinions of authors expressed herein do not necessarily state or reflect those of the United States Government or any agency thereof. 


\section{DISCLAIMER}

Portions of this document may be illegible in electronic image products. Images are produced from the best available original document. 


\section{LEGAL NOTICE}

This report was prepared as an account of Government sponsored work. Neither the United States, nor the Commission, nor Allis-Chalmers Manufacturing Company, nor any person acting on behalf of the Commission or Allis-Chalmers Manufacturing Company :

A. Makes any warranty or representation to others, expressed or implied, with respect to the accuracy, completeness, or usefulness of the information contained in this report, or that the use of any information, apparatus, method, or process disclosed in this report may not infringe privately owned rights; or

B. Assumes any liabilities to others with respect to the use of, or for damages resulting from the use of any information, apparatus, method, or process disclosed in this report.

As used in the above, 'person acting on behalf of the Commission or Allis-Chalmers Manufacturing Company' includes any employe or contractor of the Commission, or Allis-Chalmers Manufacturing Company or employe of such contractor, to the extent that such employe or contractor of the Commission, or Allis-Chalmers Manufacturing Company or employe of such contractor prepares, disseminates, or provides access to, any information pursuant to his employment or contract with the Commission or Allis-Chalmers Manufacturing Company or his employment with such contractor. 


\title{
HIGHLY SELF-SHIELDED BURNABLE POISONS
}

by R. J. Holl

\author{
U. S. ATOMIC ENERGY COMMISSION \\ NORTHERN STATES POWER COMPANY \\ and \\ CENTRAL UTILITIES ATOMIC POWER ASSOCIATES
}

by

ALLIS-CHALMERS MANUFACTURING COMPANY.

Under

Agreement datod 2nd Day of May 1957, as Amended

between

Allis-Chhalmers Mfg. Co. \& Northern States Power Co.

under

AEC Contract No. AT(i1-1)-589

Morch 6, 1963

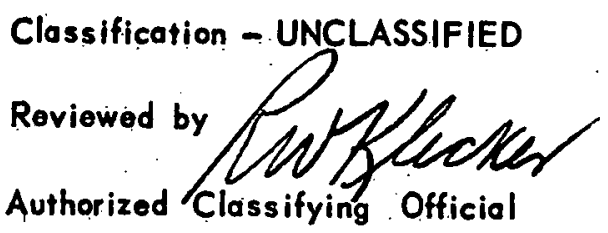

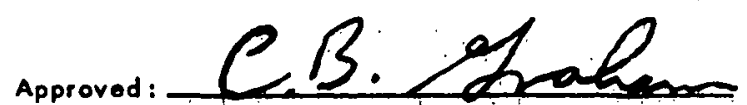

C. B. Grahom

Monager

Nuclear Power Dept.. Grnondalo

ALLIS-CHALMERS MANUFACTURING COMPANY ATOMIC ENERGY DIVISIOON MILWAUKEE I, WISCONSIN

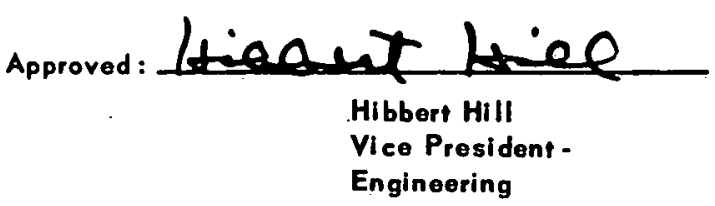

NORTHERN STATES POWER COMPANY

15 SOUTH FIFTH STREET

MINNEAPOLIS 2, MINNESOTA 
Summary Report

PATHFINDER ATOMIC POWER PLANT

HIGHLY SELF-SHIELDED BURNABLE POISONS

\section{Distribution}

USAEC, Chirago Operations Otfice--

9800 South Cass Avenue, Argonne, Illino is

USAEC, Division of Reactor Deve lopment-Washington 25, D. C.

USAEC, OTIE--

Oak Ridge, Tennessee

OFFSET MASTER p IỤS

20

Nor thern States Power Company and CUAPA

Allis-Chalmers Manufacturing Company 


\section{FOREWORD}

One of a series of reports on research and development, this particular report deals with highly self-shielded burnable poisons as investigated under section 1.1 of the Pathfinder pre-construction R\&D program.

The Pathfinder plant will be located at a site near sioux Falls, South Dakota and is scheduled for operation in 1963. Owners and operators of the plant will be the Northern States Power Company of Minneapolis, Minnesota. Allis-Chalmers is performing the research, development, and design as well as being responsible for plant construction.

The U.S. Atomic Energy Commission, through Contract No. AT(11-1)-589 with Northern States Power Company, and Central Utilities Atomic Power Associates (CUAPA) are sponsors of the research and development program. The plant's reactor will be of the Controlled Recirculation Boiling Reactor type with Nuclear Superheater, 
TABLE OF CONTENIS

Section

Page

FOREWORD . . . . . . . . . . . . 11

LIST OF TABLES . . . . . . . . . . v

LIST OF ILLUSTRATIONS . . . . . . . . v1

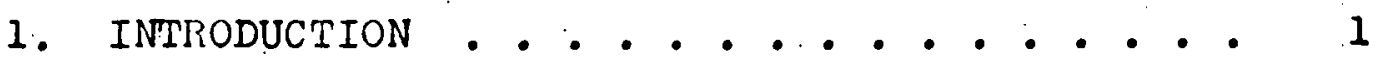

1.1 Ideallzed Depletion Characteristics of
Highly Self-Shlelded Burnable Polsons . 4

1.2 Scope of Study . . . . . . . . 7

2. REACTIVITY REQUIREMENTS . . . . . . . . 11

3. SELECTION OF BURNABLE POISON MATERIAL . . . 21

4. GADOLINIUM PROPERTIES .............. 24

4.1 Mater1al Propert1es. ....... 24

4.2 Isotopic Cross Sections ....... 24

4.3 Polson Resldue . . . . . . . . 27

5. SPATIAL REPRESENTATION ......... 31

5.1 Self-Sh1elding Factor For the D1sk . . 31

5.2 The Effect on the External Flux . . . 33

6. NEUTKON SPECTRUM EFFECTS . . . . . . 38

6.1 Average Thermal Cross Sections .... 38

6.2 Temperature Coefficient ...... 41

7. EFFECTIVE POISON CROSS SECTIONS . . . . . 51

8. DEPLETION EFFECTS . . . . . . . . . 59

8.1 Spat1ally Dependent Depletion .... 59 
8.2 Depletion of D18k Samples . . . . 60

9. EXPERIMENTAL PROORAM ......... 68

9.1 objectives and scope........ 68

9.2 Design of Reactivity Experiments . . . 69

9.3 Design of Irradiation Experiments . . 73

9.4 Preparation or Samples . . . . . . 75

9.5 Reactivity Messurements ....... 81

9.6 Data Reduction ......... 83

9.7 Results . . . . . . . . . 102

10. CONCLUSIONS . . . . . . . . . . 122

BIBLIOORAPHY ............ 124 


\section{LIST OF TABLES}

Table

Page

2.1 Uranıum and Plutonlum Isotop1c Parameters . . 16

2.2 Urantum and Plutonlum Cross Sections ..... 17

3.1: Elements Having Isotopic Cross Sections

Greater thán Boron-10........... 22

4.1 Material Properties of Gadolinium and

Gadollnia . . . . . . . . . . . . 24

4.2 Gadol1nium Isotop1c Cross Sections . . . . 25

4.3. Thermal Resonance Parameters for Gadolinium - 26

6.1 Gadolinlum Thermal Cross Sections (barns) - 39

6.2 Spectrum Averaged Absorption Rates . . . . 41

7.1 Calculated and Measured Self-Shlelding

Factors :. . . . ......... . . . 52

9.1 Summary of Samples .. . . . . . . . 80

9.2 Periods and Reactivities for Danger Coefficient Experiments . . . . . . . . . 86

9.3 Effective Thermal Cross Sections . . . . . 94

9.4 Cal1bration of Flux Monitor Wire . . . . . 99

9.5 Self-Shielding of Irradiated Samples . . . 101

9.6 Sample Irradiation . . . . . . . . 102

9.7 Self-Sh1elding of Gadolintum D1sks . . . . 109 


\section{LIST OF ILLUSTRATIONS}

Plgure

Page

1.1 Burnout Characteristlcs of Highly Self-

Shlelded Polsons ............ 10

2.1. Effective Cross Sections for Critical1ty .. 19

2.2. Polson Cross Section for Criticallty. ... 20

4.1 Gadolinium Isotop1c Cross Sections .... 29

4.2 Gadolinium Total cross Section ..... 30

5.1 Self-Shlelding Factor for Slabs . . . . 37

6.1 Maxwelilan Distributions ......... 44

6.2 Relative Absorption Rate for Slabs . . . . 45

6.3 Relative Absorption Rate Versus Th1ckness . 46

6.4 Relative Absorption Rate Versus Neutron

Temperature ............. 4 47

6.5. Changes in Absorption Rate with Temperature. 48

6.6: Temperature Coefficients ....... 49

6.7 Reactiv1ty Defect . . . . . . . . 50

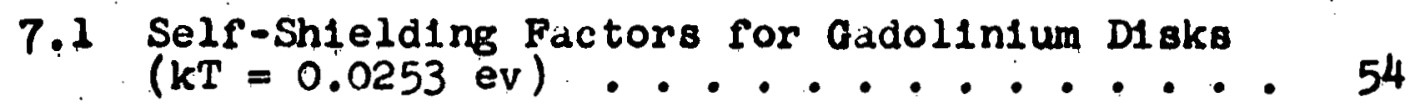

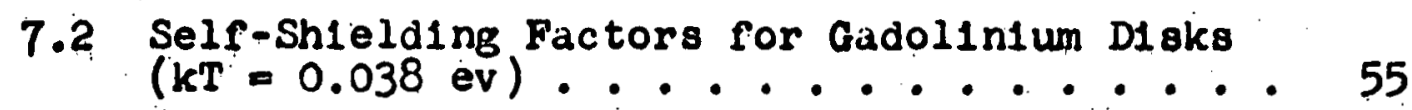

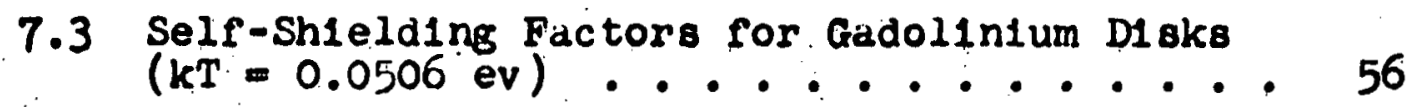

7.4 Measured and Calculated Self-Shlelding Factors ................. 57

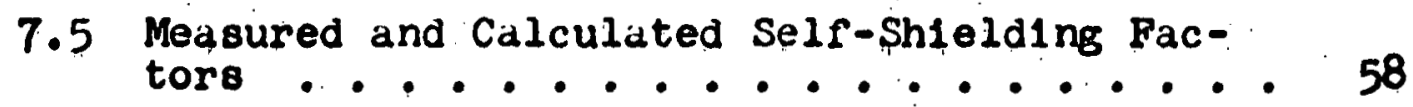


8.1 Burnout of Gadolinium slab ...... 61

8.2 Brective Cross Section Versus Irradiation. 62

8.3 Burnout Character1st1cs......... 63

8.4 Burnout Characteristics ......... 64

8.5 Burnout Characteristtcs . . . . . 65

8.6 Burnout Characterlatics ......... 66

8.7 Calculated and Measured Depletton Effect . 67

9.1 Test Assembly ............... . 111

9,2 Test Absembly . ................... 112

9.3 Test Element . . . . . . . . . . . 113

9.4 Gadolinium Crose sections Versus Irrad1a- 114

9.5 Oadolinia Particles ........ 115

9.6 Cadolinium D18ks . . . . . . . . 116

9.7 Gadolinlum D1sks ............. 117

9.8 Cadolinium D18k8 . . . . . . . . 118

9.9 Core Conf1guration - Phase I . . . . . 119

9.10 Core Conflguration - Phase II . . . . 120

9.11 Perlod Determination ......... 121 


\section{INTRODUCTION}

The concept of burnable poisons as a device for reducing the control requirements of nuclear reactors originated some ten to twelve years ago in the Naval Reactors projects and at the Knolls Atomic Power Laboratory. Most of the literature relating to the use of burnable poisons is not generally avallable in unclassified form; however, Wilbur Lakin, then of Westinghouse, E. Zebroski, of General Electric, and particularly Alvin Radkowsky, of the Naval Reactors Branch of the Afomic Energy Commission, are generally credited with having led the pioneering early efforts in this field.

Because of the lack of unclassified publications dealing with this topic, the 1958 Geneva paper by Radkowsky (reference 22) will be used for a description of the "state of the art" prior to the work described in the main body of this report,

Briefly, the basic idea involved in the use of a burnable poison is the following: The reactor must be provided with a component which has increasing reactivity throughout the reactor lifetime at the same rate that the reactivity of the rest of the system is decreasing due to fuel deplerion and fission product accumulation. One such component is, of 
course, a traditional movable control element--usually poison rods but occasionally a reflector element or even movable fuel rods. The use of a burnable polson for this component decreases the number of movable "shims" required in the reactor. Since the control system must accomodate other reactivity effects (startup, temperature compensation, etc.), the provision of a sufficient system based entirely upoun müvable shims often compromises core design and operation. For example, a high density of polson rods might require smaller fuel elements than desired. In some cases the core life might be limited by the amount of movable shim that can be employed. Also, since the "ahim" rods are in the core during early stages of power operation, while rods. to compensate for startup, etc., are largely removed, they often have a major adverse effect on the power distribution In the reactor.

If the reactivity curve (1.e., core multiplication constant versus irradiation) of the reactor could be matched exactly by a burnable polson element, the movable control elements necessary would be reduced substantially. In practice, an exact match 18 extremely difficult, if not 1mpossible. In addition to the effects of fuel depletion and fission product accumulation, in many systems there 18 a bulldup of f1ssionable materials (18otopes of plutonium or uranium-233). Th1s complicates the reactivity curve further.

Basically, the previous work (defined as that 
described by Radkowsky) considered the matching of reactors' reactivity curves by the use of one or more unahielded po1son elements and by the use of moderately self-shlelded boron. The non-uniform spatial depletion of the selfshielded poison was not considered. These results were of considerable value, and applied in many reactor designs. However, often a substantial m1ss-match occurs w1th the reactor's reactivity curve and the residue of polson 18 sometimes excessive. These effects are particularly important for slightly enriched power reactors in which the shape of the burnout curve departs signiflcantly from that of an unshlelded polson. An excessive polson residue often results if a better match 18 attempted by the use of spatial self-shlelding. The object of the research described here is to find a new and different type of burnable polson element which can be used to match essentially any decreasing reactivity curve and still have a tolerable residue. The departure from the previous work cons1sted of recognizing that the exploitation of geometrical effects, rather than elemental cross-sections, results in a greatly improved ab1lity to match reactors' burnout curves, and that a high cross-section element allowed the large self-shlelding desired and st11l gave little residue. The high cross-section of the burnable polson makes the burnout shape almost independent of the particular element used. Thus, although in this work speciflc application 1s made to gadoilnium as the polson element, the basic 
results would be simllar for any other sultable high crosssection element, for example cadmlum.

It is relt by the author that the effects being consldered here were neglected in prevlous work because, historlcally, self-shlelding was considered as providing a moderate extension to the performance of the unshielded po1sons already being employed (mainly boron-10). It 18 hoped that the results presented here w1ll provide a meaningful increment to burnable polson technology, and allow a fuller ut1lization of their potential.

The bas1s characteristics of the new concept are developed in Section 1.1. The scope of the further investigations 18 described in Section 1.2, while the work and results are given in the balance of this report.

\subsection{Idealized Depletion Characteristics of Highly Self-shlelded Burnable Po1sons}

The use of an unshlelded absorber as a burnable polson is Ilmited by the avallablilty of elements having appropriate absorption cross sections since this factor determines the endurance of the polson effect. Also, the characterist1c exponential shape of the polson's depletion 1 s generally not a good match for the reactivity requirements of a reactor. The use of a lumped absorber to provide spatial self-shlelding of the absorption rate allows the reactor designer to control somewhat both the endurance and shape 
of the polson's depletion. However, with moderate cross section materials, a penalty in the form of poison residue (polson effect remalning at the end of the design.1rradiation) 1s exacted for this match. The use of a very high cross section absorber, whlch would burn out rapldly following depletion of the shielding atoms, would remove this problem. A high cross section absorber, however, requires large inttial self-shielding in order to obtain endurances of interest to the reactor design.

In the limit of a very high cross section absorber, w1th correspondingly high inltial self-shielding, it can be assumed that all absorptions occur at the surface of the sample. Then, assuming for slabs and cylindrical cases that one dimension is much smaller than the others, the rate of depletion of the size of the sample 1s:

$$
\rho S \frac{d x}{d t}=-f \sum V \varphi
$$

where $\rho 18$ the number density of absorber atoms,

$S$ and $V$ are the surface and volume of the sample,

$x$ 1s half thickness for slab, radius for cylinder and sphere,

Q is amblent neutron flux,

$\sum$ is the macroscopic absorption cross section of sample, and 
$f$ is the self-ahielding factor of the sample. For aril, black absorbers, f approaches $s / 4 \mathrm{~V} \sum$ (reference 1 ). Using $f=s / 4 v \sum,(1.1 .1)$ becomes:

$$
\rho \frac{d x}{d t}=-\frac{Q}{4}
$$

Th1s 18 solved to yleld:

$$
\frac{x(t)}{x(0)}=1-\frac{Q t}{4 \rho x(0)}
$$

$$
\text { for } Q t<4 p \times(0)
$$

where $x(0)$ is the initial value of $x$. Then, olnce the total effective cross section is proportlonal to the absorber surface:

$$
\begin{aligned}
\frac{\sigma \text { eff }(Q t)}{\sigma_{e f f}(0)}=\left[\frac{x(t)}{x(0)}\right]^{n} & =\left[1-\frac{Q t}{4 \rho x(0)}\right]^{n} \\
\quad \text { for } \varphi t<4 \rho \times(0) & n \\
n & =0 \text { for slab } \\
n & =1 \text { for cylinder } \\
n & =2 \text { for sphere }
\end{aligned}
$$

where beff $(Q t)$ is the effective cross section of the absorber after an 1rradiation of $Q t$.

Or. In terms of the absorber's microscopic cross section, 6 , and the intial self-shleldine factor, $f(0)$ : 


$$
\frac{7}{\sigma_{e f f}(Q t)}=\left(1-\frac{\sigma f(0) Q t}{n+1}\right)^{n}
$$

Equation (1.1.4) is shown as the sol1d curves in figure 1.1. For comparison, the curve for an unshlelded poison with ten per cent residue 18 also shown.

It can be seen from figure 1.1 that spherical particles yleld little improvement in shape over an unshlelded poison. Cylinders are limited to a linear reactivity shape. However, the slab behavior allows the synthesis of any decreasing burnout characterlstics by a combination of samples with different inftial blackness factors. From equation (1.1.4), It can be seen that the endurance depends solely upon the surface density of absorber atoms $[4 \rho \times(0)]$, independent of the absorber material.

Thus with an arb1trary control over the burnable polson's endurance and burnout shape and no appreclable residue problem,...th1s polson concept has a great potent1al. The add1tional work needed to explo1t this concept is outlined in the following section.

\subsection{Scope of Study}

In order to evaluate the requirements of the burnable polson, typlcal fuel cycles w11l be evaluated in Section 2. Th1s work will provide values of the total 1rradiation 11fetime (endurance) and burnout shape that are of interest. Since this concept is dependent upon the existence and avallabllity of a sultable high cross section element, an 
evaluation of avallable materials w1ll be made in Section 3 . An element, having the best apparent propert1es, w1ll be selected for more detalled investigation. The pertinent properties of this element, gadolinium, w1ll be evaluated in Section 4.

W1 th both the poison material and desired character18t1çs selected, a more realist1c treatment w1ll be given to the development in Section 1.1. Specifically the assumptions were: that the poison had an arbitrarily large capture cross section, that the neutrons were monoenergetic, and that the sample was vanishingly small, "black," and onedimensional so that the particle self-shielding factor ( $\mathrm{S} / 4 \mathrm{~V} \Sigma$ ) could be used. The spatial self-shielding for absorbers in disk geometry w1ll be developed for monoenerget1c neutrons in Section 5. The effect of typical neutron spectra w1ll be evaluated for both the ep1thermal contribution to the polson's absorption rate and the effect1veness averaged over the thermal distribution in Section 6. Also, a thermally "black" absorber has a definite effect upon the reactor's temperature coefficlent of reactivity and temperature defect. In Section 6, these w11l be calculated for gadolinium to provide a more complete evaluation of the ut111ty of this burnable poison concept. These results w1ll be combined in Section 7 to obtain the self-shlelding factor for gadolinium disks of varlous dimensions. A sufficlently accurate value for the Initial self-shlelding factor is needed by the reactor designer in order to select the appro- 
priate amount of polson. The effective cross section following neutron 1rradiation w1ll be calculated in Section 8 for gadolinium disks. This will provide the information needed to match a reactor's reactivity requirements by use of this burnable po1son. The experimental program perrormed as part of this atudy 18 described in Section 9. Conclusions are given in Section 10 . 


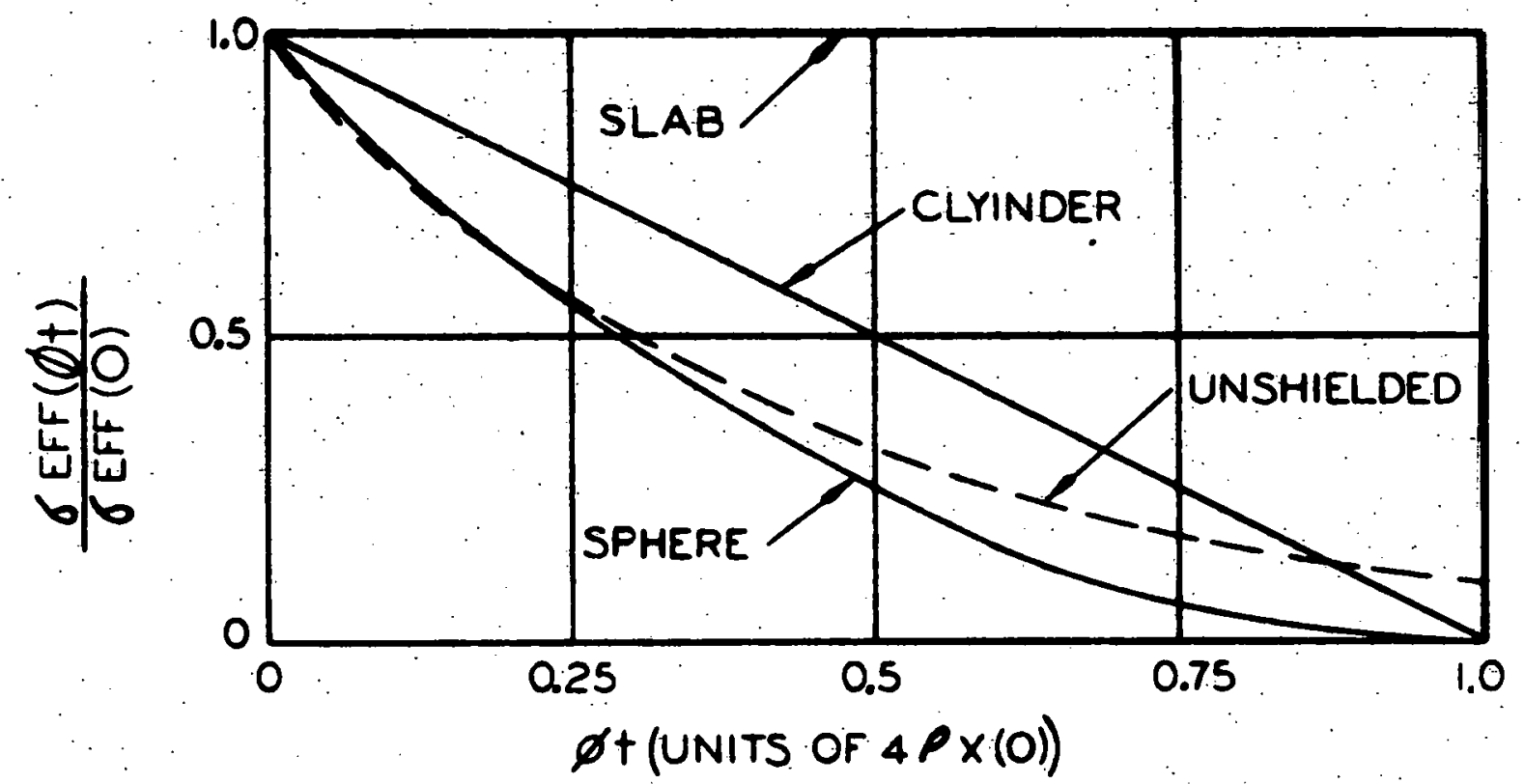

FIG. I.I BURNOUT CHARACTERISTICS OF HIGHLY SELF SHIELDED POISONS 


\section{REACTIVITY REQUIREMENTS}

In order to establish the burnout characterlstics desired for the burnable po1son, typlcal fuel cycles will be examined. Slightly enrlched uranlum w1ll be used for ruel, and the bulldup of plutonlum 180 topes and fission products w11l bo taken 1nto account. Since th1s 18 only meant as a gulde for setting the polson's range of characteristics, no provision will be made for variation over ilfe in the fast to thermal spectrum, ruel disadvantage factor, leakage, or other reactor properties.

Symbollcally, the reactor's critlcallty at beginning of I1fe can be represented as:

$$
K(0)=\frac{1}{n^{15}+P(0)+A}=1
$$

where $\eta^{25} 18$ the number of neutrons emitted per absorption in U-235

$P(0) 18$ the initial control poison effective cross section required for criticality divided by $M \xi_{2}^{25}(0)$, and

A represents all non-fuel-or-polson neutron losses, Including leakage and equilibrium $\mathrm{Xe}$ and $\mathrm{Sm}$, 
divided by $n \varepsilon_{a}^{25}(0)$.

During l1fe the criticallty constant w11l be:

$$
k(q t)=\frac{\nu^{25} \Sigma_{f}^{25}+\nu^{49} \varepsilon_{f}^{49}+\nu^{41} \Sigma_{f}^{41}}{\sum_{a}^{25}+\Sigma_{a}^{49}+\Sigma_{a}^{40}+\Sigma_{a}^{41}+\Sigma_{a}^{42}+\sum_{a}^{F p}+(P+A) \eta^{25} \Sigma_{a}^{25}(0)}=1
$$

where $\sum_{f}^{i}$ and $\sum_{a}^{i}$ represent the macroscop1c fission and absorption cross sections, respectively, of 1sotope 1. $\nu^{i}$ is the number of neutrons emitted per flssion for 180 tope 1 .

The following notation is used for superscripts: 25 - U-235, 28 - U-238, 49 - Pu-239, 40 - Pu-240, 41 - $-241,42$ - Pu-242, FP - P18sion Product.

$P+A=\frac{1}{\eta^{25} \sum_{a}^{25}(n)}\left\{\left(\eta^{25}-1\right) \Sigma_{a}^{25}+\left(\eta^{49}-1\right) \Sigma_{a}^{49}+\left(\eta^{41}-1\right) \Sigma_{a}^{41}-\Sigma_{a}^{40}-\Sigma_{a}^{42}-\Sigma_{a}^{F P}\right\}$

Where the argument (Qt) 18 assumed for cross sect1ons without explic1t arguments. Using $\sigma_{j}^{i}$ to represent the spectrally averaged microscopic cross section for reaction $f$ in 1 sotope 1 , and $\Phi$ for the neutron flux, the balance equation for the uranium-235 concentration 18:

$$
\frac{d N^{05}}{d t}=-\sigma_{a}^{25} \varphi N^{25}
$$


Integration y1elds:

$$
N^{25}(t)=N^{25}(0) \epsilon^{-\sigma_{a}^{25} \phi t}
$$

S1nce pluton1um-239 18 produced by neutron capture react1ons with uranium-238, the balance equation for plutonium239. 18:

$$
\frac{d N^{49}}{d t}=\sigma_{c}^{28} Q N^{28}-\sigma_{a}^{19} Q N^{49}
$$

Assuming that $N^{28}$ is constant, multiplying by $\exp \left(\sigma_{a}^{49} Q t\right)$, Integrating, and assuming that the initial plutonlum concentration 18 zero gives:

$$
N^{49}(t)=\frac{\sigma_{a}{ }^{28} N^{28}}{\sigma_{a}{ }^{49}}\left(1-e^{-\sigma_{a}{ }^{49} \phi t}\right)
$$

The inftial conversion rat10, ICR, 1s $\sigma_{c}{ }^{28} N^{28} \sigma_{q}{ }^{25} N^{25}(0)$. Making this substitution, and multiplying by $\sigma_{a}^{49}$ gives:

$$
\frac{\sum_{a}^{49}(t)}{\sum_{a}^{25}(0)}=\operatorname{ICR}\left(1-e^{-\sigma_{a}^{49} \varphi t}\right)
$$

Since plutonlum-240 18 produced by neutron capture reactions in plutonlum-239, the balance equation for plutonium240 18:

$$
\frac{d N^{40}}{d t}=\sigma_{c}^{49} Q N^{49}-\sigma_{a}^{40} Q i^{40}
$$


Multiplying by exp $\left(\sigma_{a}^{40} \phi t\right)$, rearrangling terms, subst1tuting equation (2.8), and Integrating the left side gives:

$N^{40}(t) e^{\sigma_{2}^{40} Q t}=\frac{\sigma_{c}^{49} \phi I C R \sum_{a}^{25}(0)}{\sigma_{a}^{49}} \int_{0}^{t} e^{\sigma_{u}^{40}} \phi t^{\prime}\left(1-e^{-\sigma_{a}^{49} \phi t^{\prime}}\right) d t^{\prime}$

performing the integration and simplifyling ylelds:
$\frac{\sum_{a}^{40}(t)}{\sum_{a}^{25}(0)}=I C R \cdot \frac{\sigma_{c}^{49}}{\sigma_{a}^{40}}\left[1-\frac{\left.\sigma_{a}^{49} e^{-\sigma_{a}^{40} Q t}-\sigma_{a}^{40} e^{-\sigma_{a}{ }^{49}} Q t\right]}{\sigma_{a}^{49}-\sigma_{a}^{40}}\right]$

Since the fission reaction in plutonium-240 is negligible, all absorptions w1ll result in the production of plutonium241. The balance equation 18:

$$
\frac{d N^{41}}{d t}=\sigma_{a}^{40} Q N^{40}-\sigma_{a}^{41} Q N^{41}
$$

Subst1tuting (2.11) Into (2.12) and solving as before gives:

$$
\begin{aligned}
& \frac{\sum_{a}^{41}(Q t)}{\sum_{a}^{25}(0)}=\operatorname{ICR} \sigma_{a}^{49} \sigma_{a}^{40} \sigma_{a}^{41}\left[\frac{1}{\sigma_{a}^{40} \sigma_{a}^{41} \sigma_{a}^{49}}\right. \\
& \left.+\frac{e^{-\sigma_{a}^{49}} Q t}{\sigma_{a}^{49}\left(\sigma_{a}^{41}-\sigma_{a}^{40}\right)\left(\sigma_{a}^{41}-\sigma_{a}^{49}\right)}-\frac{e^{-\sigma_{a}^{40}} \sigma_{a}^{40}\left(\sigma_{a}^{49}-\sigma_{a}^{40}\right)\left(\sigma_{a}^{41}-\sigma_{a}^{40}\right)}{\sigma_{a}^{41}\left(\sigma_{a}^{41}-\sigma_{a}^{40}\right)\left(\sigma_{a}^{41}-\sigma_{a}^{49}\right)}\right]
\end{aligned}
$$

Then, assuming that Pu-242 does not burn out appreclably 
15

$$
\begin{aligned}
& \text { over a fuel cycle: } \\
& \frac{\sum_{2}^{42}(Q t)}{\sum_{a}^{2 t}(0)}=\frac{\sigma_{a}^{42}}{\sigma_{a}^{41}} \int_{0}^{t} \sigma_{c}^{41} \frac{\sum_{a}^{41}(Q t)}{\sum_{a}{ }^{25}(0)} \Phi d t^{\prime} \\
& =I C R \frac{\sigma_{c}^{49} \sigma_{c}^{42}}{\sigma_{a}^{49} \sigma_{a}^{41}}\left[\sigma_{c}^{41} Q t+\frac{\sigma_{c}^{41} \sigma_{a}^{40} \sigma_{2}^{41}\left(1-\epsilon^{-\sigma_{a}^{49} a t}\right)}{\left.\sigma_{a}^{49}\left(\sigma_{a}^{49}-\sigma_{c}^{40}\right) \sigma_{a}^{41}-\sigma_{a}^{49}\right)}\right. \\
& \left.-\frac{\sigma_{c}^{41} \sigma_{a}^{49} \sigma_{a}^{41}\left(1-e^{-\sigma_{a}^{40} a^{t}}\right)}{\sigma_{a}^{40}\left(\sigma_{a}^{49}-\sigma_{a}^{40}\right)\left(\sigma_{a}^{41}-\sigma_{a}^{40}\right)}-\frac{\sigma_{c}^{41} \sigma_{a}^{40} \sigma_{a}^{41}\left(1-e^{-\sigma_{a}^{41} Q t}\right)}{\sigma_{a}^{41}\left(\sigma_{a}^{41}-\sigma_{a}^{40}\right)\left(\sigma_{a}^{41}-\sigma_{a}^{47}\right)}\right]
\end{aligned}
$$

Assuming that the non-saturating fission product cross sectron is proportional to the total number of fissions that have occurred:

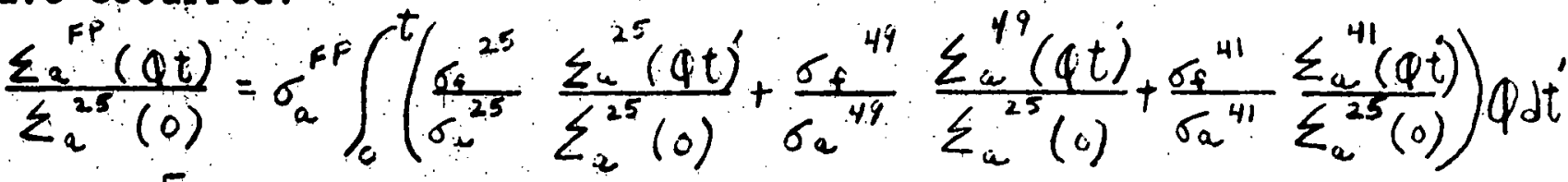

$$
\begin{aligned}
& =\sigma_{a}^{F P}\left[\frac{\sigma_{f}{ }^{25}}{\sigma_{a}^{25} \sigma_{a}^{25}}\left(1-e^{-\sigma_{a}^{25} Q t}\right)+\frac{1 C R}{\sigma_{a}^{49}}\left\{\sigma_{f}^{49} Q t-\frac{\sigma_{f}^{49}}{\sigma_{a}^{49}}\left(1-e^{-\sigma_{a}^{49} Q t}\right)\right\}\right. \\
& \left.+\frac{\sigma_{t}^{41}}{\sigma_{c}^{41} \sigma_{i}^{42}} \frac{\sum_{a}^{42}(Q t)}{\sum_{a}^{25}(0)}\right]
\end{aligned}
$$

The westcott method was used to obtain cross sections (2). The only modification made to the treatment was to normalize cross sections to the average thermal flux, rather than to the $2200 \mathrm{M} / \mathrm{S}$ flux. This was done to facilitate comparson with the burnout of the poison's effective cross section in a Maxwellian distribution. With this method:

$$
\bar{\sigma}=\sqrt{\frac{\pi T_{0}}{4 T}} \sigma_{2200}(g+r s)
$$

$(2.16)$ 
Where $\sigma_{220018}$ the cross section at $2200 \mathrm{~m} / \mathrm{s}$,

8 represents the departure of the cross section

from $1 / v$ in the thermal region (

- represents the departure from $1 / v$ in the ep1thermal region (for $1 / v, s=0$ ), and

$r$ represents the rat1o of ep1thermal to total neutron density.

Uoing $\mathrm{T}=300^{\circ} \mathrm{C}$ and a cutoff at $5 \mathrm{kt}$, the parameters in Table 2.1 were obtalned from reference (2).

TABLE 2.1

URANIUM AND PLUTONIUM ISOTOPIC PARAMETERS

\begin{tabular}{lccccccc}
\hline Isotope & $\boldsymbol{B}_{\mathrm{f}}$ & $\boldsymbol{s}_{\mathrm{f}}$ & $\boldsymbol{g}_{\mathrm{a}}$ & $\mathbf{s}_{\mathrm{a}}$ & $\sigma_{\mathrm{f}} 2200$ & $\sigma_{\mathrm{a}} 2200$ & $\nu$ \\
\hline U-235 & 0.9291 & 0.0431 & 0.9357 & 0.1626 & 582 & 683 & 2.43 \\
Pu-239 & 1.4507 & 1.182 & 1.5895 & 1.519 & 742 & 1028 & 2.89 \\
Pu-240 & - & - & 1.1160 & 46.78 & - & 278 & - \\
Pu-241 & 1.2920 & 0.3464 & 1.2920 & 0.3464 & 1015 & 1397 & 3.06 \\
Pu-242 & - & - & 1.025 & 52.48 & - & 30 & - \\
\hline
\end{tabular}

With a value of $r=0.2$, which 18 appropriate for typical water moderated power reactors, the cross sections in Table 2.2 were calculated. Where needed, the capture cross sect1on. was taken as the difference between the absorption and f1s8ion cross sections. 
TABLE 2.2

URANIUM AND PLUTONIUM CROSS SECTIONS

\begin{tabular}{lcccc}
\hline Isotope & $\sigma_{a}$ & $\sigma_{f}$ & $\sigma_{c}$ & $\eta$ \\
\hline U-235 & 419 & 346 & 73 & 2.01 \\
Pu-239 & 1233 & 793 & 440 & 1.86 \\
Pu-240 & 1845 & - & 1845 & - \\
Pu-241 & 1206 & 876 & 330 & 2.22 \\
Pu-242 & 219 & - & 219 & - \\
\hline
\end{tabular}

The rission product cross section was taken from analysis of the PWR-2 seed. Curves for ep1thermal and thermal effective cross sections are given in reference (3). W1th the spectrum used in th1s section, an average $2200 \mathrm{M} / \mathrm{S}$ cross section over life of 143 barns was obtalned.

These cross sections were used to calculate $P+A$, using equation (2.3), for various values of the initial conversion ratio. These results are shown in figure 2.1 . starting with the 1rradiation lifetime of the fuel, and with all components of $A$ except the fertile absorption rate, these results can be used to establish: the inltial fuel enrichment, the initial conversion rat1o, and the required control polson. Equation 2.15 can be used to calculate the total number of flssions per inftial atom of uranium-235. Th1s can be converted to integrated power. 
Choosing varlous initial enrichments, the number of atoms of uranlum-235 per metric ton of uranium 1s obtalned. Comblning this with the integrated power per initial atom of uranlum-235 y1elds the 1rradiation in megawatt days per ton of urantum, versus inltial enrichment, for each of the curves In f1gure 2.1. Applying the fuel irradiation lifetime (Nw/T) establ1shes the 1ntegrated Flux ( $Q t)$ versus uranium-235 enrichment for various initial conversion rat1os. Then, since at end of life $(P=0)$, combining the other components of $A$ with the inftial converston ratios allows selection of the Irradiation 11fetime from figure 2.1. Th1s y1elds the in1tlal enrlchment and initial converalon ratio. The difference between beginning and end of 11 fe values of $P+A$ gives the control polson requifement. Two typlcal poison demand curves, obtained in this manner, are shown in figure 2.2. The polson is normalized to unlty at beginning of $11 \mathrm{fe}$ and allowed to go to zero at end of 11fe. Parameters for these cases are given in the rigure.

The shape of the required control poison can be seen In both f1gures 2.1 and 2.2. The inttial increase in poison for some of the curves cannot be matched with burnable po1son but must be controlled by other means--such as control rod Insertion. However, the shapes of the curves show the desirability of malntalning the burnable poison's effect1ve cross section over the early portion of life. 


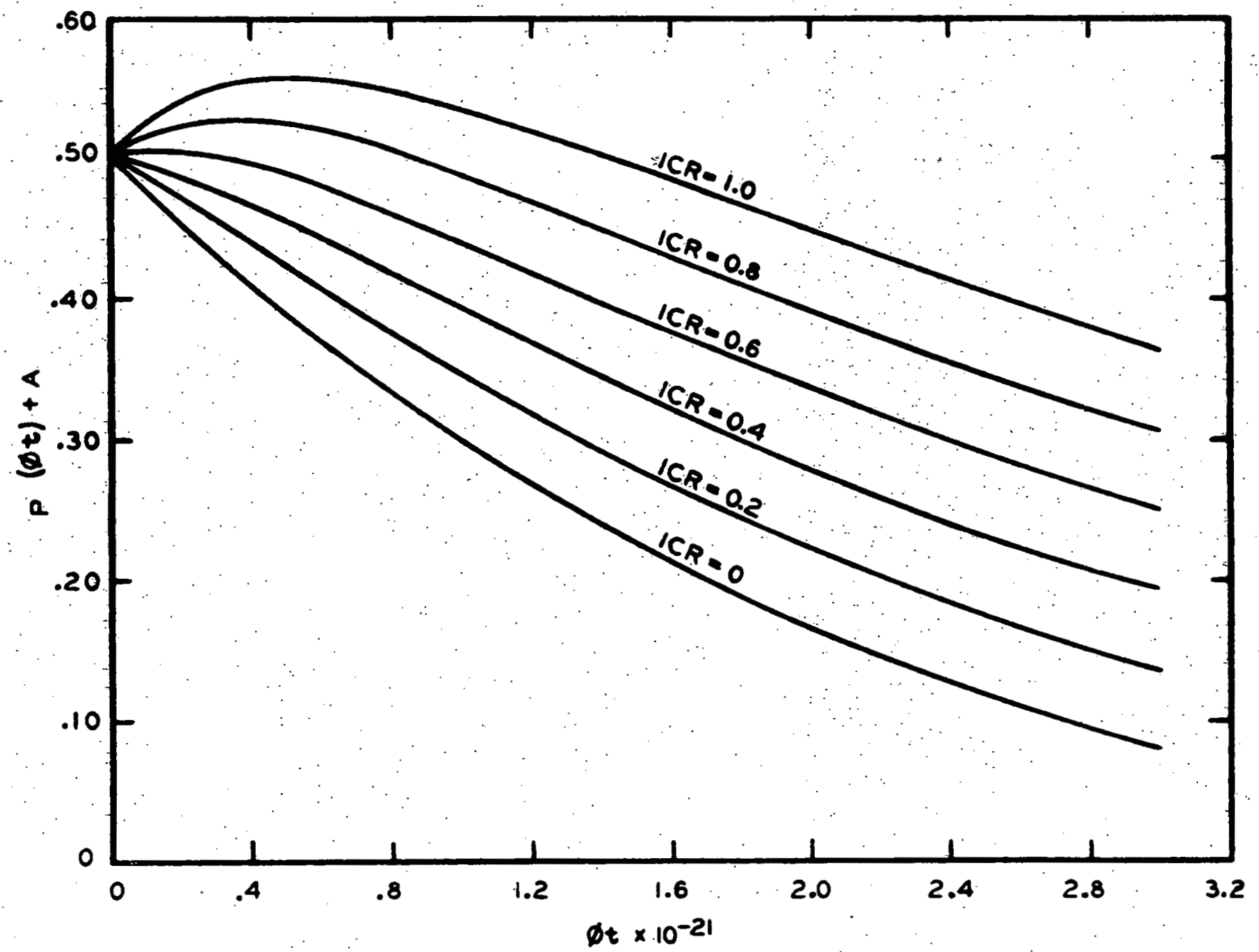

قै

FIG 2.1 EFFECTIVE CROSS SECTIONS FOR CRITICALITY 


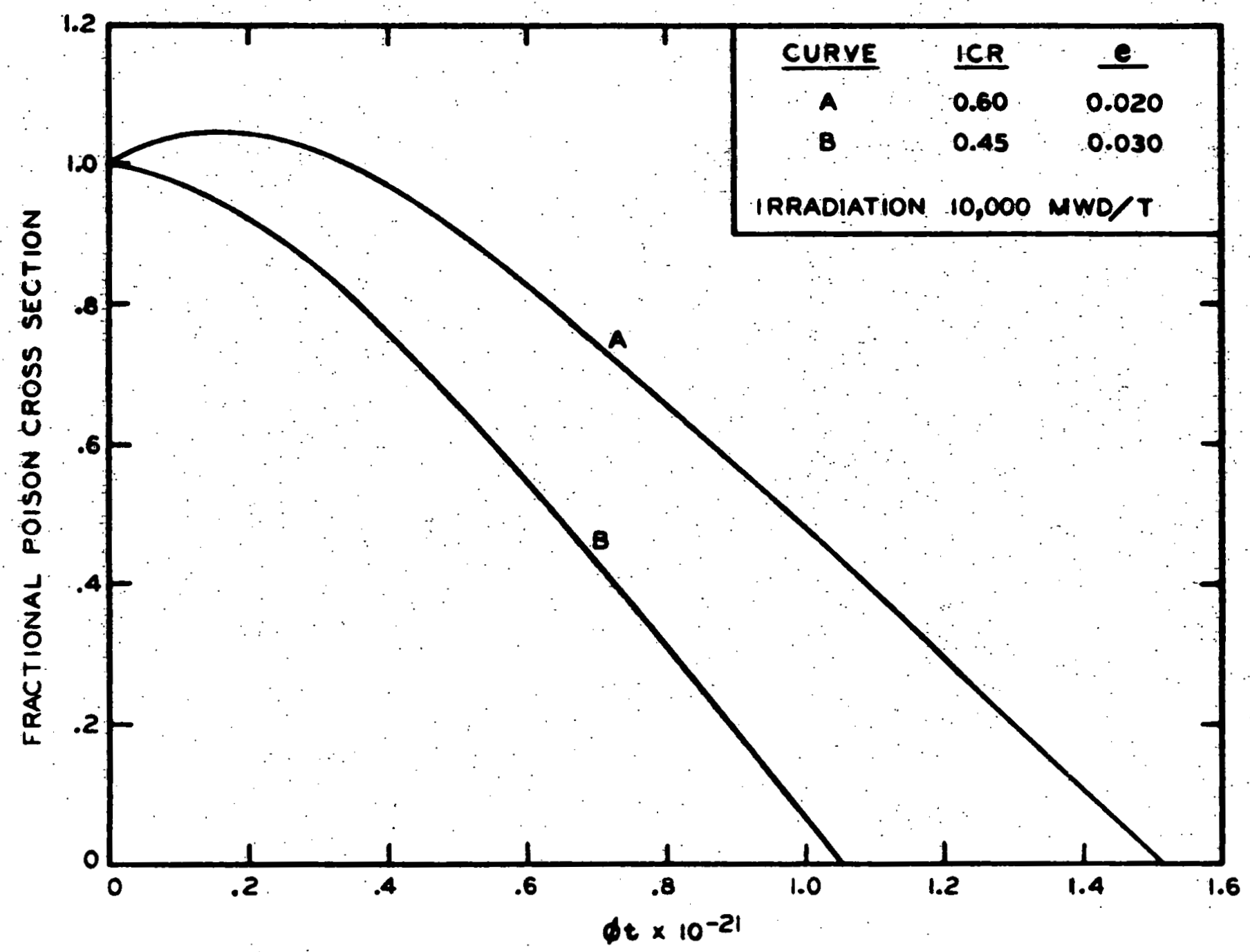

FIG. 2.2 POISON CROSS SECTION FOR CRITICALITY 


\section{SELECTION OF BURNABLE POISON MATERIAL}

In the last section it was found that irradiation lifetImes of the order of $10^{21}$ nvt were desired for the use of burnable polsons in reactors. In order to utilize the highiy self-ahlelded properties of the polson, the exponential ta1l must be of short duration relative to the total irradiation 11fetime. This ylelds the following inequality for a ten per cent residue from an unsh1elded absorber:

б.> $2.3 \mathrm{~cm}^{2} / 10^{21}=2300$ barns. Since this 18 approximately the effective cross section of boron-10 in an operating power reactor, consideration will be limited to elements with larger cross sections. The only avallable elements having 1sotopes with thermal absorption cross sections greater than that of boron-10 are cadmium, samarlum, europlum, and gadolinium. Significant cross sections for these elements are given in Table 3.1 .

Europlum can be immediately discarded due to the high cross section daughter products.

Samarlum had daughter products (and other 1sotopes) with unknown cross sections. The thermal cross section 18 mainly due to the 149 180tope while the ep1thermal 18 due to the 152 1sotope. These w1ll have different self-shlelding and w1ll burn out at different rates. It is unlikely that 


\section{TABLE 3,1}

BLEUENTS HAVIN ISOTOPIC CROSS SECTIONS GREATER THAN BORON-10

\begin{tabular}{|c|c|c|c|c|}
\hline Element & $\begin{array}{l}\text { Major Isotopes } \\
\text { Abundances (4) }\end{array}$ & $\sigma(2200 \mathrm{M} / \mathrm{s})$ & RI & $\begin{array}{l}\sigma \text { Residue } \\
\text { (Thermal) }\end{array}$ \\
\hline \multirow[t]{2}{*}{ cd } & . & 2.537 & & \\
\hline & $\therefore 113(0.123)$ & 20,000 & & \\
\hline \multirow[t]{3}{*}{$\sin$} & & 5,828 & $1790(5)$ & \\
\hline & $149(0.238)$ & 40,800 & & \\
\hline & $152(0.266)$ & 216 & $>1750(6)$ & \\
\hline \multirow[t]{3}{*}{ Bu } & & 4,300 & $950(6)$ & \\
\hline & $251(0.478)$ & 7,700 & & $5,500(4)$ \\
\hline & $153(0.522)$ & 450 & & $1,500(4)$ \\
\hline \multirow[t]{3}{*}{ ad } & & 46,300 & $67(5)$ & \\
\hline & $155(0.147)$ & 56,200 & & $<1,000$ \\
\hline & $1.57(0.157)$ & 242,000 & & $4(4)$ \\
\hline
\end{tabular}

152 would burn out soon enough to reduce the effective residue to an acceptable value. When comblned with the relative abundances, the thermal cross section of 15218 about one per cent of that of 149.. With inftial self-shlelding factors of between one-tenth and one-twentieth, the effective thermal residue of 152 would be ten to twenty per cent (w1th no depletion). Added to an epithermal effect of comparable magnitude, 
the residue from samarlum appears prohibltive for use as a highly self-shlelded burnable poison.

Cadmium has acceptably low residue and an adequate thermal cross section. The major limitation on 1ts use is 1 ts low melting point $\left(321^{\circ} \mathrm{C}\right)$. For low temperature applications, cadmium could be used in this burnable polson concept.

Gadolinium has the largest thermal cross section of any naturally avallable element. The resonance integral is small, so that even with large self-shielding, the thermal effect will predominate. The melting point of the metal $\left(1312^{\circ} \mathrm{C}\right)$ and the existence of the ceramic material, gadolinia, makes 1t attractive for power reactor applications. The major uncertainty is the residue. The 156 1sotope has an abundance of about twenty per cent. It is also produced by the burnup of 155. So a cross section of 1000 barns for 156 would yleld an effective cross section of less than one per cent of that of natural gadolinium. With the high initial self-shielding factors belng considered, this is about the limit of residue that is permissable. The estimate for the residue given in Table 3.1 was made by the author on the bas1s of total cross section measurements made with gadolinium samples having three different isotoplc concentrations. This 1s discussed in Section 4.2. With this one qualification of residue in mind, gadolinium was selected as the most promising materlal for this burnable polson concept. 
4. OADOLINIUM PROPERTIES

4.1 Material Properties

The material properties of gadolinium metal and gadolinia are given in Table 4.1. These properties will be used in the balance of this report.

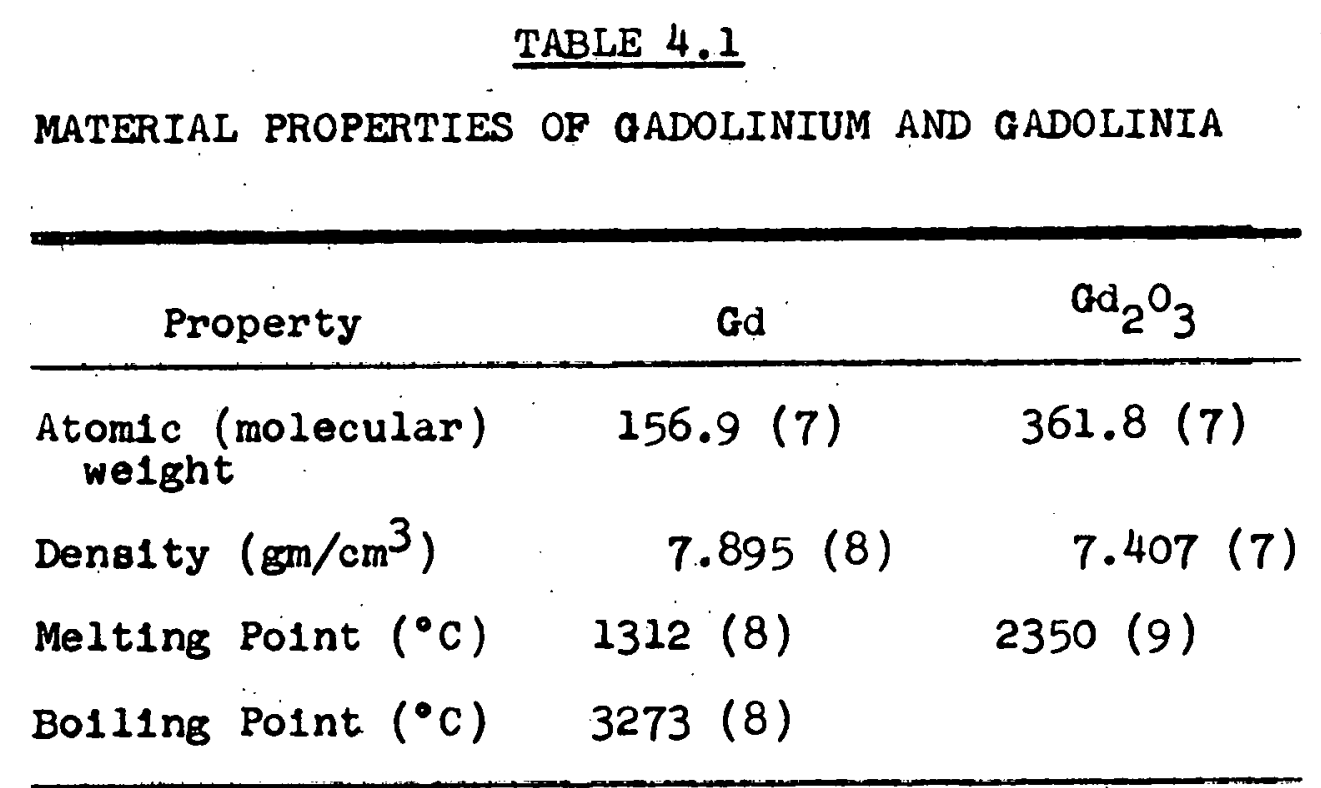

4.2 Isotop1c Cross Sections

Table 4.2 11sts the 180topic abundances and cross sections for the stable 1sotopes of gadolinium as given in reference (4).

It can be seen in the table that the major contributions 
to the thermal absorption cross section are from the 180topes 155 and 157. Both of these values are sufficlently large to burn out with a nominal additional 1rradiation after the sample becomes "grey." The polson residue w11l then be largely due to the other 18otopes. Those which activate $(152,158$ and 160$)$ have been measured and are acceptably omall.

\author{
TABLE 4.2 \\ AADOLINIUM ISOTOPIC CROSS SECTIONS
}

\begin{tabular}{lcc}
\hline Isotope & Abundance $(\not)$ & $\sigma$ abs $(2200 \mathrm{~m} / \mathrm{s})$ \\
\hline Natural & 100 & 46,000 \\
152 & 0.20 & $<125$ \\
154 & 2.15 & \\
155 & 14.73 & $56,200 \pm 1000$ \\
156 & 20.47 & $242,000 \pm 4000$ \\
157 & 15.68 & $3.9 \pm 0.4$ \\
158 & 24.87 & $0.8 \pm 0.3$ \\
160 & 21.90 & \\
\hline
\end{tabular}

The 1sotopes 154 and 156 do not activate and the1r cross sections have not been measured. The latter is especially Blgnificant since it 18 present in natural gadolinium and 18 produced by neutron capture in 155 for a total concentration 
of over 35 per cent in a depleted sample. Thus, a cross section of 1000 barns would yleld a residue of nearly one per cent of the 1n1tial polson cross section. Th18, with an Inttial self-shlelding factor of 20 , would have an effective cross section near 20 per cent. However, the probab1lity that an even-even nuclide has th1s large a cross section 18 small.

Improved values of the cross sections for 155 and 157 were measured by Mller, et al., at Brookhaven (10). They measured the total cross section of three samples having different 1sotopic abundances over the range of 0.018 to $1 \mathrm{ev}$. They flt the data for Individual cross sections with the resonance parameters given in Table 4.3 .

TABLE 4.3

THERMAL RESONANCE PARAMETERS FOR GADOLINIUM

\begin{tabular}{cccccc} 
Isotope & $E_{o}(\mathrm{ev})$ & $\Gamma(\mathrm{ev})$ & $\Gamma_{\gamma}(\mathrm{ev})$ & $2 \mathrm{~g} \Gamma_{\mathrm{n}}(\mathrm{mv})$ & $2 \mathrm{~g} \Gamma_{\mathrm{n}}{ }^{\circ}(\mathrm{mv})$ \\
\hline gd-155 & 0.0268 & 0.108 & 0.108 & 0.130 & 0.800 \\
od-157 & 0.0314 & 0.107 & 0.106 & 0.590 & 3.350 \\
\hline
\end{tabular}

These cross sections are plotted in flgure 4.1 . The total cross section of natural gadolinium due to these parameters plus the 2.01 ev resonance in 155 is plotted in figure 4.2 together w1th the total cross section curve from BNL-325, 
supplement 1 which 1ncludes Argonne slow chopper as well as Brookhaven crystal spectrometer measurements.

The abillty to reproduce the total cross section so well by assigning resonance parameters to only the 155 and 157 1sotopes strongly suggests that the thermal cross section for 15618 small. If the 156 1sotope had a resonance In the thermal range, whose shape could be confused with those of 155 or 157 , it is likely that the magnitude of the cross section would be large enough to be dist1ngulshed when measuring samples of different 1sotopic abundances. In the more probable case of $1 / v$ dependence in the thermal region, some departure between the total cross section and the 155-157 components should be apparent in the 0.1 to 1.0 ev region. A cross section of 1000 barns at $2200 \mathrm{~m} / \mathrm{s}$ for 156 would contribute over 32 barns to the total cross section of 37 barns at $1.0 \mathrm{ev}$. For th1s reason, an upper limit of 1000 barns was assigned to Gd-156 in Table 3.1.

\subsection{Po1son Residue}

Because the feasibility of using gadolinium for a burnable polson depends upon the residue, a search was made for 1rradiation experiments. As part of the Atomic Energy Commission's control material evaluation program, the General Electric Company has performed reactivity measurements on 1rradlated gadolinium (11). Seven samples were 1rradiated to nvt $=1.3$ to $27.5 \times 10^{19}$. The spread in the data was too great to yleld a conclusive result for the resldue. In fact, two cases gave residue values of 1.5 and 
2.5 standard deviations below zero.

Lacking a definitive value for the residue, an 1rradiation experiment to nut $=6.2 \times 10^{19}$ was executed. The reactivity of the 1rradiated sample was measured. The deta1ls of these experiments are described in Chapter 9.

Assigning all of the residue to gadolinium-156 gave a measured value of $300 \pm 300$ barns for the effectlve thermal absorption cross section. This result is adequate to consider the use of gadolintum as feasible. 


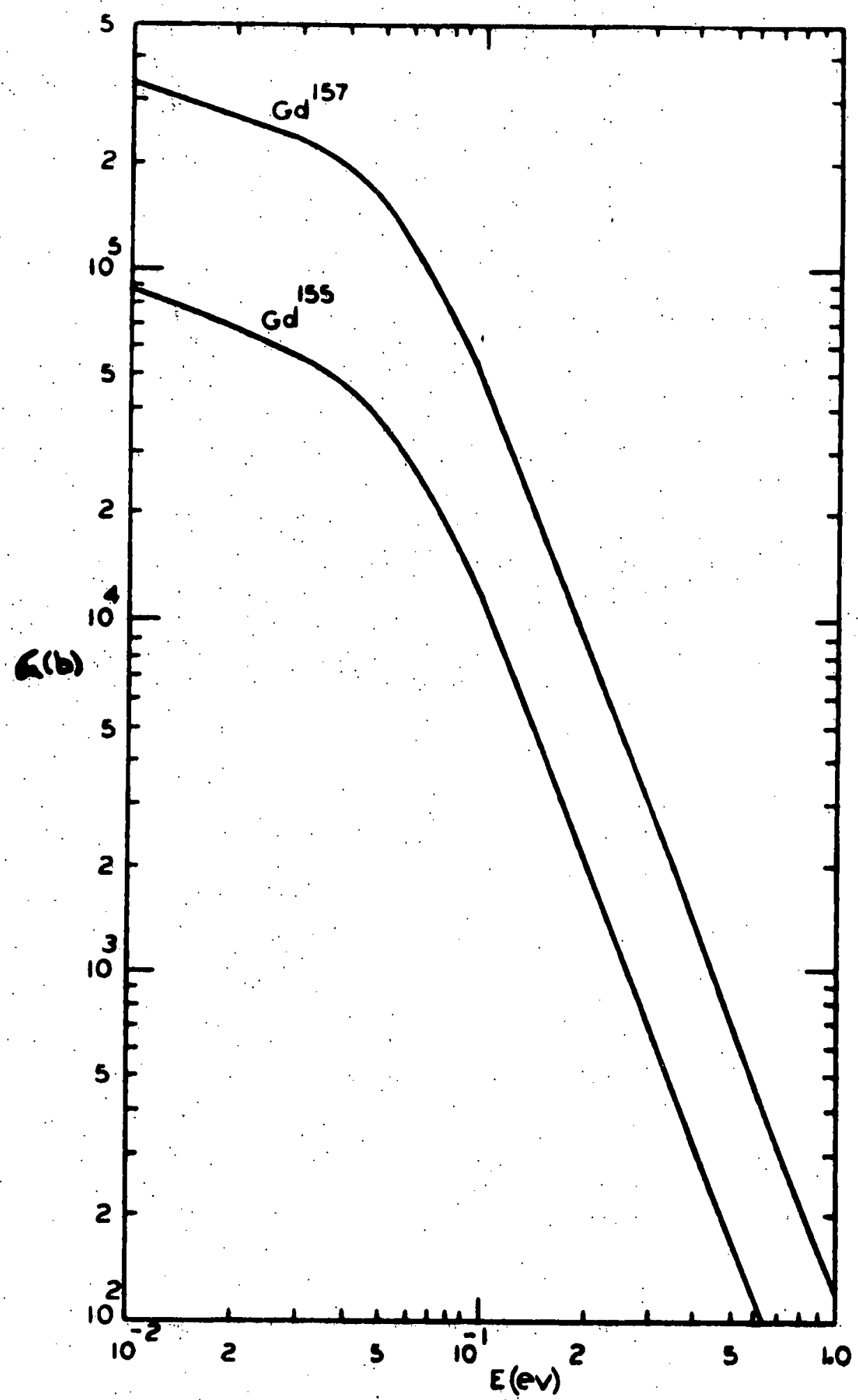

FIG 4.1 CADOLINIUM ISOTOPIC CROSS SECTIONS 


$$
10
$$




\section{SPATIAL REPRESENTATION}

In order to obtain the burnout characteristics selected in Section 1, the burnable poison must be in the form of a slab with large optical thickness and other dimensions much larger than the thlckness. Generally, a large "black" absorber 18 undesirable in a reactor due to the flux depression Induced in the adjacent material. Because of the large macroscoplc thermal absorption cross section of gadolinium, about $1000 \mathrm{~cm}^{-1}$, it 18 possible to consider polson elements having the above properties, but still small relative to the mean free path in the reactor. In the following, the model w1ll be a "black" c1rcular d1sk. The effect of disk dimensions upon the self-shielding factor and upon the external medlum w11l be investigated.

5.1 Self-Shielding Factor for the Disk

The oelf-shielding factors used in Section 1 were the asymptotic expressions, as the optical dimension becomes large, for one-dimensional absorbers immersed in a untform, 1sotroplc source of neutrons in a vacuum. These selfshielding factors can be calculated directly and exactly for th1s case. From reference (1), for a slab:

$$
f=1 / x\left[1 / 2-E_{3}(x)\right]
$$


where $X 18$ the thickness in mean free paths and $E_{3}$ is the exponential integral tabulated in reference (i). Equation (5.1.1) 18 shown in figure 5.1. By the reciprocity theorem, th1s self-shielding factor is 1dentical with the first flight escape probabllity for the case having a uniform, 1sotroplc source of neutrons within the sample surrounded by vacuum (1). Th1s has also been calculated for one-dimensional cases. Nelther method has been successfully applied to a finite, right cylinder. However, the escape probab1lity is the complement of the collision probabllity, and some useful theorems have been developed for the latter quantity $(12,13)$. Theorem three states that if $\mathrm{V}_{1} 18$ the volume common to a cylinder, $V_{3}$, and a slab, $V_{2}$, perpendicular to $1 t, P_{1} 2 P_{2} P_{3}$. Take $v_{1}$ to be a disk of thickness $x$, and diameter $D_{;} V_{2}$ to be an infinite slab of thickness $X_{;}$and $v_{3}$ to be an infinite cylinder of diameter $D$. All dimensions are measured in unt ts of mean free paths. For $X$ and $D$ much larger than unity, the asymptotic collision probab1lities become:

$$
P_{2}=1-1 / 2 X \text { and } P_{3}=1-1 / D
$$

Th1s gives

$$
P_{1} 2(1-1 / 2 x)(1-1 / D)
$$

Then, since the self-shlelding factor, $f$, 18 the complement of the collision probab1lity,

$$
f_{1} \leq 1 / 2 x+(1 / D)(1-1 / 2 X) .
$$


For large optical thicknesses $x$, this limlt approaches $1 / 2 X+1 / D$. Since this is just the generalized form for the self-shlelding factor for a "black" absorber, $S / 4 \mathrm{~V}$, it is expected that it w1ll closely approximate the actual self-shlelding factor for large samples where the "corner" effects become small. For $D \gg X$, the limit approaches that of an infinite slab $(1 / 2 x)$.

5.2 The Effect on the External Flux

Scattering in the medium surrounding the sample will reduce the self-shlelding factor from the value calculated in the last section for a vacuurn environment. Th1s can be vlewed as due to an external flux depression, caused by the current of neutrons into the sample, wh1ch reduces the magnitude and destroys the 1sotropy of the flux incldent on the sample. Alternately, for the problem with a source inside the sample, external scattering reflects some neutrons back 1nto the sample, thus reducing the escape probab1lity. Self-shlelding factors for an infinite absorbing slab In a scattering medium are given in reference (14). However, for small disks, no such formulation exists. An approximate correction, which 18 often used, accounts for the external flux depression but not for the change in the neutron angular distribution. According to the development by Bothe, as modified by Tittle (15), the flux depression due to a d1sk absorber 18:

$$
F_{s P}=1+\frac{0.34 B R}{\lambda_{t r}} \quad R<<\lambda_{t r}
$$


where $F_{8 p}$ is the ratio of flux it $\infty$ to flux at surface, $R=\operatorname{radlus}$ of $\mathrm{dlsk}$, $\beta=$ absorption probablitty of disk, and $\lambda_{t r}=$ transport mean free path in surrounding medium. This is a maximum for a black foll so $\beta=1$ will be used. The transport mean free path in cold water $(\lambda t r=3 D=$ $0.48 \mathrm{~cm}$ ) $1 \mathrm{~s}$ generally smaller than in other materials or mixtures; 80 , to produce a maximum effect that value w1ll be used. This ylelds:

$$
F_{\text {sp }}=1+0.71 R
$$

for $R$ in $\mathrm{cm}$.

A thlckness of gadolinium metial of $0.010 \mathrm{~cm}$ gives a self-shlelding factor of $1 / 20$, which is in the range of 1nterest. A diameter-to-th1ckness ratio of five $(R=0.025$ cm) produces less than a two per cent flux depression in the external medium. Th1s is quite acceptable for the effect on the power distribution in the reactor. The small value also makes the uncertainty in the calculated selfshlelding factor acceptable--probably comparable to corner effects in Section 5.1 .

In order to establish another limit for the flux depression and a relationship between 1 t and the self-shielding factor, a diffusion calculation w1ll be made for a small, black sphere immersed in an infinite, diffusing medium with a uniform source. Outside the sample: 


$$
\varphi(r)=A_{1} \frac{e^{-k r}}{r}+\frac{S}{\sum_{a}}
$$

Ht the surface of the sphere, b:

$$
\left.\frac{1}{Q(b)} \frac{d Q}{d r}\right|_{b}=\frac{1}{\delta \lambda_{t r}}
$$

where $\delta \lambda_{\text {tr }} 18$ the extrapolation distance. Th1s yields:

$$
\Phi(r)=\frac{S}{\sum_{2}}\left(1-\frac{b^{2} e^{k(b-r)}}{r\left[\delta t_{r}(1+k b)+b\right]}\right)
$$

4. balance between the current into the sample and the aboorption rate in the sample 1s:

$$
\left.4 \pi b^{2} D \cdot \frac{d q}{d r}\right|_{b}=4 / 3 \pi b^{3} \Sigma_{p} \bar{Q}_{p}
$$

where $\Sigma_{p}$ is the absorption cross section in the sample and $\bar{\Phi}_{p}$ is the average flux in the sample.

Then, the self-shielding factor,

$$
f=\frac{\bar{\phi}_{p}}{\phi(\infty)}
$$

Bo,

$$
f=\frac{1}{\sum_{p} b c}\left[\frac{1}{1+\frac{b}{\delta \lambda_{t r}(1+k b)}}\right]
$$


In the $11 \mathrm{~m} 1 \mathrm{t}$ as $\mathrm{b} \rightarrow 0, \delta \rightarrow 4 / 3$; and

$$
f \rightarrow \frac{3}{4 \varepsilon_{p} b}\left[\frac{1}{1+\frac{3 b}{4 \lambda_{t r}(1+k b)}}\right]
$$

In equation (5.2.9), the f1rot term 18 just the selfonlelding factor for a black sphere in a vacuum. The term in brackets can be viewed as a correction due to scattering in the external medium. Using (5.2.5);

$$
\frac{Q(b)}{Q(\infty)}=\frac{1}{1+\frac{3 b}{4 \lambda_{t r}(1+k b)}}
$$

It can be seen that in this approximation, the correction to the self-ohlelding factor in $(5,2.9)$ is equal to the flux depression as given in (5.2.10). In $(5.2 .10)$, Kb can be neglected relative to unity. Then, the reciprocal of $(5.2 .10)$ differs from (5.2.1) only In the constant $3 / 4$ as compared w1th 0.34 . Since a sphere would be expected to have about twice the effect of a disk with equal radius, this supports the applicablilty of (5.2.1) for evaluating the perturbation in the flux outside the sample. 


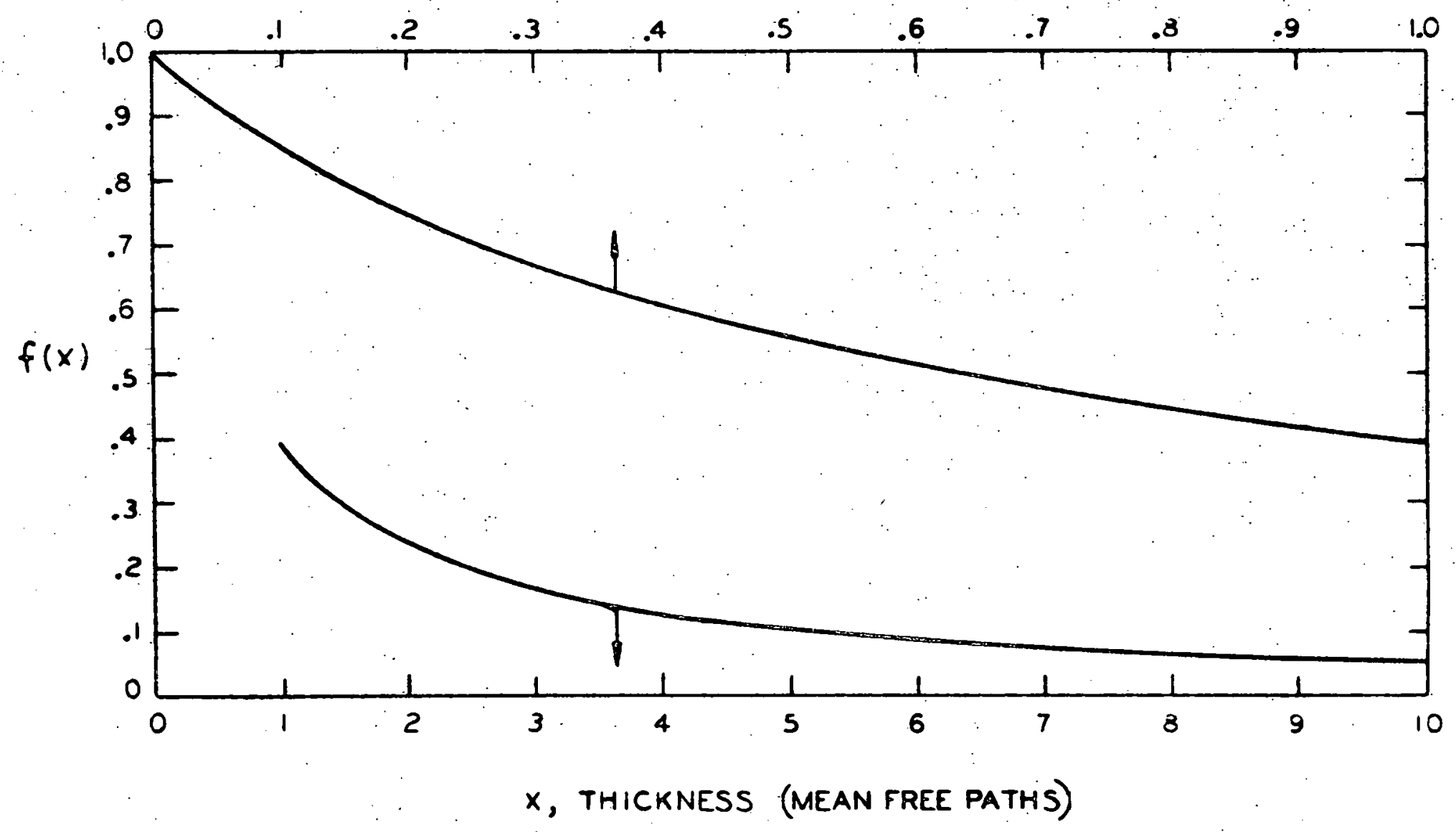

FIG. 5.1 SELF SHIELDINC FACTOF FOF ILABS 


\section{NEUTRON SPECTRUM EFFECTS}

The development in Section 1.1 assumed that the poison's cross section and self-shlelding factor were constant for all neutrons incldent on the sample. The effect of a more real1st1c neutron spectrum for a thermal reactor w11l now be 1nvestigated.

Dividing the neutron distribution 1nto epithermal and thermal components, 1 can be seen that epithermal absorption 18 negligible. Using the resonance integral given in table 3.1 for gadolinium and applying a thermal self-shieldIng factor of $1 / 20$, the eplthermal absorption rate is less than one per cent of the thermal rate for a reactor w1th the spectrum used in section 2. Since this will not materially effect elther the polson's effective cross section or burnup characterist1cs, ep1thermal absorption will be neglected in further development.

\subsection{Average Thermal Cross Sections}

The neutron flux in the thermal region was taken as a Maxwellian $\left[\varphi(E)=E /(k T)^{2} \exp (-E / K T)\right]$. Flux distributions for $k T=0.0253,0.038$, and $0.0506 \mathrm{ev}$ are shown in figure 6.1. The gadolinium microscoplc absorption cross sections, shown in figures 4.1 and 4.2 , were averaged over these distributions. For all spectrum averaging, the following 
energy Intervals were used:

$\begin{array}{ll}\frac{E(e v)}{0-0.100} & \frac{\Delta E(e v)}{0.005} \\ 0.100-0.200 & 0.010 \\ 0.200-0.400 & 0.020\end{array}$

For all cases, the contribution from above $8 \mathrm{kT}$ was neglig1ble, so the averaging terminated there. Table 6.1 gives the gadolinium microscoplc cross sections averaged over these distributions.

TABLE 6.1

OADOLINIUM THERMAL CROSS SECTIONS (barns)

\begin{tabular}{llll}
\hline$k T(e v)$ & $G d-155$ & $G d-157$ & $G d$ \\
\hline 0.0253 & 40,700 & 171,000 & 32,800 \\
0.0380 & 30,300 & 125,000 & 24,100 \\
0.0506 & 22,300 & 94,700 & 18,100 \\
\hline
\end{tabular}

Th1s ylelds a macroscopic absorption cross section of $994 \mathrm{~cm}^{-1}$ for gadolinium metal in the $0.0253 \mathrm{ev}$ spectrum. To calculate the spectrum effect for self-shielded slabs, the self-shlelding factor given by equation 5.1.1 was used. For a given thickness, Y, the optical thlckness, 
$x$, corresponding to each energy interval was calculated. Since the absorption rate per untt area $18 \mathrm{Xf}(\mathrm{X})$, this quant1ty was formed for each interval. Th1s equals $1 / 2$ for a black absorber; so the effective cross section relative to a black absorber $18 \operatorname{2xf}(X)$. Th1s 18 shown in figure 6.2. The values of $2 \operatorname{Xf}(x)$ were averaged over each of the spectra shown in figure 6.1 for four different thicknesses. These results are given in table 6.2 . In figure 6.3 , the relative absorption rate versus gadolinium thickness 18 shown, and In figure $6.41 t 18$ cross plotted versus neutron temperature. It can be kept in mind that the opt1cal thickness, using the average cross section in the 0.0253 ev spectrum, 16 about 1000 times the thickness given in these figures. The assumption made here is that the spectrum incident on the sample is unaffected by absorptions in the sample. Th1s is valld when the burnable polson's absorption rate 18 small relative to other absorptions in the reactor. The nearly unfform absorption rate over the thermal spectrum also 1mproves this approximation. 
TABLE 6.2

SPECTRUM AVERAGED ABSORPTION RATES

\begin{tabular}{llll}
\hline \hline & \multicolumn{3}{c}{$\frac{}{2 X_{f}(X)}$} \\
\cline { 2 - 4 }$Y(\mathrm{~cm})$ & $\mathrm{kT}=0.0253 \mathrm{ev}$ & $0.038 \mathrm{ev}$ & $0.0506 \mathrm{ev}$ \\
\hline 0.0025 & 0.860 & 0.748 & 0.638 \\
0.0050 & 0.949 & 0.859 & 0.759 \\
0.0100 & 0.983 & 0.930 & 0.857 \\
0.0200 & 0.996 & 0.970 & 0.922 \\
\hline
\end{tabular}

6.2 Temperature Coefficient

The slopes of the curves in figure 6.4 were measured to obtaln the rate of change of thermal absorption with neutron temperature. For a $1 / v$ cross section, the corresponding change $18-1 / 2 \mathrm{~T}$ for $\mathrm{T}$ in ${ }^{\circ} \mathrm{K}$. These results are plotted in figure 6.5 .

In order to convert this thermal absorption effect into a reactivity coefficient, it will be assumed that the fuel and all materials but the polson are $1 / v$ thermal absorbers. Then the thermal utilization,

$$
F=\frac{\sum_{a}^{F}}{\sum_{a}^{\top}+\sum_{a}^{P}}
$$

w1th $\sum_{a}^{F}=$ macroscoplc absorption cross section of fuel.

$\Sigma_{a}^{\top}=$ total macroscopic absorption cross section without polson 
$\quad Z_{a}^{P}=$ macroscoplc absorption cross section of poison $\frac{\partial F}{\partial T}=\frac{1}{\sum_{a}^{T}+\sum_{a}^{P}} \cdot \frac{\partial \sum_{a}^{F}}{\partial T}-\frac{\Sigma_{F}}{\left(\sum_{a}^{T}+\sum_{a}^{P}\right)^{2}}\left(\frac{\ddot{\partial} \varepsilon_{a}^{T}}{\partial T}+\frac{\partial \varepsilon_{a}^{p}}{\partial T}\right)$

$-F\left(\frac{1}{\sum_{a}^{F}} \frac{\partial \sum_{a}^{F}}{\partial T}\right)-F \frac{\sum_{a}^{T}}{\sum_{a}^{T}+\sum_{a}^{P}}\left(\frac{1}{\xi_{a}^{T}} \frac{\partial \sum_{a}^{T}}{\partial T}\right)-F \frac{\sum_{a}^{P}}{\sum_{a}^{T}+\sum_{a}^{P}}\left(\frac{1}{\sum_{a}^{P}} \frac{\partial \sum_{a}^{P}}{\partial T}\right)$

$(6.2 .2)$

But

$$
\frac{1}{\sum_{a}^{F}} \cdot \frac{\partial \sum_{a}^{F}}{\partial T}=\frac{1}{\sum_{a}^{T}} \cdot \frac{\partial \sum_{a}^{T}}{\partial T}
$$

18 the quantity plotted in flgure 6.5 for a $1 / v$ absorber,

$$
\frac{\sum_{a}^{p}}{\Sigma_{a}^{r}+\sum_{a}^{p}}=\rho p
$$

18 the reactivity held in poison, and

$$
\frac{1}{\sum_{a}^{p}} \cdot \frac{\partial \sum_{a}^{p}}{\partial T}
$$

1s the quantity plotted in figure 6.5 for self-shielded poisons. Applying these 1dentifications:

$\frac{1}{K} \cdot \frac{\partial K}{\partial T}=\frac{1}{F} \frac{\partial F}{\partial T}=\rho_{p}\left(\frac{1}{\sum_{a}^{T}} \frac{\partial \Sigma_{a}^{T}}{\partial T}-\frac{1}{\sum_{a}^{p}} \frac{\partial \Sigma_{a}^{p}}{\partial T}\right)$

Th1s result 18 plotted in figure 6.6 . The temperature defect from $20^{\circ} \mathrm{C}$ to the operating neutron temperature was obtalned by integrating the curves 
in P1gure 6.6. These results are given in figure 6.7.

The temperature coefficlent curves, figure 6.6, show that the coefficlent becomes more negative with decreasing temperatures. Since for most water reactors the coefficlent becomes less negative (or positive) with decreasing temperature, this phenomenon could be explolted in reactor design. A "wetter" latt1ce, wh1ch in the absence of the poison would have had a positiye cold temperature coefficient, could be utilized.

The temperature defect, shown in flgure 6.7, would generally affect reactor performance adversely--less holddown for the reactor cold than operating. However, utilization of the temperature coefficlent shape could result in a reactor with a smaller net temperature defect.

A final evaluation of the effect of this contribution to a reactor's temperature coefficient will have to be made for each speciflc reactor design. However, it does not appear as though these effects will necessarlily be deleterious. Considered as a replacement for shim control rods, the temperature coefficlent is like that of thermally black rods so that no improvement can be obtalned from that phenomenon. The temperature defect then limits the replacement to about seventy per cent (or more) of the shim rods. Th1s $1 \mathrm{~s}$ still a substantial improvement in control rod requirements. Cons1dered as a replacement for an unshielded burnable poison, the balance between the temperature coefficlent and the defect should give the shlelded poison concept equal or better performance. 


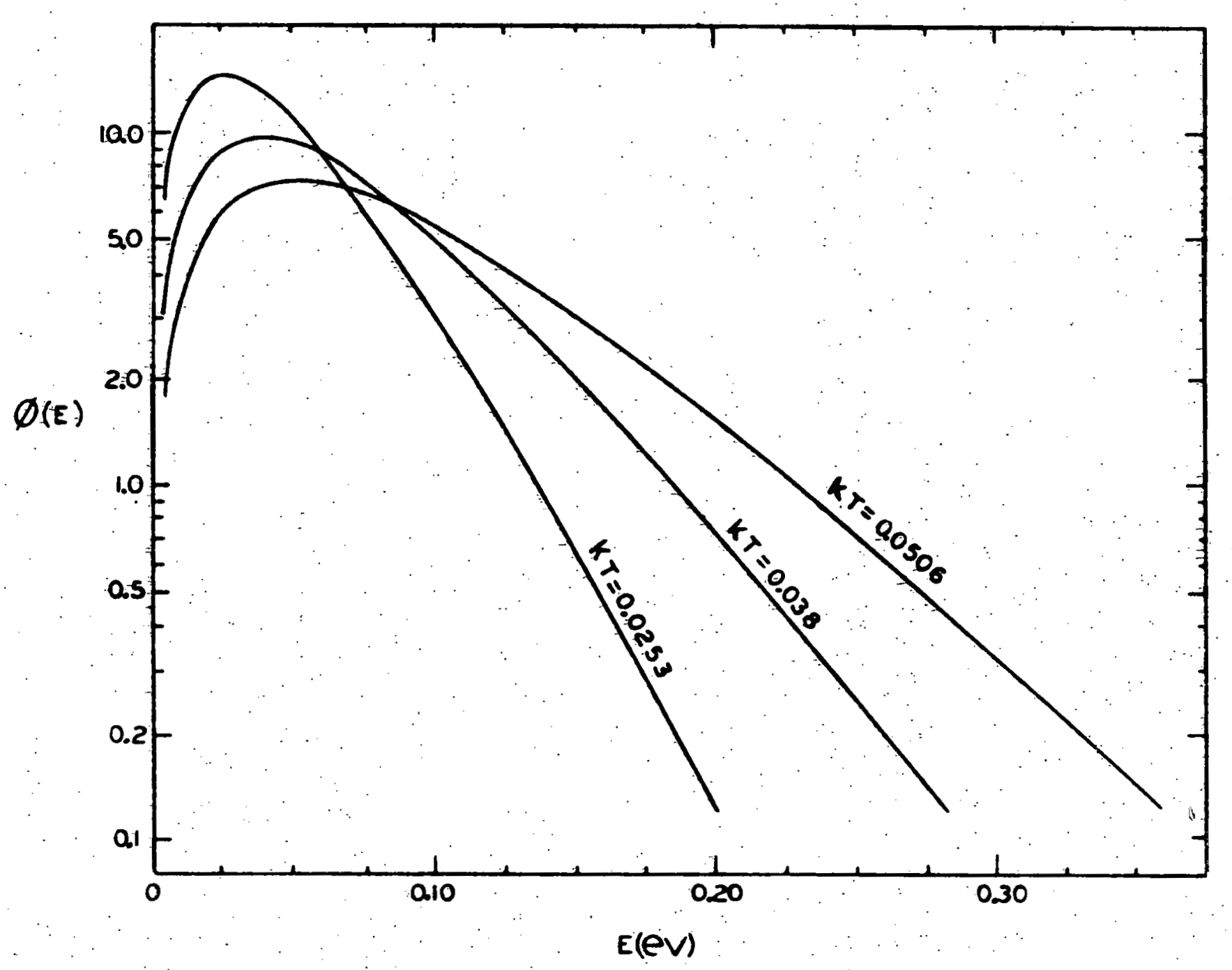

$\pm$

FIG. 6.I MAXWELLIAN DISTRIBUTIONS 


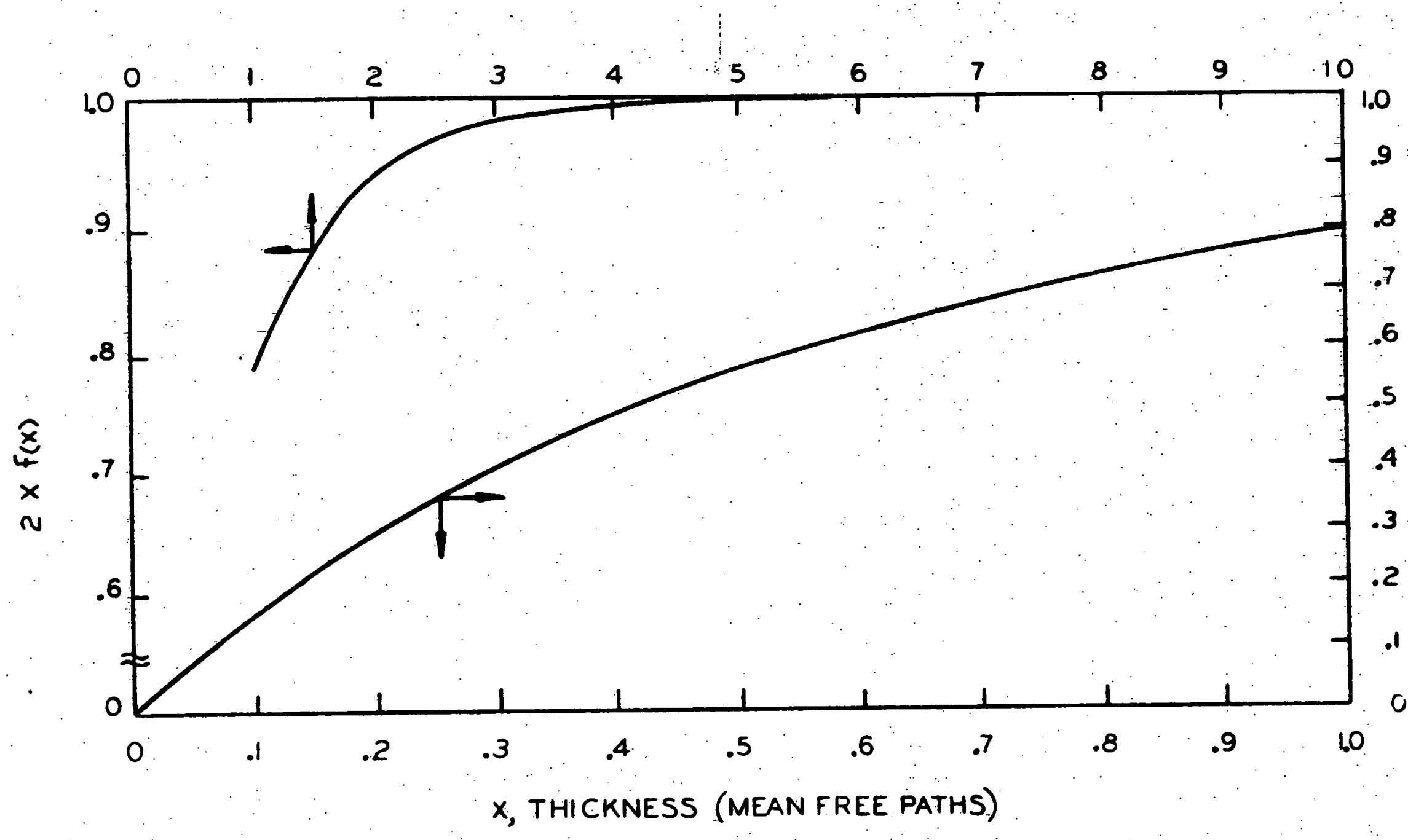

FIG 6.2 RELATIVE ABSORPTION RATE FOR SLASS 


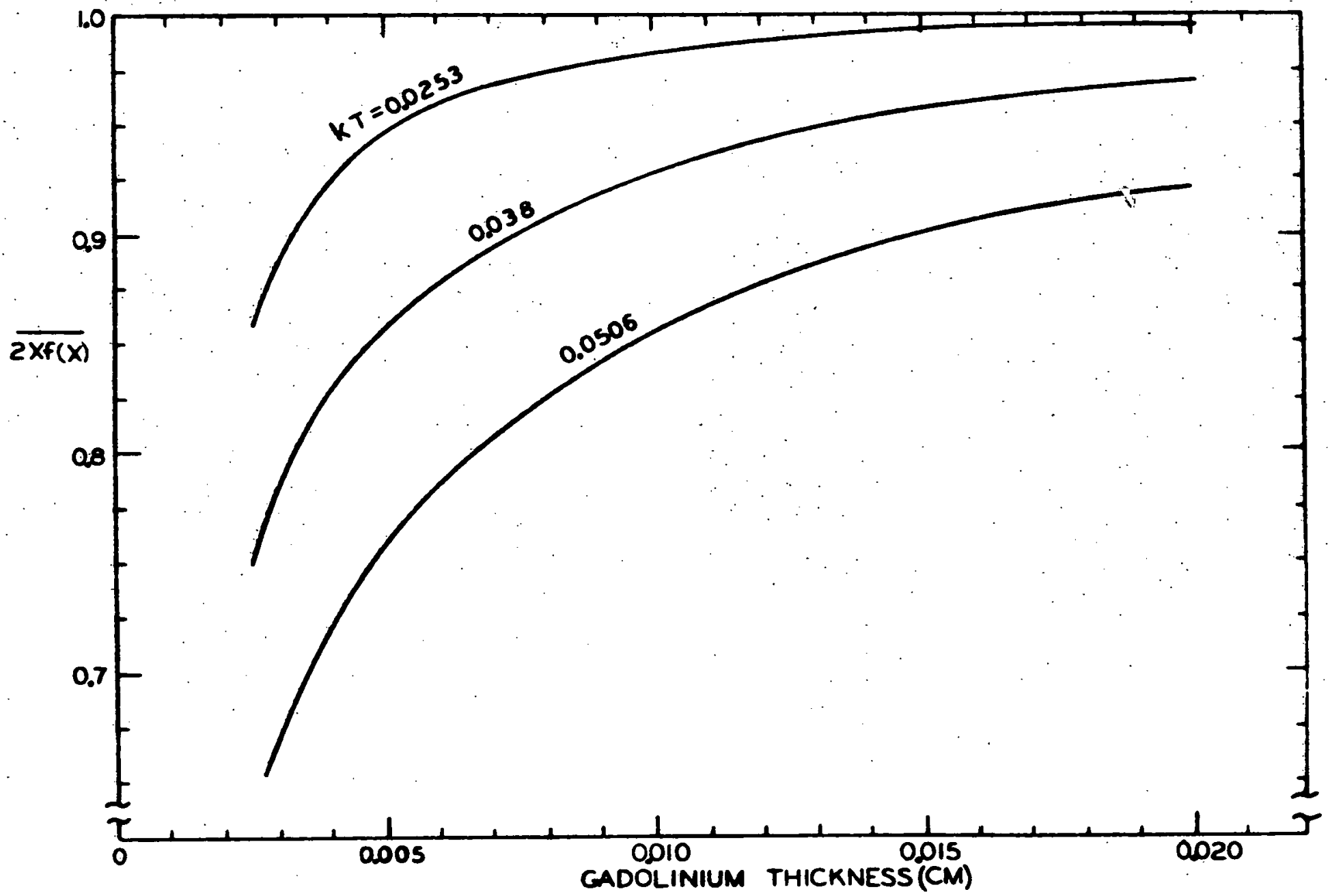

FIG.63 RELATIVE ABSORPTION RATE VERSUS THICKNESS 


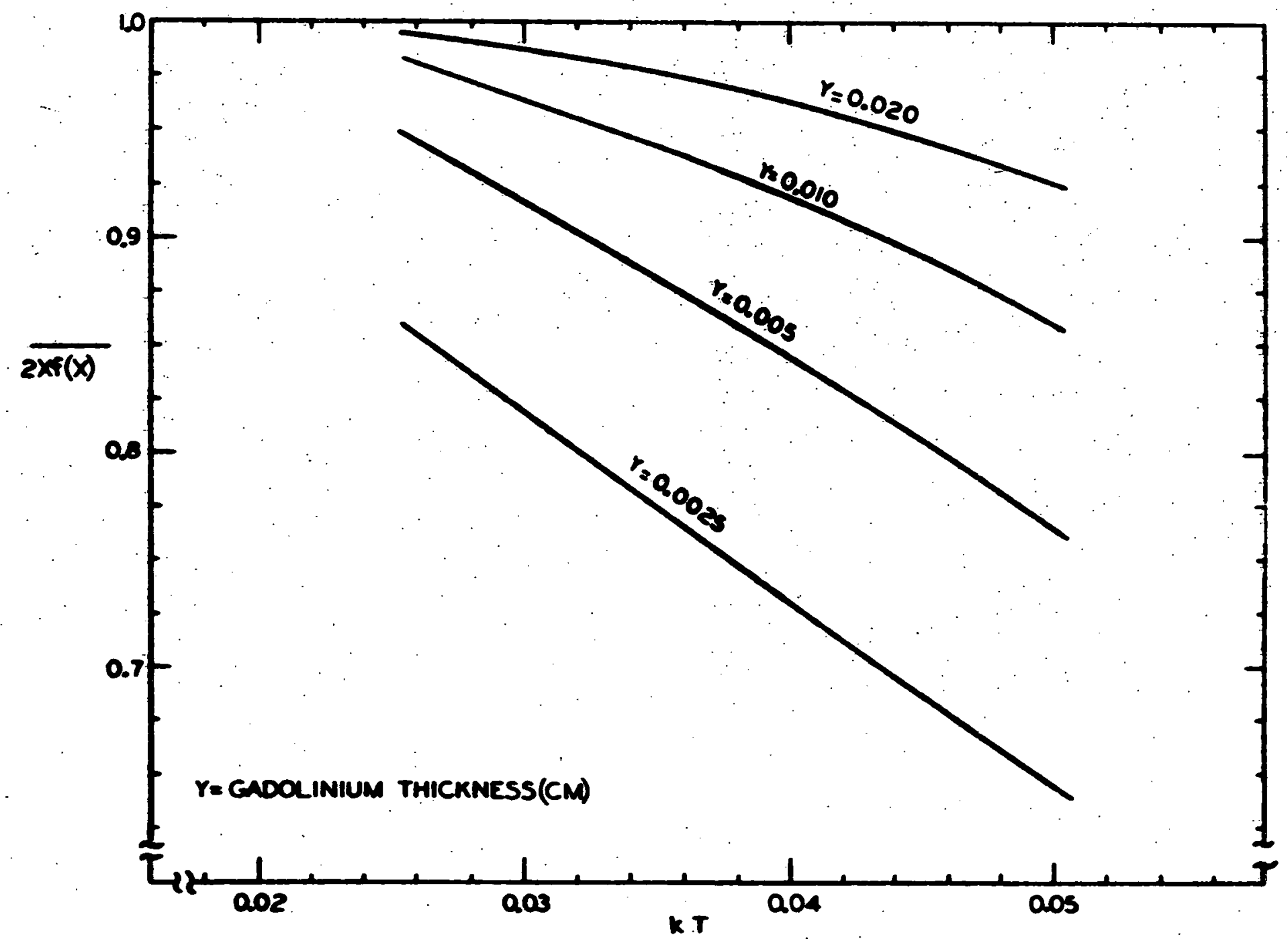

FIG 6.4 RELATIVE ABSORPTION RATE VERSUS NEUTRON TEMPERATLRE 


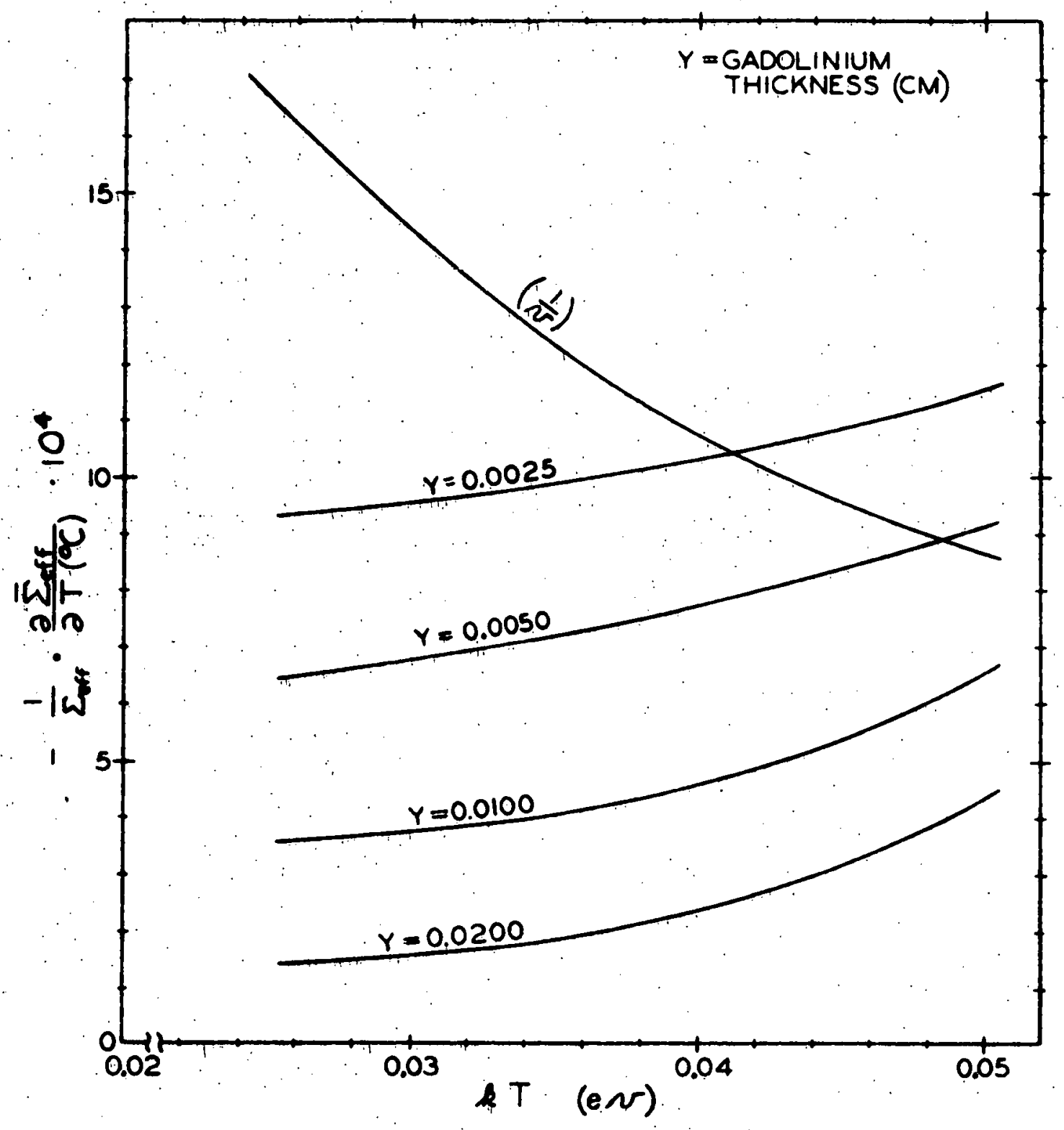

FIG. 6.5 CHANGES IN ABSORPTION RATE WITH TEMPERATURE 


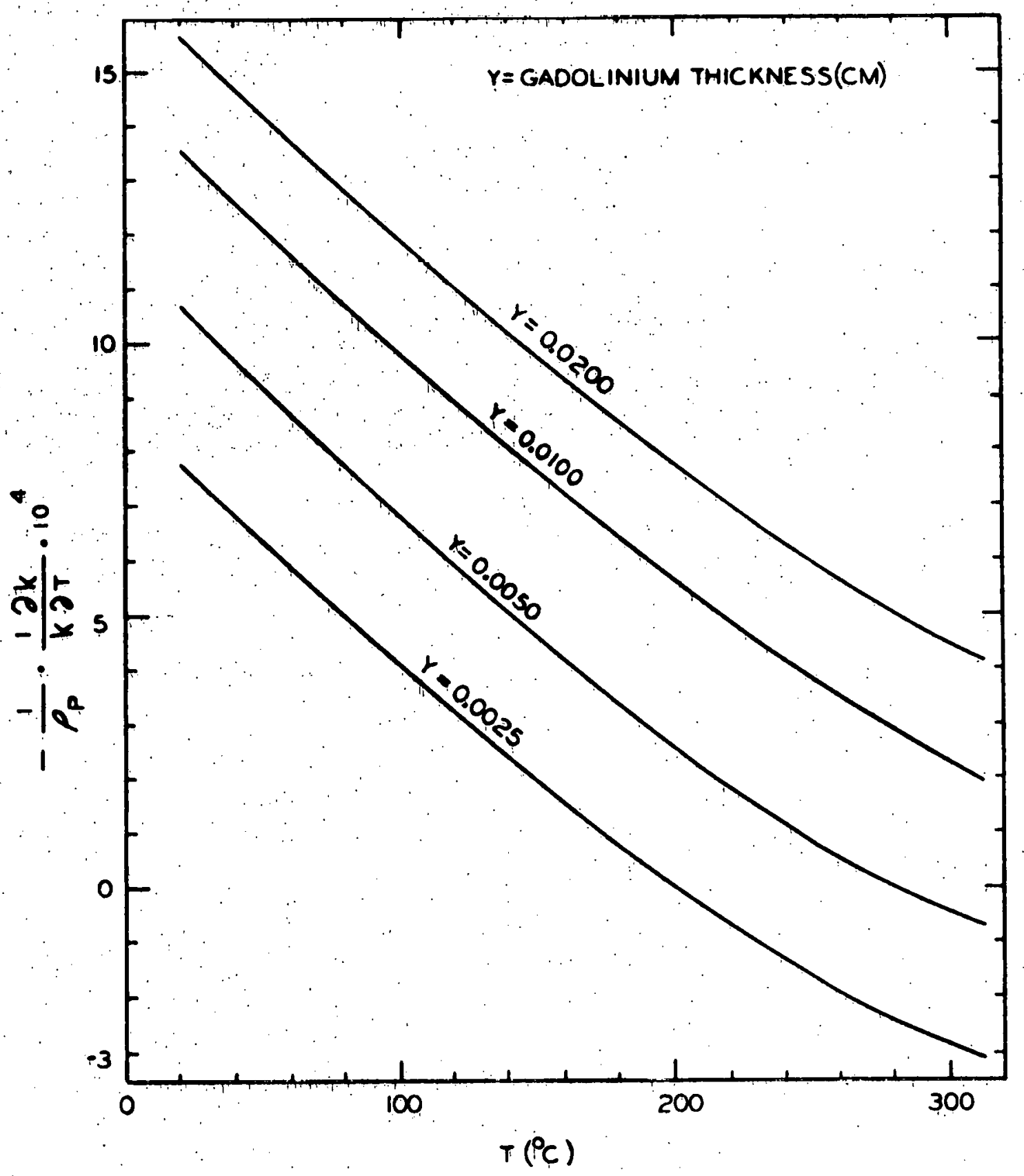

FIG. 6.6 TEMPERATURE CPEFFICIENTS 


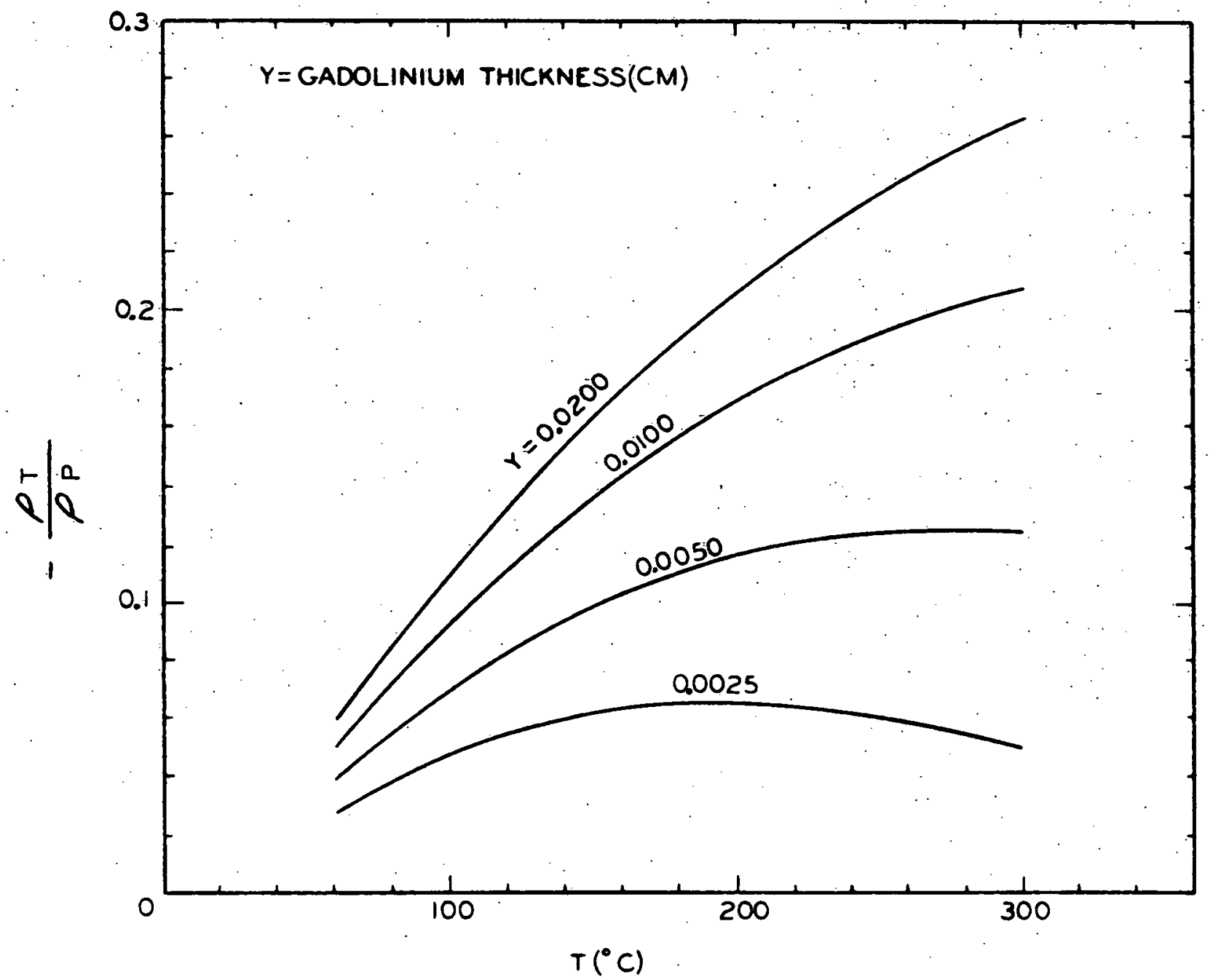

FIG. 6.7 REACTIVITY DEFECT 


\section{EPPECTIVE POISON CROSS SECTIONS}

Using the results of the last two sections, effective cross sectlons for gadolinium disks w11l now be calculated. The model consists of the upper limit on the self-shielding factor, established with Dresner's theorems $[1 / 2 X+(1 / D)(1-1 / 2 X)]$. for a black absopber, and a correction for spectral hardening In the sample as given in figure 6.4. No correction w111 be applied for scattering in the external medium since, for most disk s1zes, this factor 18 small, and 1t depends upon the properties of a particular reactor. Self-shielding fac: tors for different disk sizes in the three spectra were calculated. Figures $7.1,7.2$, and 7.3 show the reciprocal of the self-shielding factor for these cases. The reciprocal 1s plotted in order to distingulsh more easily between cases with large self-shlelding:

These predictions are compared with the experimental results from Section 9 in table 7.1 . The agreement is excellent. That this 18 not entirely fortultous can be seen from the reproducibil1ty of similar samples. Samples 24 and 25 were made from different batches of gadolinium foll. Each was rolled, punched, and blended separately. Samples 26 and 27 were made from the same batch of folls and were blended together. Samples 30 and 32 were made from the same batch 
of folls but blended separately to give samples with foll concentrations differing by a factor of two.

\section{TABLE 7.1}

CALCULATED AND MEASURED SELF-SHIELDINO FACTORS

\begin{tabular}{ccccc}
\hline Sample No. & $\mathbf{Y}(\mathrm{cm})$ & $\mathbf{c}(\mathrm{cm})$ & $\mathbf{f}($ calculated $)$ & $\mathbf{f}$ (measured) \\
\hline 24 & 0.00263 & 0.0635 & 0.175 & 0.172 \\
25 & 0.00268 & 0.0635 & 0.172 & 0.178 \\
26 & 0.00442 & 0.0635 & 0.118 & 0.113 \\
27 & 0.00442 & 0.0635 & 0.118 & 0.113 \\
30 & 0.01226 & 0.0635 & 0.0555 & 0.0537 \\
32 & 0.01226 & 0.0635 & 0.0555 & 0.0522 \\
34 & 0.01714 & 0.0635 & 0.0443 & 0.0451 \\
35 & 0.01687 & 0.1270 & 0.0373 & 0.0382 \\
36 & 0.01761 & 0.0381 & 0.0539 & 0.0527 \\
\hline
\end{tabular}

F1gure 7.4 compares the reclprocal of the measured self-shlelding factors, for the $0.0635 \mathrm{~cm}$ dlameter disks, with the calculated values and with the upper 11mit of an Infinte slab. The spectral correction was applied to the measured values in order to compare them with the calculations of a black disk.

Figure 7.5 compares the reciprocal of the measured and 
53

calculated self-shlelding factors for disks wi th different diameters. The calculated values are for black disks with the average thickness of the samples measured. So, the measured points are corrected for the small differences in thickness and for the spectral hardening.

The agreement between calculated and measured values of the self-shielding factor is adequate to establish the effective initial cross section of the burnable poison sampres. 


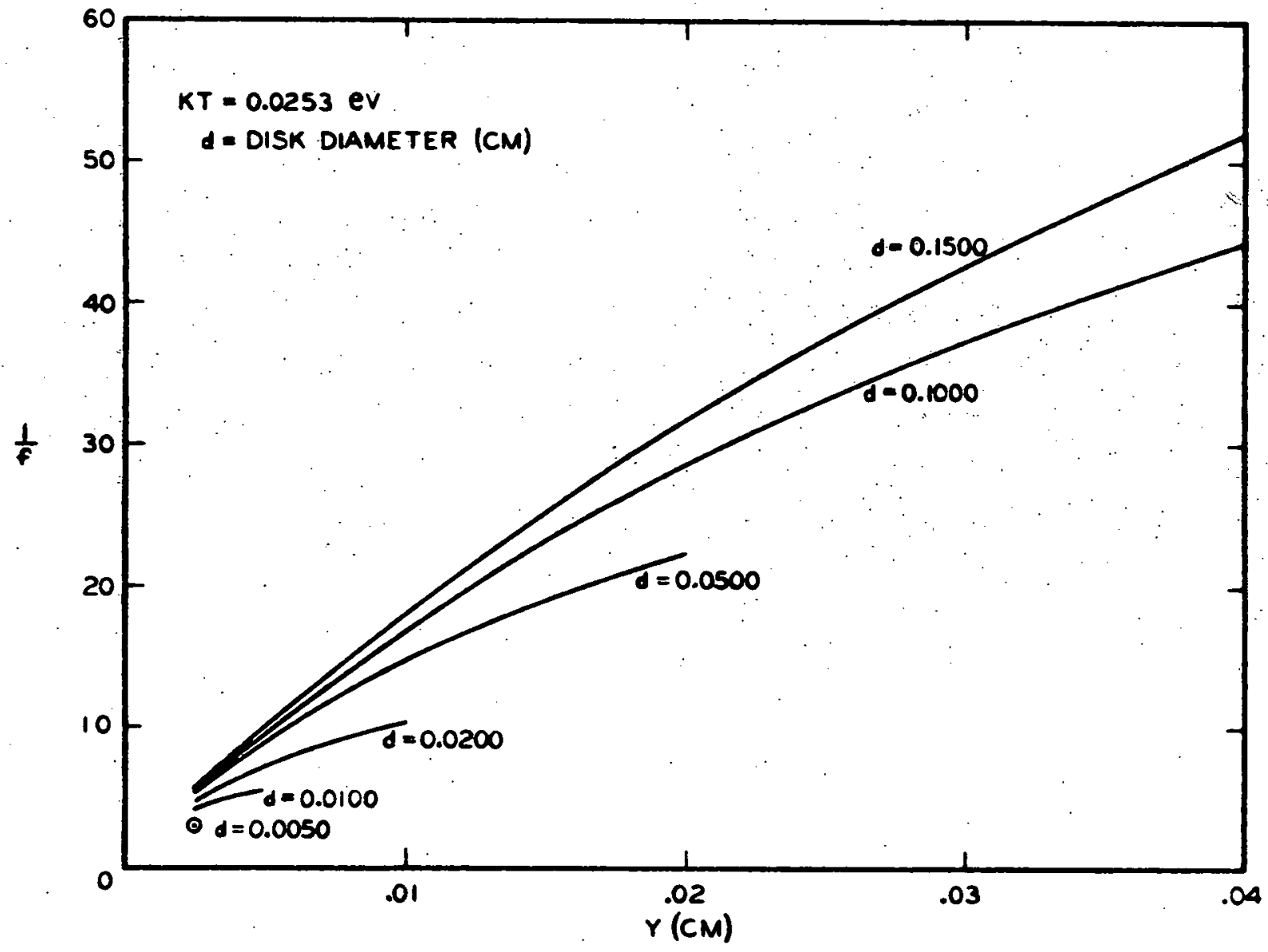

FIG. 7.1 SELF SHIELDING FACTORS FOR GADOLINIUM DISKS 


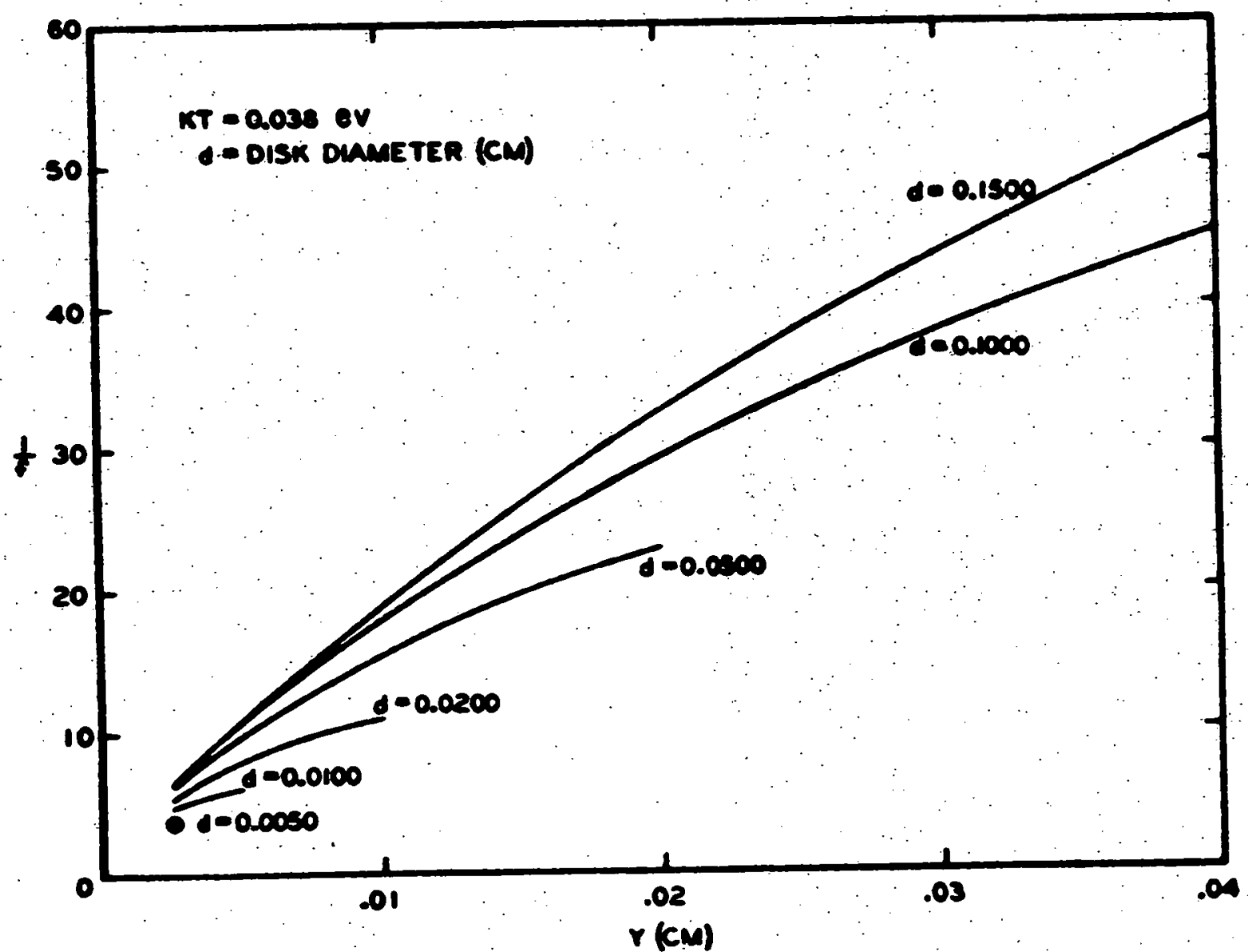

FIG 72 SELF SHIELDING FACTORS FOR GADOLINIUM DISKS 


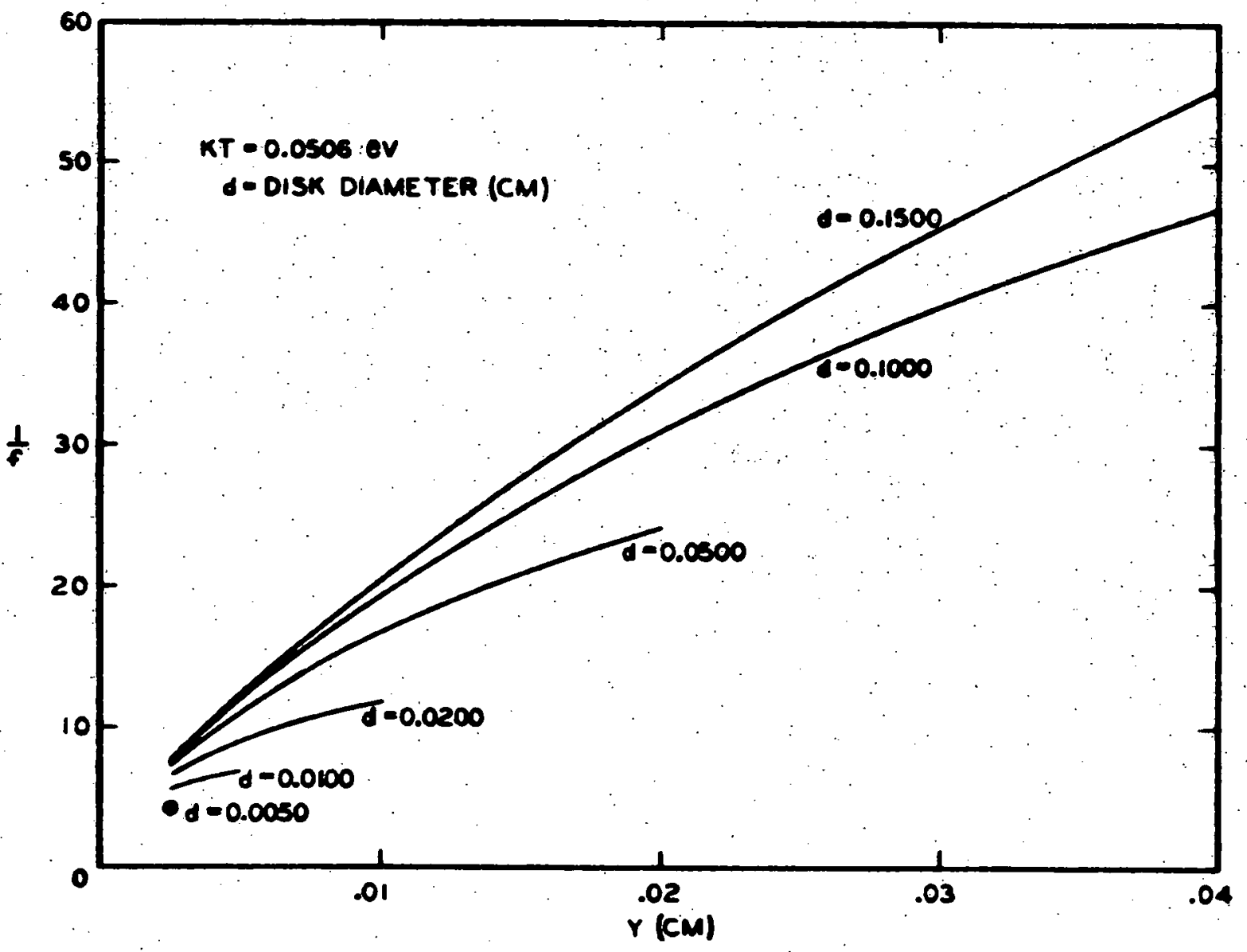

FIG 7.3 SELF SHIELDING FACTORS FOR GADOLINIUM DISKS 


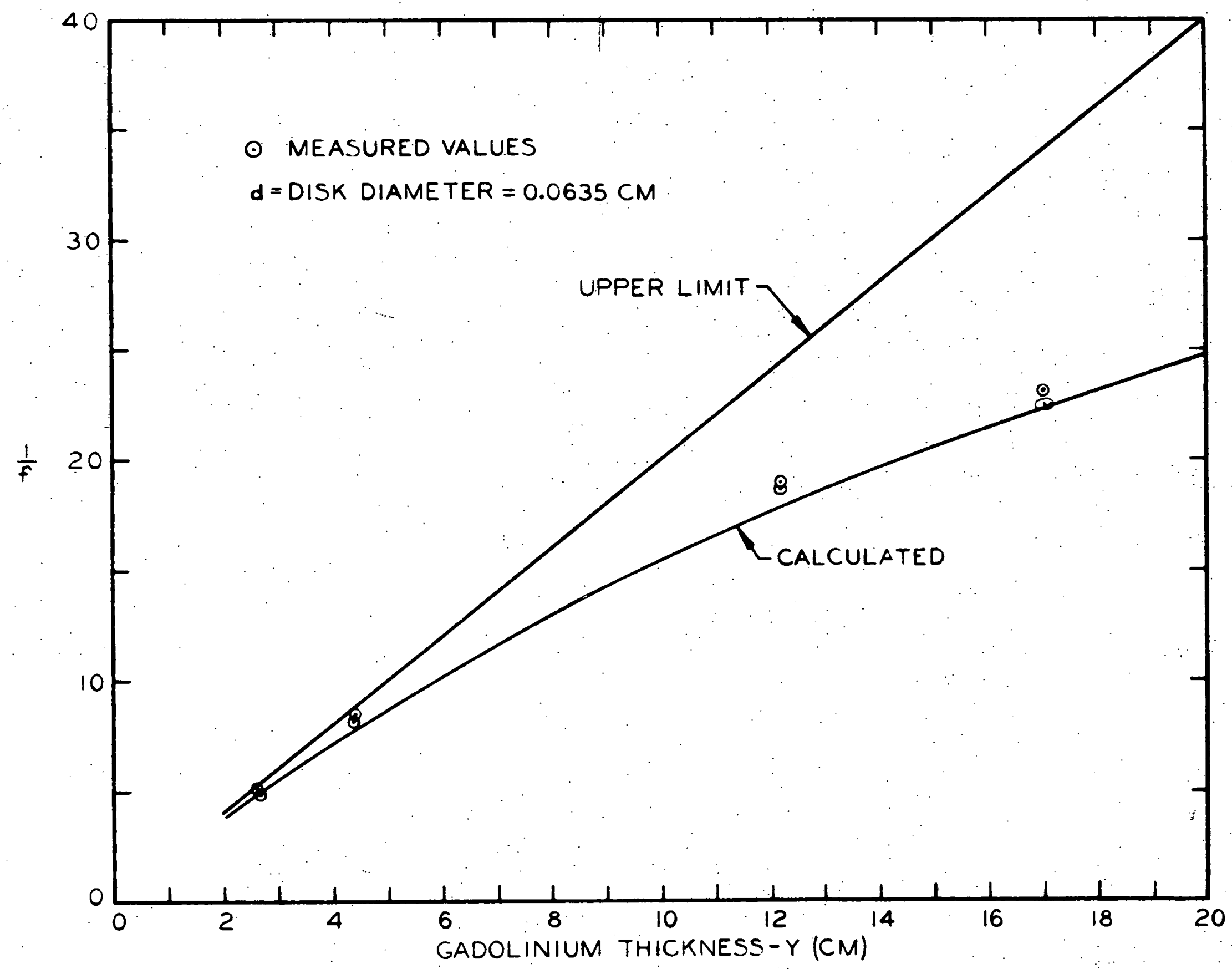

FIG 7.4 MEASURED AND CALCULATED SELF SHIELDING FACTORS 


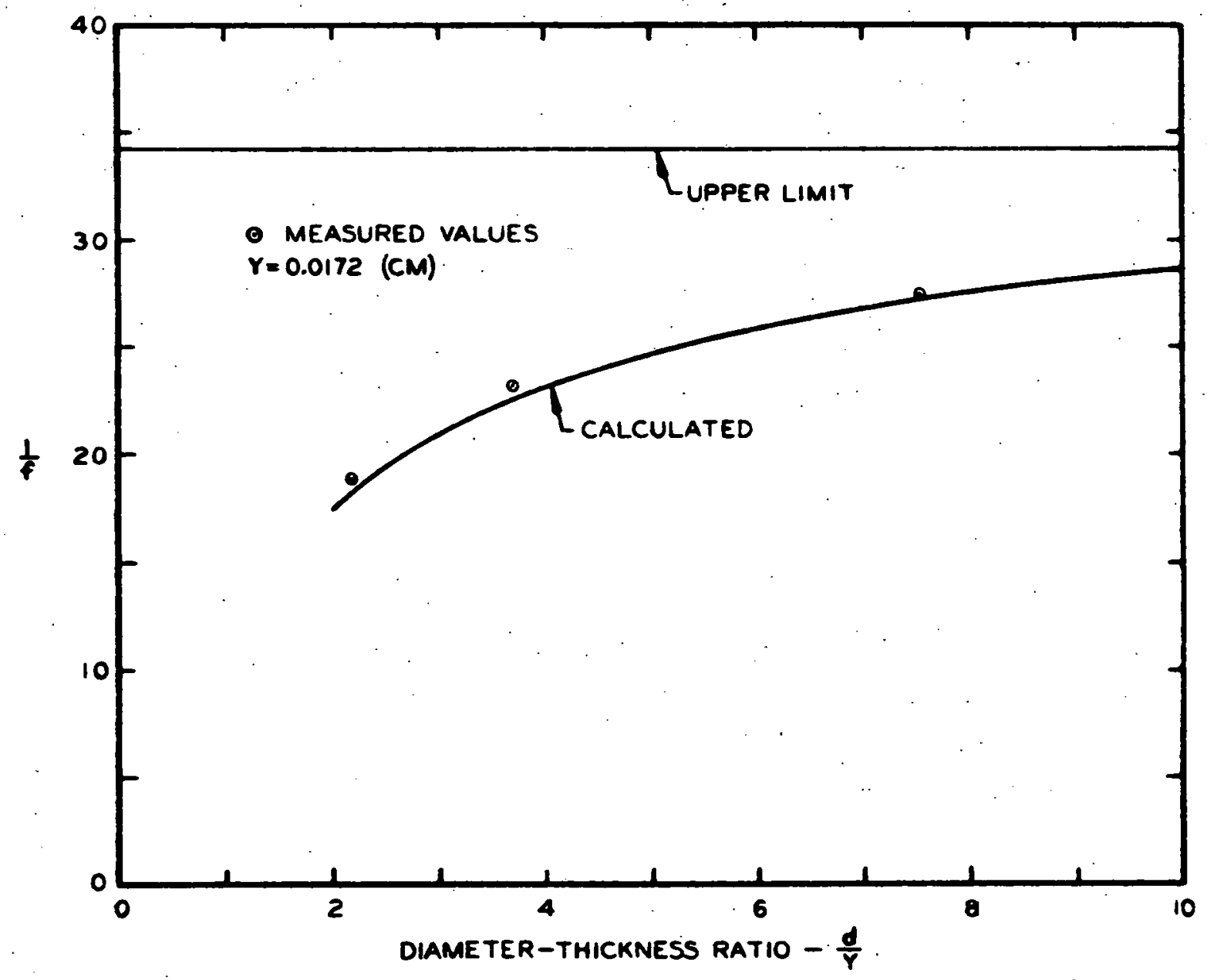

FIG. 7.5 MEASURED AND CALCULATED SELF SHIELDING FACTORS 


\section{DEPLETION EFFECTS}

W1th the Initial effective cross section of the absorber established, the effect of depletion w1ll now be investigated. The actual burnout shape, Including transition from the "black" through the "grey" to the unshlelded state will be calculated. Effective cross sections versus irradiation w1ll be obtained for disks of different dimensions.

\subsection{Spat1ally Dependent Depletion}

Since the gadolinium-155 cross section 18 about a factor of four lower than that of gadolinlum-157, it is expected that the final exponential "tall" w1Il be determined by the 1551 18otope. To calculate the effect of the spatially dependent 18otopic concentrations with burnup, a numerical calculation was performed. A slab of gadolinium, $0.01226 \mathrm{~cm}$ th1ck, was divided 1nto thirty increments. Neutron flux was assumed to be incldent on both faces. The flux at a distance, $z$, from one face of the sample of thickness, $y$, was taken to be:

$$
Q(z)=Q_{0} / 2\left\{E_{2}(\Sigma z)+E_{2}[\Sigma(y-z)]\right\}
$$

The absorption rate in the sample was spectral averaged as in section 6. Ten time increments were used in depleting 
the sample. The results of this calculation are shown in figures 8.1 and 8.2. Figure 8.1 gives the optical thickness as a function of 1rradiation. The Inttial rapid decrease in optical thickness 18 due to burnout of the 157 1sotope in the surface layers. The latter stages in life are dominated by the 155 180tope. Pigure 8.2 gives the relative effective cross section as a function of 1rradiation. For comparison, the 1dealized behavior from section 1.1 is shown as the dashed curve. It can be seen from figure 8.2 that the duration of the effective "tall" (grey and exponential) of the burnout curve 18 about $\varphi t=2 \times 10^{20}$. Th1s behav1or w111 be Incorporated, by superposition, in the balance of the depletion curves calculated.

\subsection{Depletion of Disk Samples}

The effective cross sectlons for disk samples following Irradiation was calculated for varlous size disks. The calculations used the 0.0506 ev spectrum as belng representative of the operating case. These results are shown in f1gures 8.3, 8.4,8.5, and 8.6. As can be seen from the curves, almost any decreasing effective cross section can be formed by selection of diameter and thickness of the polson sample.

A comparison with the measured value described in Section 9, 18 shown in figure 8.7. The agreement with the prediction 18 very good. Th1s burnout model should be adequate for design purposes. 


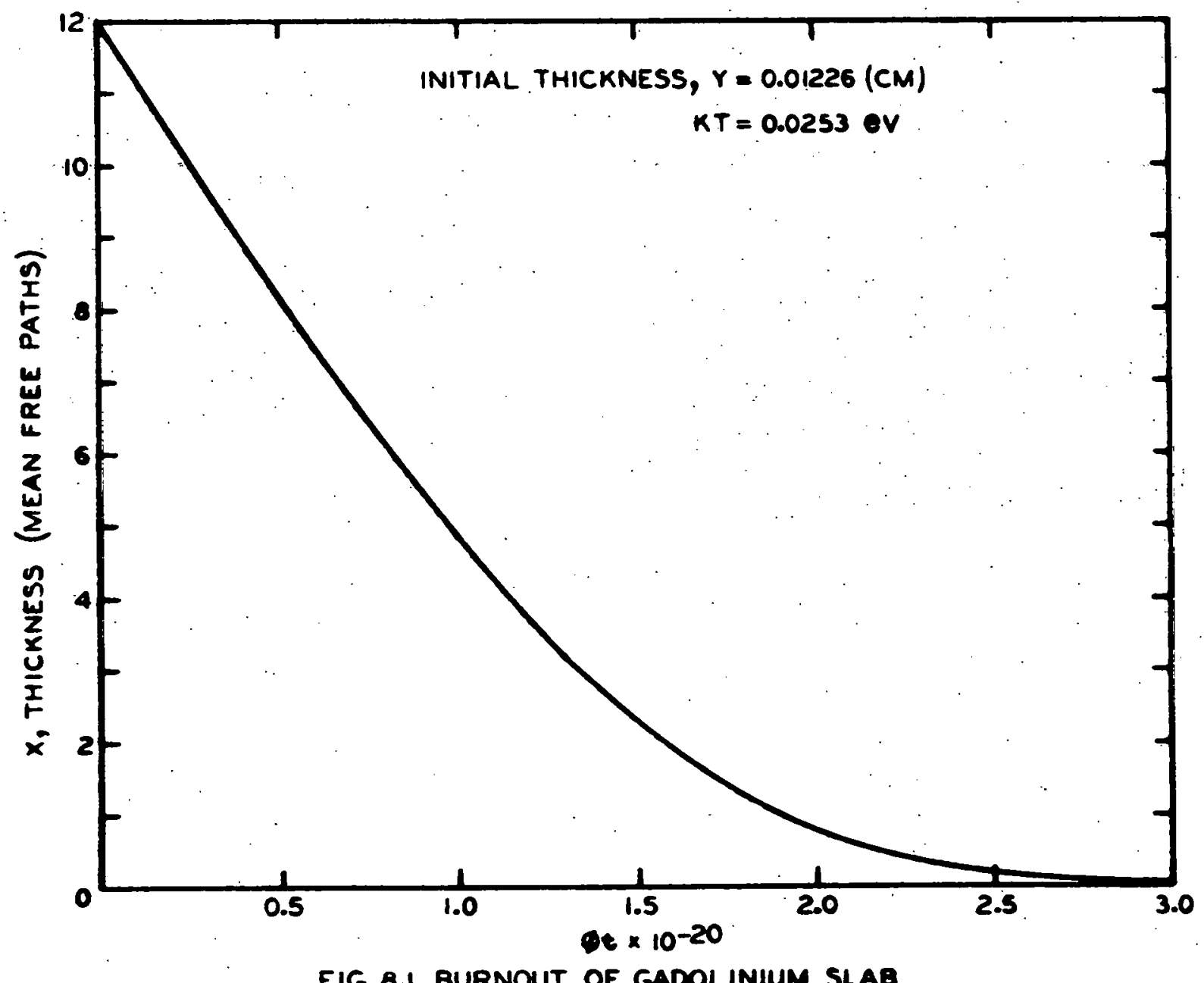

FIG 6.1 BURNOUT OF GADOLINIUM SLAB 


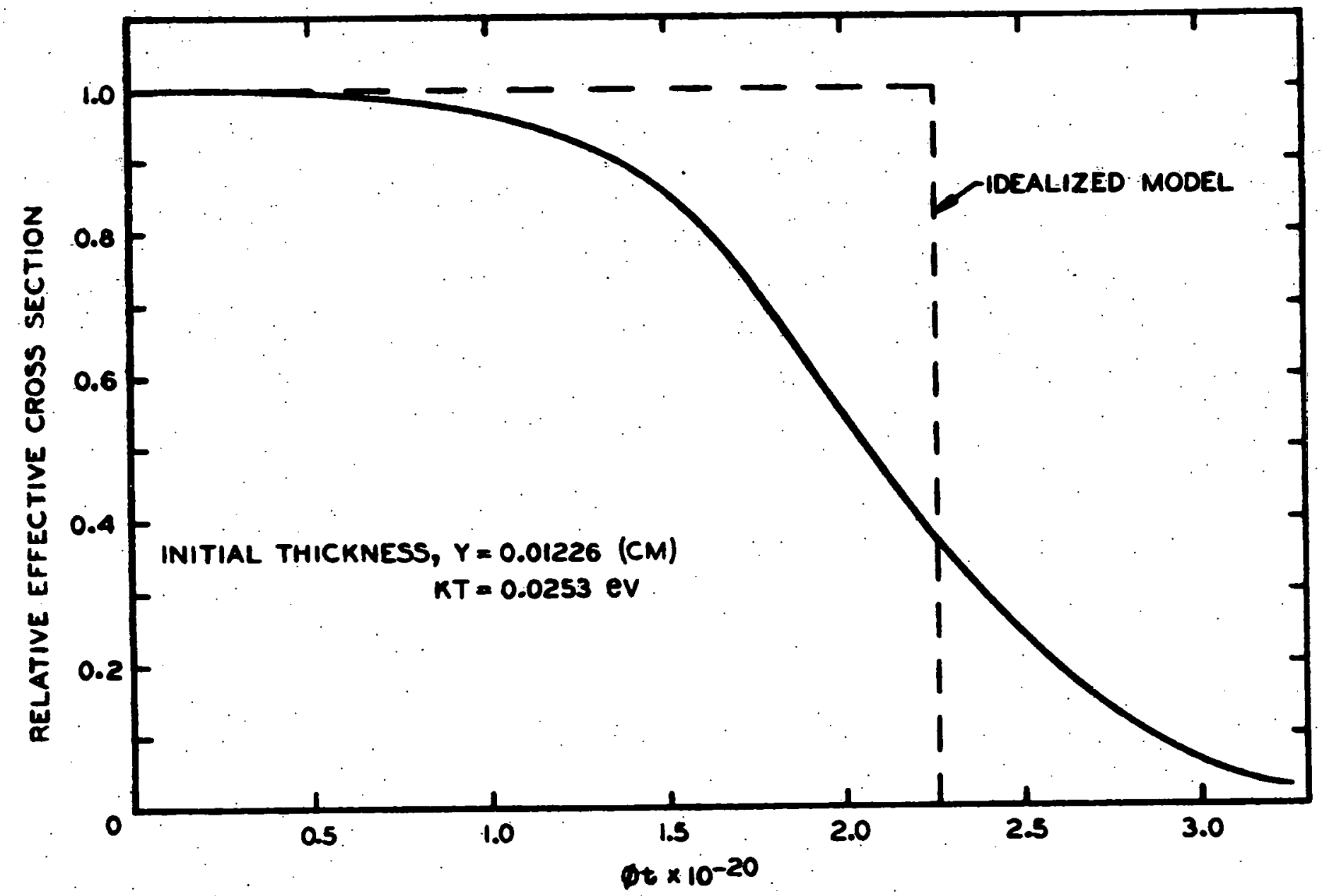

กิ

FIG. 8.2 EFFECTIVE CROSS SECTION VS. IRRADIATION 


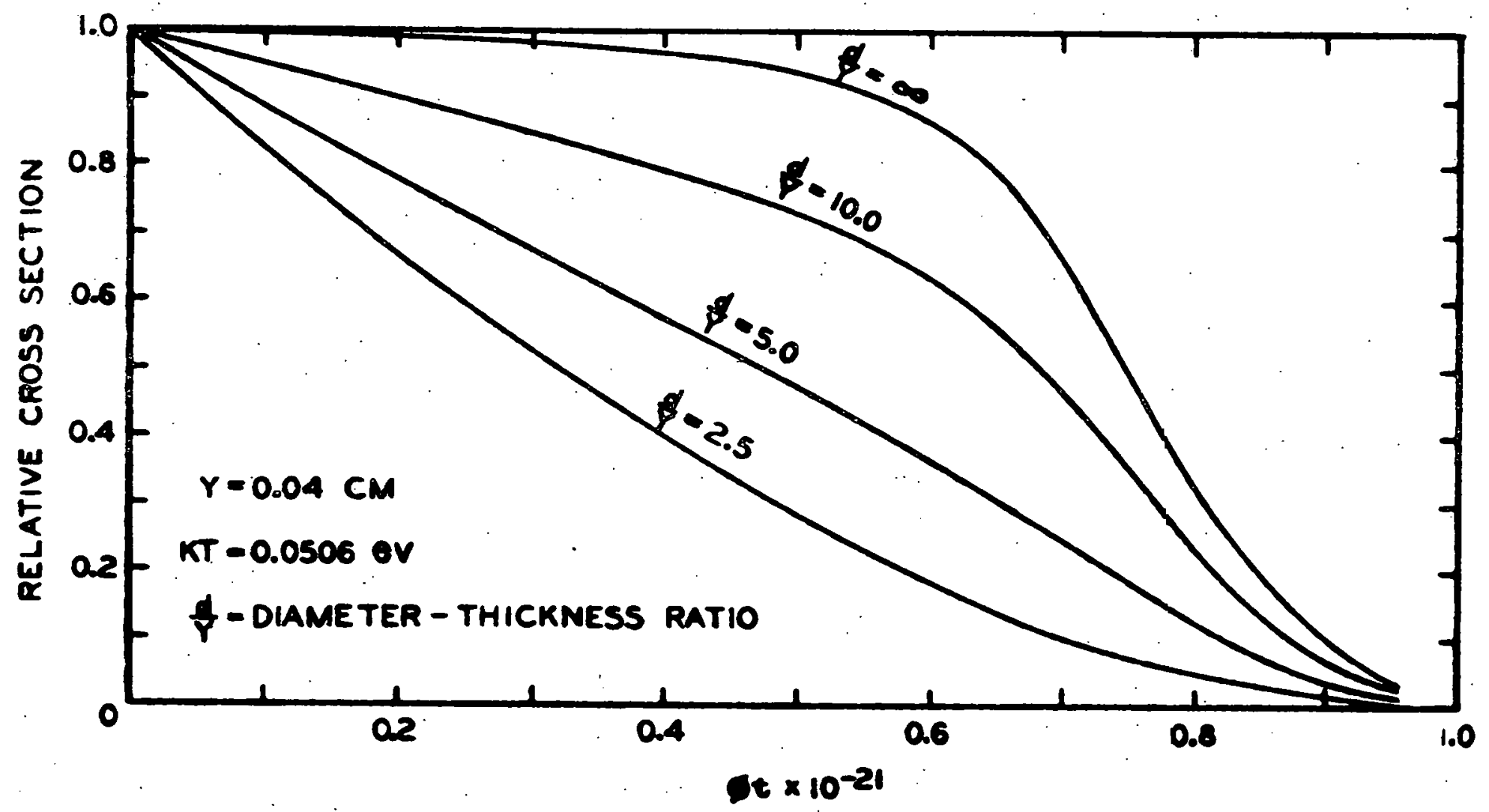

on

FIG. 8.3 BURNOUT CMARACTERISTICS 


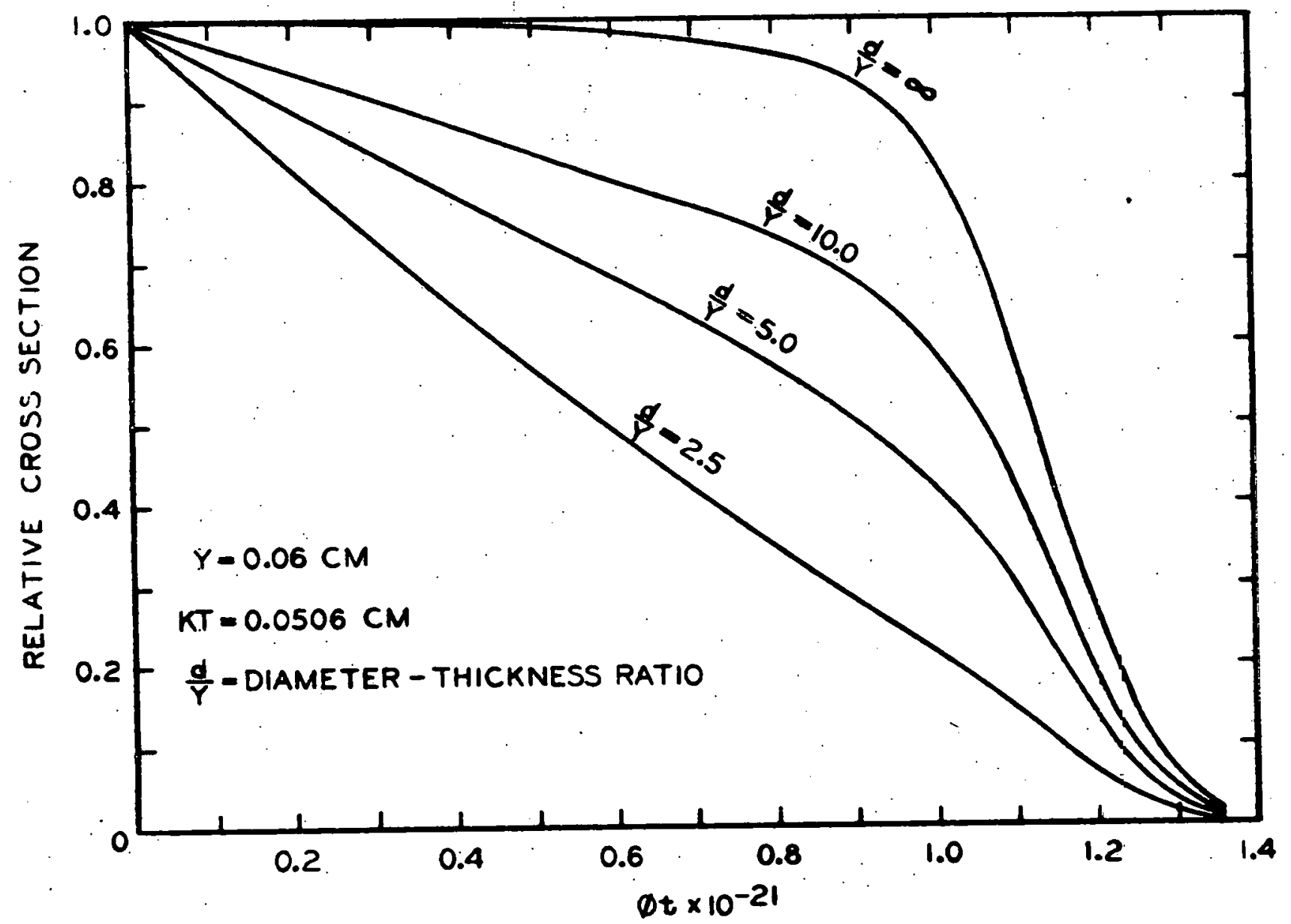

9

FIG. 8.4 BURNOUT CHARACTERISTICS 


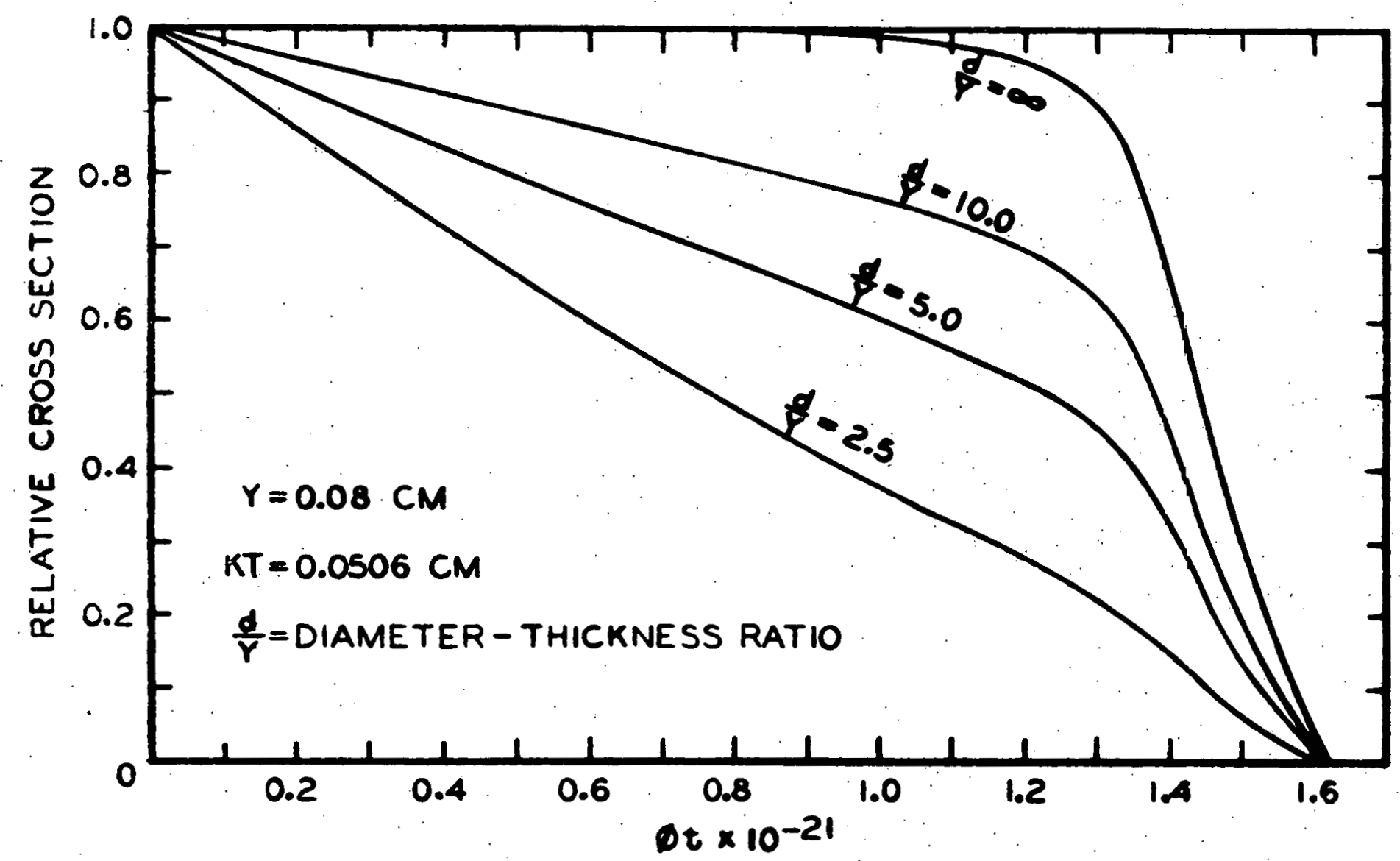

i

FIG 8.5 BURNOUT CHARACTERISTICS 


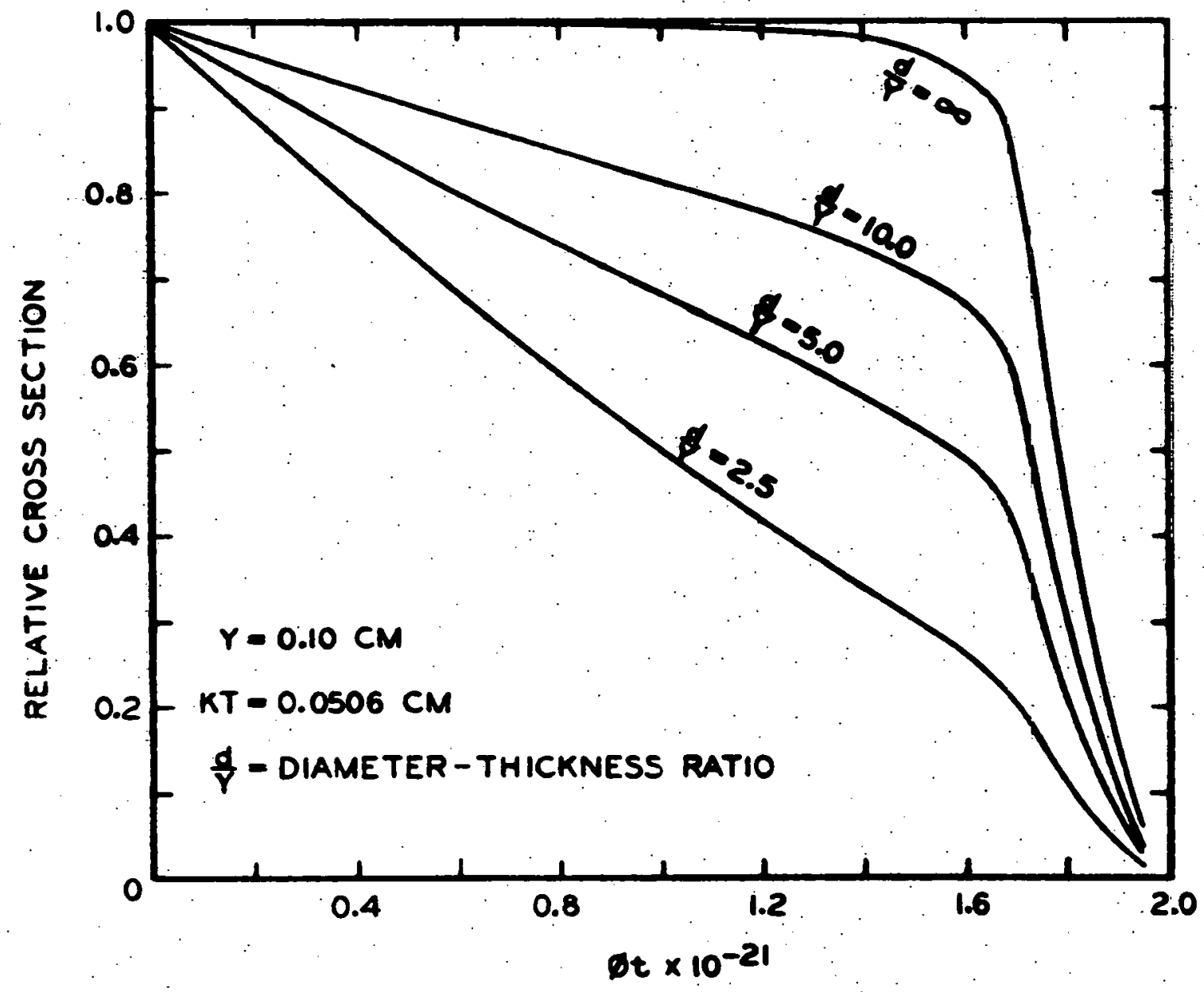

\%

FIG. 8.6 BURNOUT CHARACTERISTICS 


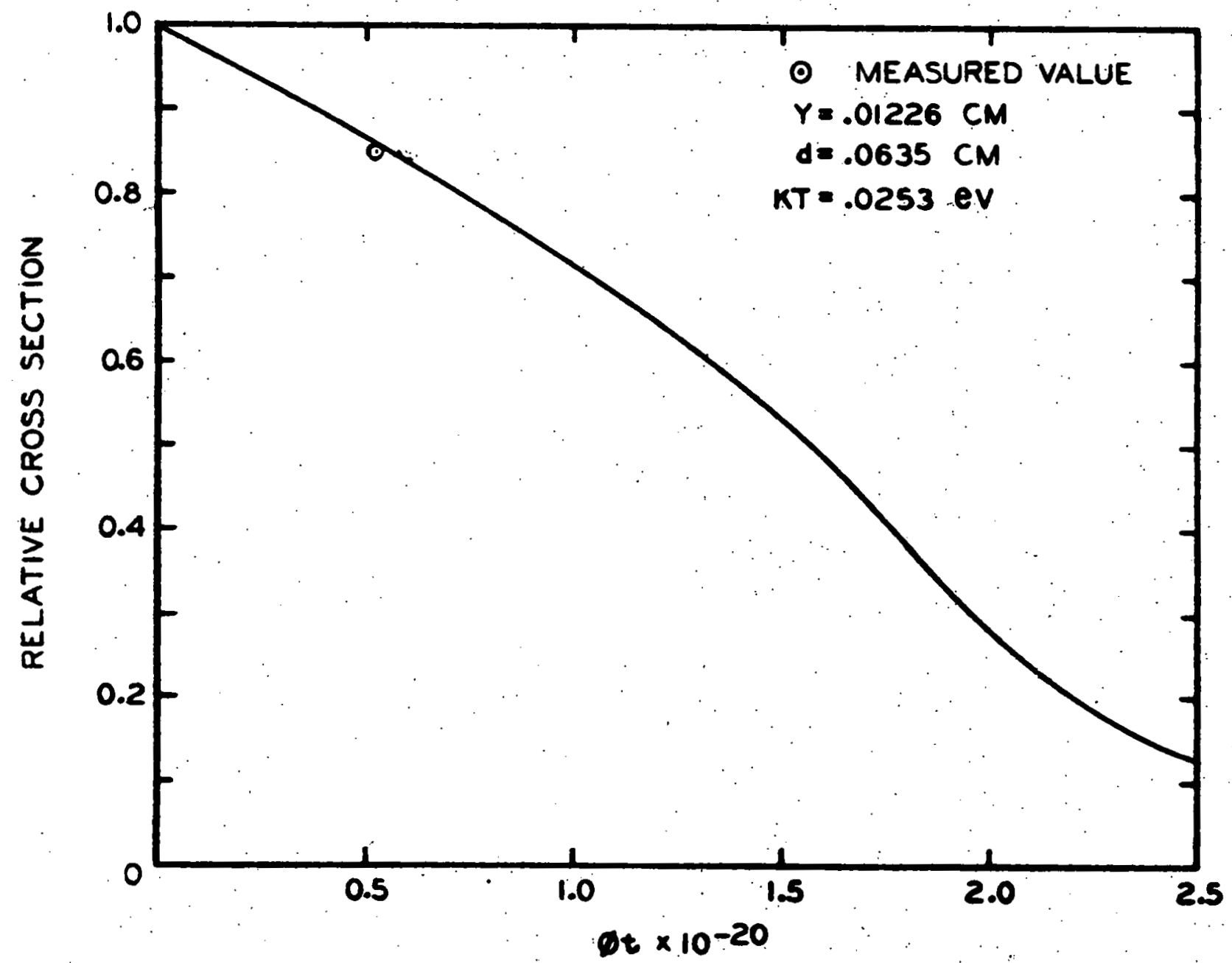

9

FIG 8.7 CALCULATED AND MEASURED DEPLETION EFFECT 


\section{EXPERIMENTAL PROORAM}

\subsection{Objectives and Scope}

The experimental program was designed to obtain the Information necessary to evaluate th1s burnable polson concept. Several of the important factors were unsupported by experiment. Accordingly, experiments were performed to obtain the following information:

(1) the polson residue from gadolinium,

(2) the self-shielding factor for gadolinlum disks, and

(3) the burnout bohavior of gadolinium d1sks.

The measurement of the polson residue from gadolinlum was accomplished by measuring the relative effective absorption cross sections of Irradiated and unirradiated samples of natural gadolinium. The 1rradiation was sufficlent to burn out most of the high cross section 180topes (155 and 157). The effective cross section of the irradiated sample, reduced by the calculated contributions from the remalning high cross section 180topes, was considered as polson residue. The cross sections were measured by the danger coefflclent method. Th1s gave the poison residue in terms of natural gadolinium.

The self-shlelding factor for gadolinium disks was. detejmined ky performins danger coefficlent measurements 
for samples contalning dispersions of gadolinium disks. A olenificant varlation was made in the dianeter and thicknese of the d1sks. Each ample contained disks of a specific s1ze. The danger coefflclent measurements were made relative to both unahlelded gadolintum, in the form of gadolinia, and gold.

The burnout behavior of gadolinium d1sks was measured by comparing the danger coefflcient measurements for 1rrad1ated and unirradiated samples of gadolinium d18ks. The high cost of neutron 1rradiation limited th1s measurement to a 81ngle s1ze disk with only nominal burnup. However, the reoult obtained 1s considered significant.

\subsection{Design of Reactivity Experiments}

Since the high cross section 180topes of gadolinium do not activate, measurements of the effective cross section of self-shlelded amples had to be made by means of reactiv1ty determinations. Th1s 18 also true for measurements of the poison residue. Elther the danger coefficient or pile osc1llator method could have been used for reactivity measurements. Since a pile osc1llator was not avallable at the Pord Reactor, and since adequate size samples could be prepared, the danger coefflclent method was evaluated. Th1s ylelded a satisfactory experimental design, so it was selected.

A dummy box was fabricated wh1ch could be subst1tuted for a fuel element in the Ford Reactor grid. Th1s was used as the test location for the danger coefficient measurements. 
In order to reproduce the sample position in the core for all of the runs, opec1al care was taken with the structure Inside the box. An aluminum tube, olightly larger than the test element, was centered in the box to act as a sample gulde tube. Orlentation of the gulde tube was provided by central holes in the top and bottom luclte plugs and by luc1te opacers to each corner of the box. The position of the corner spacers was maintained by slots in the top and bottom luc1te plugs. The sample was centered at the vert1cal core midplane by means of a luc1te opacer inside the aluminum gulde tube. The locating spacer, the bottom plug, and the box nozzel were cored to provide a water passage through the assembly. Th10 was done to prevent alr bubbles from forming inside the aseembly which could affect the safety of the experiment by their release. It also allowed a closer tolerance between the gulde tube and sample wh1ch would have to be lowered into the assembly while in the core. The top lucite plug was coned to guide the test element into the alumimum gulde tube. Flgure 9.118 a picture of the box, Internal structure, and test sample. Figure 9.2 is a schematic of the test assembly with the sample in place. The test element 18 shown in flgure 9.3.

The location of the test assembly was chosen in the outer row of fuel along an edge of the core. Th1s resulted. from a compromise between obtaining a maximum reactivity effect for the sample and the core reactivity 1083 and possible hazard with the box in a more central location. 
The size of the sample and amount of absorber were Belected to provide reactivity changes of sufficient magnitude to obtaln the desired accuracy of the measurements.

A series of one-dimensional, two-group, diffusion calculations was performed for the reactivity estimates. These calculations were performed in cylindrical geometry. The test assembly, represented by an equivalent volume of water, was located at the core center surrounded in turn by fuel, graphlte reflector, and water. Both.flux and adjolnt calculations were made. The worth of various amount of ab- . sorption, at the center of the test assembly, was calculated by elgenvalue problems and by perturbation methods. These agreed very closely. The central results were translated to the actual test assembly location by assuming that the thermal flux peaking and the thermal adjoint flux depressions were the same in this location as at the center. The central resuits were then simply multiplied by the ratio for the two locations of the product of the unperturbed flux and adjolnt flux. Correction for the finlte length of the sample was made by assuming the axial flux and adjolnt flux to have cosine distributions with an extrapolated core helght of 75 $\mathrm{cm}$. The ratio of the integral over the sample length to the integral over the helght of the core was used for this factor. In order to keep the uncertalnty in the correction factor for flux depression in the sample small, an optical radius of 0.1 was selected. W1th a sample length of $s 1 x$ inches and diameter of 0.805 inches (a standard aluminum tube 
ID), this gave an effective cross section of $4.90 \mathrm{~cm}^{2}$ for the sample. The reactivity estimate for this was $667 \mu^{\mathrm{k}}$ $\left(10^{-6} \Delta \mathrm{k} / \mathrm{k}\right)$. With a desired accuracy for the measurements of about $2 \%$, and with an uncertainty in the above reactivity estimate of a factor of two, this required an experimental accuracy of about $5 \mu \mathrm{k}$. With care, this is consistent with reasonable experiment times. This sample size was selected, although modifled slightly during fabrication to that shown in figure 9.3. The actual measured reactivity effect for a sample of $4.90 \mathrm{~cm}^{2}$ was $625 \mu \mathrm{k}$. Th1s agreement, was fortultous since the actual core was larger and the sample location, near the center of one face, more favorable than used for the estimates. Although these are of opposite effect, the latter had been recognized and considered as an additional conservative factor.

For the Irradiated sample, used to measure the residue, 1t was desired to measure an effect of one per cent of that of the reference samples w1th an accuracy of fifty per cent. Th1s gave $6.7 \pm 3.3 \mu \mathrm{k}$. Since this only involved one sample, plus reference dummy and standard, it was felt that suff1clent time could be spent to attain this accuracy. However, to cover the factor of two uncertainty in the reactivity est1mates, a sample with double the reference loading was 1rrad1ated.

Gold was used as a standard for most of these measurements. Cadmium ratios were measured in order to relate the reactiv1ty effect to the thermal absorption cross section. 
Sufficlent time, following shutdown from full power operation, was allowed 80 that the xenon transient would not mask the measurements.

\subsection{Design of Irradiation Experiments}

In order to measure the residue from gadolinium and to determine the shape of the burnout curves for self-shielded particles, three samples were 1rradiated. Reactivity measurements, as described in section 9.2, were performed for the Irradiated samples.

To establish the 1rradiation needed to measure the residue, the cross section for unshielded gadolinium was calculated as a function of irradiation. The average cross sect1ons in the $0.0253 \mathrm{ev}$ spectrum from table 6.1 were used for the 155 and 157 1sotopes. These were welghted w1th their respective 1sotopic abundances to give their contribution to the natural gadolinium cross section. The contribution from gadolinium-156, with an assumed effective cross section of 1000 barns, was also calculated and weighted with 1ts increasing 1sotopic abundance as 155 burns out. These results, showing the contributions from each 1 sotope and the total gadolinium cross section w1th both zero and 1000 barns for the 156 1sotope, are shown in f1gure 9.4. It can be seen that the contribution of a 1000 barn cross section for gadolinium-156 equals that of the remaining 155 1sotope, and thus can be distinguished from 1t, at about ot $=7 \times 10^{19}$. At this point the unshielded gadolinium cross section is about iof its initial value. This established the minimum 
Irradiation desired and the reactivity to be measured in the Irradiated sample.

The 1rradiation was performed in the Materials Testing Reactor. In order to insure meeting the 1rradiation requirements obtained above, the minimum unperturbed irradiation was specified as $10^{20}$, with a maximum to minimum variation along the length of the sample of no more than 10\%. Th1s degree of over design was needed since the sample recelved a maximum unperturbed 1rradiation of $0.917 \times 10^{20}$ and $a$ varlation of nearly $20 \%$ to the minimum value. Th1s resulted in an average irradiation to the sample of $6.2 \times 10^{19}$. Since the reactivity measurement was better than the minimum specIfled in Section 9.2, this ylelded a satisfactory measurement of the residue.

A sample of gadolinium disks was also 1rradiated. The desired irradiation, limited by costs, was specifled to be the same as for the unshielded sample. As the disks burn out, their effective cross section decreases both due to diminuation in sample size with predominantly surface absorption, and due to transmission through the sample having a decreased optical thickness. The effect due to the decrease in effective sample size was consldered most uncertain. So, a d1sk size was selected which, within the specifled Irradiation limits, gave a fifteen to twenty per cent effect due to change in effective disk dimensions and only four to five per cent due to transmission. Agaln, the irradiation recelved was less than specified, but an adequate measurement 
was made.

To 1llustrate further the effect of surface absorptions, a sample of gadolinia sphere-like particles was 1 rradiated. The same 1rradiation spec1fication was made. Th1s sample recelved the requested irradiation and a substantial effect was measured.

Aluminum wires containing $0.01 \mathrm{w} / 0$ cobalt were used to monitor the samples' 1rradiation. Four wires, 0.030 inch in diameter, were orlented 90 degrees apart and ran the full length of the samples. The ends were inserted into holes drilled in the top of the end cap and tack welded in place. To normalize the monitor wire activation, a set of 1dentical cobalt folls welghing $0.1 \mathrm{gm}$ were obtalned. One of the folls had an accurately known disintegration rate. Another of the folls was 1rradiated, together with a section of the monitor wire, in the CP-5 reactor at Argonne. Th1s auxillary measurement was used to obtain the integrated flux at the surface of the samples. A calculated correction was applied to give the average irradiation of the sample.

9.4 Preparation of Samples

The size and absorption cross section of the danger coefficlent samples was selected in Section 9.2. Aluminum was used for the tube and end caps and alumina $\left(\mathrm{Nl}_{2} \mathrm{O}_{3}\right)$ was used as the dispersing medium for the gadolinium. These materials were selected because of their avallablilty and low thermal absorption cross section. The samples were suded to preven: water inleakage 
from affecting the measurements, and to protect the MTR and Ford Reactors from contamination with gadolinium. Since all low melting point aluminum braze materials contain some cadmlum, welding was selected for the closure. After many fallures, the design shown in figure 9.3 proved successful. The end cap was trepanned to provide an edge with a thickness about the same as the tube wall. Then both edges heated evenly and welded. To prevent blowout as the closure was being completed, a hole was drilled lengthwlse through the end cap. Before welding, a vacuun was drawn on the sample through this hole. The weld was performed rapidly, before the volume of the sample heated enough to blow out, while turning the sample on a lathe. It was found to be impossible to repair a sample after even a little contaminant was blown 1nto the weld zone. After this technique was perfected, it was possible to seal samples with about an elghty per cent yield.

A spectal die and ram were made for loading the tubes by compaction. To achieve homogenelty, the tube loading was divided 1 nto 14 batches which were loaded and tamped individually. A serles of tubes was loaded with only alumina to establish loading procedures for reproducibility. A compacted density of 2.1 grams per cubic centimeter was consistently attained with less than two per cent variation. The actual samples were loaded w1th the full amount of nixture specifled. 'This corresponded to 96 grams of alumina plus gadolinium for most samples. 
Samples containing three forms of gadolinium were fabricated--fine gadolinia powder $\left(\mathrm{ad}_{2} \mathrm{O}_{3}\right)$, sintered particles of gadolinia, and gadolinium metal disks.

The gadolinia powder, as recelved, was of submicron size. A Fischer sub-sieve analysis gave an average dlameter of 0.7 microns. In order to prevent agglomeration of the gadolinia powder, thus producing self-shlelding, and to insure that no water was included in the welght of gadolinia loaded, the puwder was heated to $400^{\circ} \mathrm{F}$ and held there for one hour just before blending and loading. The gadolinia and alumina powder were blended for two hours in a V-blender.

Gadolinia particles were produced by pressing the gadolinia powder into pellets, sintering, and ball-milling to the desired size range. Sieves were used to select size fractions for the samples. The green pellets were formed by adding four per cent carbowax, dissolved in acetone, as a binder, and pressing to 40 tons per square 1nch. The binder was then bolled off by heating the pellets to $400^{\circ} \mathrm{F}$. The pellets were sintered at $2550^{\circ}$ F for six hours. A sintered density of 7.0 grams per cublc centimeter was attalned (95\% of theoretical). Pictures of two size fractions of these particles are shown in figure 9.5. As can be seen from the pictures, these particles are not very spherical. To try to produce better particles, another set of pellets was prepared as before and sintered at $2800^{\circ} F$ for six hours. These gave pellet densities of almost 100 per cent of theoretical. Upon ball-milling, even more angular particles were 
produced. So the first set was used for the samples.

The integrity of the particles was investigated by blending with alumina and going through a mock loading procedure. The material was then separated by sleves and the gadolinia compared with the initial amount blended. Adequacy of blending time, for homogenelty, was also checked in this manner. In all cases the recovery of the inftial sleve fraction was greater than 97 per cent. Essentlally all the mlosing gadolinia was found in the next lower sleve fraction. This small loss was attributed to the angular shape of the particles. So, it was concluded that the particles would largely retain thelr size during sample fabrication. Unfortunately this was not the case. Following the experiments, where it was found that the self-shielding factor was much less than predicted, the samples were opened and the particle sizes determined by sleve analysis. The particles were found distributed among several smaller mesh fractions. The particles stored also showed a deterloration--probably due to water absorption. This made the measurements of the particle samples of questionable value. Fortunately they were not cruclal to the experimental program. Qadolinlum metal disks were prepared covering a slze range which would test the predicted self-shlelding factors. Po1ls of the desired thickness were rolled and disks of the desired diameter punched. Nominal thicknesses of 0.001 , $0.002,0.005$, and 0.007 inches were made with a diameter of 0.025 1nch. These samples were successfully fabricated and 
tested. Following the measurements, the samples were cut open and the gadolinium foll recovered and welghed. The recovery was always in excess of 98 per cent of the amount blended. Homogene1ty was checked by recovery in quarters, and, in one sample, by sixteenths. The variation in the concentration of gadolinium in quarter sections was within two per cent. In sixteenths it was within $81 x$ per cent. For tandards, samples contalning gold folls were prepared. The gold fo118, 0.800 inch in diameter and 0.003 Inch thlck, were equally spaced along the length of the tube. Alumina was used as flller material. Three samples contalning 28, 10, and 3 gold folls were prepared.

Two samples were prepared for cadmlum rat1o measurement of gold. These each contalned flve equally spaced gold f0118. In one sample three alternate folls were covered with 0.020 inch cadmium, and in the other sample two fo11s were covered.

Table 9.1 118ts the samples that were prepared and tested. 
TABLE 2.2

SUMOLARY OF SAMPLES

\begin{tabular}{|c|c|c|c|}
\hline $\begin{array}{c}\text { Sample } \\
\text { No. }\end{array}$ & Material & size & $\begin{array}{l}\text { We1ght } \\
(\mathrm{gm})\end{array}$ \\
\hline 1 & dummy & - & $\cdots$ \\
\hline 2 & dummy & -- & -- \\
\hline 3 & $\mathrm{Gd}_{2} \mathrm{O}_{3}$ Powder & $<1 \mu$ & 0.0848 \\
\hline 4 & $\mathrm{Gd}_{2} \mathrm{O}_{3}$ Powder & $<1 \mu$ & 0.0848 \\
\hline 8 & $\operatorname{cod}_{2} \mathrm{O}_{3}$ Powder & $<1 \mu$ & 0.0406 \\
\hline 10 & $\mathrm{Gd}_{2} \mathrm{O}_{3}$ Powder & $<1 \mu$ & 0.00848 \\
\hline 11 & $\mathrm{Gd}_{2} \mathrm{O}_{3}$ Powder & $<1 \mu$ & 0.00085 \\
\hline 13 & $\mathrm{Od}_{2} \mathrm{O}_{3}$ Part1cles & $35-44 \mu$ & 0.0917 \\
\hline 14 & $\mathrm{Gd}_{2} \mathrm{O}_{3}$ Part1cles & $35-44 \mu$ & 0.0917 \\
\hline 16 & $\mathrm{ad}_{2} \mathrm{O}_{3}$ Part1cles & $62-74 \mu$ & 0.1420 \\
\hline 17 & $\mathrm{Gd}_{2} \mathrm{O}_{3}$ Particles & $105-125 \mu$ & 0.2387 \\
\hline 18 & $\mathrm{Od}_{2} \mathrm{O}_{3}$ Particles & $105-125 \mu$ & 0.2388 \\
\hline 19 & $\mathrm{Od}_{2} \mathrm{O}_{3}$ Part1cles & $177-210 \mu$ & 0.4029 \\
\hline 21 & $\mathrm{ad}_{2} \mathrm{O}_{3}$ Part1cles & $350-420 \mu$ & 0.7973 \\
\hline 23 & $\mathrm{Od}_{2} \mathrm{O}_{3}$ Part1cles & $350-420 \mu$ & 0.7973 \\
\hline 24 & Od disks & $0.0010,0.0250$ 1n. & 0.1804 \\
\hline 25 & Gd disks & $0.0010,0.02501 \mathrm{n}$. & 0.1678 \\
\hline 26 & ad disks & $0.0017,0.0250 \mathrm{in}$ & 0.3137 \\
\hline 27 & Gd disks & $0.0017,0.0250 \mathrm{in}$ & 0.3307 \\
\hline 28 & ad d1 sks & $0.0048,0.0250$ in. & 0.8238 \\
\hline 30 & Gd disks & $0.0048 ; 0.2500 \mathrm{in}$ & 0.8238 \\
\hline 32 & Gó d18kB & $0.0048,0.0250$ in. & 0.4231 \\
\hline
\end{tabular}


TABEE 2.1 (Conts nued)

\begin{tabular}{llll}
$\begin{array}{c}\text { Sample } \\
\text { No. }\end{array}$ & Material & \multicolumn{1}{c}{ S1ze } & $\begin{array}{c}\text { We1ght } \\
\text { (gm) }\end{array}$ \\
\hline 34 & Gd disks & $0.0067,0.0250$ in. & 1.1887 \\
35 & Gd disks & $0.0066,0.0500$ in. & 1.1155 \\
36 & Gd disks & $0.0069,0.0150$ in. & 0.6615 \\
37 & Au Fo11s & $0.003,0.800$ in. & 13.315 \\
38 & Au Fo11s & $0.003,0.800$ in. & 4.657 \\
39 & Au Fo11s & $0.003,0.800$ in. & 1.398 \\
40 & Au Fo11s & 2 cadmium covered & \\
41 & Au Fo11s & 3 cadmium covered & \\
\hline
\end{tabular}

\subsection{React1vity Measurements}

Danger coefficlent measurements were made in the Ford Reactor for the samples described in table 9.1. The test assembly was loaded in the reactor grid, and core adjustments were made unt1l the desired excess reactivity was obtalned with all control rods out of the core. This gave the core configuration shown in f1gure 9.9. Th1s was used for all measurements with reference reactivity worths. To increase the worth of the test location for the residue experiment, a fuel element was moved to a location Immediately behind the test assembly. This gave the core configuration shown in figure 9.10, and it increased the sample worth by about 60 per cent. 
In order to minimize activation of the experimental equipment, the measurements were performed at a reactor power of about one watt. Because of the xenon transient, the flrst measurements were made on the fourth day following shutdown from full power. Th1s made the background neutron level in the core low enough to use this power. Perlod measurements were made from the output of one of the reactor startup fission chambers at a slightly withdrawn posit1on. The neutron background at this position was less than one count per second. A preset scaler was used to control the counting time of the scaler recelving counts from the f1ssion chamber. A ten second counting time, with two seconds off, was used for most runs. The counts during the active counting perlods were printed out on paper tape.

Throughout the course of the experiments, readings were taken of three temperatures in the pool, two near the reactor. No variation was found during the runs on any particular day. Each day's runs were made as an entity, so any variation between days did not affect the results.

All perlod measurements were made with all rods fully out of the core. For each individual run, the control rod was inserted to the full in position (about $-0.3 \% \Delta k / k$ ). The sample was changed, using a long line attached to the lifting eye. When the count rate had decayed to about 50 counts per second, the control rod was moved to the full out position and data taken. The full out control rod position was noted for every run. It never varled by a discernable 
amount $(1 / 50$ inch would have been less than $0,3 \mu \mathrm{k})$. When the count rate reached 10,000 counts per second, the control rod was inserted, terminating the run. The time at the beginning and end of each run was marked.

The perlods for the first set of runs, using samples with reference reactivity worths, ranged between 100 and 200 seconds. The dummy elements had perlods around 70 seconds. These values were selected to yleld an accuracy of about $5 \mu k$ with experiment times of about 20 minutes. The second set of runs used perlods of about 300 seconds and experiment times of about 40 minutes. The first set gave accuracles of about $3 \mu k$ whlch were as good as for the second set.

Two runs, with the shorter perlods, were made to count rates of about 50,000 counts per second in order to measure the dead time of the counting equipment. Two runs, at a power of about ten watts for ten minutes, were made to 1rradiate the samples used to measure the cadmlum ratio of gold.

The experiments were performed over three days with the last day belng devoted to the resldue measurement. A summary of the runs and data is given in the following section.

9.6 Data Reduction

General subheadings w1ll be used in this section as an ald in distingulshing the stages in reducing the data. Dead Time Correction

The first correction applied to the data was for the dead 
time of the equipment. The corrected counting rate is related to the observed counting rate through: $c_{c}=c_{0} /\left(1-\tau c_{0}\right)$, where $\tau$ is the dead time.

The dead time was obtained using data from the two runs made to high counting rates. The observed counting rates were corrected for various assumed values of the dead time. These were then fitted to a positive exponential by the method of least squares. The restdue from these f1ts were plotted as a function of dead time and the minimum selected. The difference between the two runs was only 0.3 microseconds. The average value of 1.6 microseconds was selected. At the maximum counting rate for the measurements, this was only a 1.6 per cent correction. Terminating all of the runs at the same counting rate minimized any effect due to inaccuracies in the dead time.

React1vity Values

The corrected counting rates for the last decade, between 1000 and 10,000 counts per second, were plotted on sem1log paper for each run. The polnts toward the end of the run were fit with a stralght line. To insure that the period determined represented the asymptotic period as closely as possible, the points from 2000 counts per second and above were used to fit an exponential by the method of least squares. Departure from the stralght line, near the beginning of the plot, was never pronounced. Figure 9.11 shows an example. To investigate further the adequacy of the period determinat1os., ine sane points from several of the 
runs with long perlods were divided into three segments. Each segment was separately f1t w1th an exponentlal. No systematic departure was found which would indicate that the period was changing. The perlod and standard deviation for the points used are given in table 9.2 .

The reactivity, in dollars, was calculated from the perlod with the in-hour formula. The delayed neutron data for uran1um-235, reported by Keep1n, was used (16). W1th a prompt neutron 11felime of $5 \times 10^{-5}$ seconds, th1s gave the following relationship between period and reactivity.

$$
\begin{aligned}
\frac{\rho}{\beta_{\text {eff }}} & =5 \times 10^{-5} /(\mathrm{T})+0.033 /(1+0.0124 \mathrm{~T}) \\
& +0.219 /(1+0.0305 \mathrm{~T})+0.196 /(1+0.111 \mathrm{~T}) \\
& +0.395 /(1+0.301 \mathrm{~T})+0.115 /(1+1.13 \mathrm{~T}) \\
& +0.042 /(1+3.00 \mathrm{~T})
\end{aligned}
$$

Th1s was used to calculate the reactivity for each of the runs. The standard deviation of the period, $\Delta T$, was expressed as reactivity, $\Delta P$, by differentiating $(9.6 .1)$ with respect to $T$, evaluating this at the period obtained, and multiplying by $\Delta T$. For convenlence, the reactivities calculated were converted from dollars to absolute values using a value of 0.0075 for $\beta_{\text {eff }}$. Since only ratios of results are used, there is no significance in the selection of $\beta_{\text {eff }}$. Reactivities and corresponding devistions are given in table 9.2. The time given for each run Indicates the day of the experiment and the time at the end of the run. Each day's runs are 11sted together. 
TABLE 9.2

PERIODS AND REACTIVITIES FOR DANGER COEFFICIENT EXPERIMENTS

\begin{tabular}{|c|c|c|c|c|c|c|c|c|}
\hline $\begin{array}{c}\text { Sample } \\
\text { No. }\end{array}$ & $\begin{array}{l}\text { Run } \\
\text { No. }\end{array}$ & Time & $\left(\sec ^{\mathrm{T}}\right)$ & $\frac{\Delta T}{(\sec .)}$ & $\left(\mu^{e} k\right)$ & $\Delta(4 k)$ & $\begin{array}{c}\text { Pxg } \\
(4 k)\end{array}$ & $\begin{array}{l}(4 k) \\
\text { Corr. }\end{array}$ \\
\hline
\end{tabular}

F1rst Day

$\begin{array}{lllllllll}1 & 3 & 1006 & 69.3 & 0.4 & 977.6 & 4.1 & 115.1 & 1092.7\end{array}$

$\begin{array}{lllllllll}1 & 22 & 1606 & 65.4 & 0.2 & 1019.4 & 2.2 & 74.0 & 1093.4\end{array}$

$\begin{array}{lllllllll}2 & 14 & 1330 & 65.7 & 0.2 & 1016.0 & 2.2 & 89.7 & 1105.7\end{array}$

$\begin{array}{lllllllll}4 & 24 & 1643 & 373.1 & 1.0 & 239.8 & 0.7 & 70.7 & 310.5\end{array}$

$\begin{array}{lllllllll}8 & 2 & 0942 & 169.2 & 0.7 & 483.5 & 1.8 & 118.6 & 602.1\end{array}$

$\begin{array}{lllllllll}8 & 11 & 1234 & 162.0 & 1.1 & 501.0 & 3.0 & 96.1 & 599.1\end{array}$

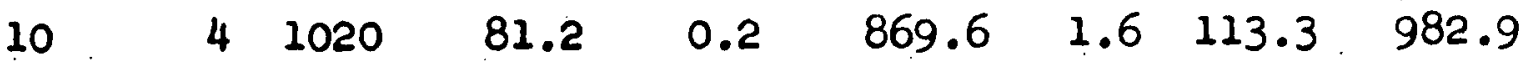

$\begin{array}{lllllllll}10 & 12 & 1249 & 77.9 & 0.2 & 897.0 & 1.7 & 94.3 & 991.3\end{array}$

$\begin{array}{lllllllll}13 & 5 & 1036 & 245.1 & 0.8 & 350.3 & 1.0 & 110.9 & 461.2\end{array}$

$\begin{array}{lllllllll}14 & 19 & 1514 & 226.6 & 0.5 & 375.4 & 0.7 & 79.0 & 454.4\end{array}$

$\begin{array}{lllllllll}16 & 7 & 1121 & 209.0 & 0.5 & 402.8 & 0.8 & 105.0 & 507.8\end{array}$

$\begin{array}{lllllllll}16 & 15 & 1353 & 197.9 & 0.6 & 422.4 & 1.1 & 87.2 & 509.6\end{array}$

$\begin{array}{lllllllll}17 & 6 & 1100 & 325.8 & 1.2 & 271.4 & 0.9 & 107.8 & 379.2\end{array}$

$\begin{array}{lllllllll}18 & 13 & 1314 & 312.2 & 1.0 & 282.1 & 0.8 & 91.6 & 373.7\end{array}$

$\begin{array}{lllllllll}19 & 9 & 1155 & 73.1 & 0.3 & 940.2 & 2.7 & 100.7 & 1040.9\end{array}$

$\begin{array}{llllllllll}19 & 18 & 1452 & 71.1 & 0.4 & 959.5 & 4.0 & 81.1 & 1040.6\end{array}$

$\begin{array}{lllllllll}23 & 10 & 1217 & 270.4 & 1.1 & 321.0 & 1.2 & 98.1 & 419.1\end{array}$

$\begin{array}{lllllllll}23 & 20 & 1536 & 255.8 & 0.6 & 337.3 & 0.7 & 76.8 & 414.1\end{array}$

$\begin{array}{lllllllll}37 & 1 & 0922 & 151.6 & 1.0 & 529.7 & 2.9 & 121.5 & 651.2\end{array}$

$\begin{array}{lllllllll}37 & 8 & 1141 & 143.8 & 0.1 & 553.4 & 0.3 & 102.6 & 656.0\end{array}$

$\begin{array}{lllllllll}37 & 23 & 1623 & 135.7 & 0.3 & 580.5 & 1.1 & 72.6 & 653.1\end{array}$ $\begin{array}{lllllllll}38 & 21 & 1551 & 85.0 & 0.2 & 840.1 & 1.5 & 75.4 & 915.5\end{array}$ 
TABLE 9.2 (Continued)

Sample Run $T$, $\Delta T$

No. No. Time (sec.) (sec.) $\rho(u k) \Delta \rho(u k)$ Pefuk) P(uk)

Second Day

$\begin{array}{lllllllll}1 & 31 & 1020 & 57.0 & 0.2 & 1123.6 & 2.7 & 19.1 & 1142.7\end{array}$

$\begin{array}{lllllll}1 & 45 & 1417 & 71.6 & 954.6 & 14.2 & 968.8\end{array}$

$\begin{array}{lllllllll}21 & 51 & 1603 & 117.5 & 0.5 & 652.5 & 2.2 & 12.5 & 665.0\end{array}$

$\begin{array}{lllllllll}21 & 52 & 1623 & 113.0 & 0.3 & 669.9 & 1.4 & 12.2 & 668.1\end{array}$

$\begin{array}{lllllllll}24 & 28 & 0933 & 116.7 & 0.5 & 656.1 & 2.2 & 20.3 & 676.4\end{array}$

$\begin{array}{lllllllll}24 & 40 & 1255 & 115.1 & 0.3 & 663.4 & 1.4 & 15.7 & 679.1\end{array}$

$\begin{array}{lllllllll}24 & 49 & 1526 & 114.9 & 0.4 & 664.3 & 1.8 & 13.0 & 677.3\end{array}$

$\begin{array}{lllllllll}25 & 29 & 0948 & 113.5 & 0.4 & 671.2 & 1.9 & 19.9 & 691.1\end{array}$

$\begin{array}{lllllllll}25 & 39 & 1239 & 113.2 & 0.3 & 672.3 & 1.4 & 16.1 & 688.4\end{array}$

$\begin{array}{lllllllll}26 & 30 & 1005 & 127.5 & 0.4 & 610.8 & 1.5 & 19.5 & 630.3\end{array}$

$\begin{array}{lllllllll}26 & 50 & 1543 & 126.2 & 0.4 & 616.0 & 1.6 & 12.7 & 628.7\end{array}$

$\begin{array}{llllllllll}27 & 36 & 1148 & 131.8 & 0.3 & 594.6 & 1.1 & 17.2 & 611.8\end{array}$

$\begin{array}{lllllllll}28 & 53 & 1041 & 126.8 & 0.3 & 613.6 & 1.2 & 11.9 & 611.5\end{array}$

$\begin{array}{lllllllll}28 & 54 & 1702 & 126.8 & 0.5 & 613.6 & 2.0 & 11.6 & 611.2\end{array}$

$\begin{array}{lllllllll}30 & 27 & 0916 & 153.0 & 0.5 & 525.6 & 1.4 & 20.7 & 546.3\end{array}$

$\begin{array}{lllllllll}30 & 38 & 1223 & 151.6 & 0.4 & 529.7 & 1.2 & 16.4 & 546.1\end{array}$

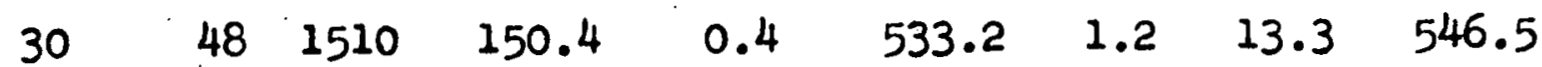

$\begin{array}{lllllllll}32 & 26 & 0900 & 95.8 & 0.3 & 766.5 & 1.9 & 21.1 & 787.6\end{array}$

$\begin{array}{lllllllll}32 & 41 & 1310 & 95.7 & 0.3 & 767.2 & 1.9 & 15.4 & 782.6\end{array}$

$\begin{array}{lllllllll}34 & 32 & 1040 & 182.7 & 0.4 & 453.0 & 0.8 & 18.6 & 471.6\end{array}$

$\begin{array}{lllllllll}34 & 43 & 1345 & 182.3 & 0.4 & 453.3 & 0.8 & 14.8 & 467.8\end{array}$

$\begin{array}{llllllllll}35 & 33 & 1059 & 146.6 & 0.4 & 544.7 & 1.2 & 18.2 & 562.9\end{array}$ 
TABLE 9.2 (Continued)

\begin{tabular}{|c|c|c|c|c|c|c|c|c|}
\hline $\begin{array}{l}\text { Sample } \\
\text { No. }\end{array}$ & $\begin{array}{l}\text { Run } \\
\text { No. }\end{array}$ & T1me & $\left(\begin{array}{c}\mathrm{T} \\
(\sec .)\end{array}\right.$ & $\left(\begin{array}{c}\Delta T \\
\left(\sec _{0}\right)\end{array}\right)$ & $\rho(\mu k)$ & $\Delta \rho / 4 k)$ & $P_{x e}(4 k)$ & $\begin{array}{l}\text { Pluk) } \\
\text { Corr. }\end{array}$ \\
\hline 35 & 42 & 1325 & 85.3 & 0.2 & 837.9 & 1.5 & 15.1 & 853.0 \\
\hline 35 & 47 & 1451 & 145.9 & 0.4 & 546.8 & 1.2 & 13.6 & 560.4 \\
\hline 36 & 34 & 1116 & 125.5 & 0.3 & 618.8 & 1.2 & 17.8 & 636.6 \\
\hline 36 & 44 & 1402 & 124.9 & 0.4 & 621.2 & 1.6 & 14.5 & 635.7 \\
\hline 37 & 25 & 0845 & 110.9 & 0.2 & 683.3 & 1.0 & 21.5 & 704.8 \\
\hline 37 & 35 & 1131 & 110.5 & 0.3 & 685.3 & 1.5 & 17.5 & 702.8 \\
\hline 37 & 46 & 1434 & 109.9 & 0.2 & 688.3 & 1.0 & 14.0 & 702.3 \\
\hline 37 & 55 & 1715 & 106.6 & 0.2 & 705.1 & 1.0 & 11.4 & 702.5 \\
\hline 38 & 37 & 1204 & 72.9 & 0.3 & 942.1 & 2.8 & 16.8 & 958.9 \\
\hline \multicolumn{9}{|c|}{ Th1rd Day } \\
\hline 1 & 58 & 0947 & 279.0 & 1.8 & 312.1 & 1.8 & 3.2 & 315.3 \\
\hline 1 & 63 & 1129 & 289.8 & 0.9 & 301.7 & 0.9 & 2.8 & 304.5 \\
\hline 1 & 71 & 1853 & 284.2 & 0.8 & 307.0 & 0.8 & 1.6 & 308.6 \\
\hline 3 & 57 & 0916 & 339.8 & 3.0 & 261.2 & 2.1 & 3.3 & 264.5 \\
\hline 3 & 61 & 1101 & 336.8 & 1.0 & 263.3 & 0.7 & 3.0 & 266.3 \\
\hline 3 & 64 & 1445 & 334.0 & 0.7 & 265.3 & 0.5 & 2.8 & 268.1 \\
\hline 3 & 70 & 1837 & 327.4 & 5.1 & 270.2 & 3.9 & 1.7 & 271.9 \\
\hline 11 & 60 & 1035 & 312.0 & 1.8 & 282.2 & 1.5 & 3.0 & 285.2 \\
\hline 11 & 62 & 1117 & 305.6 & 1.3 & 287.6 & 1.1 & 2.9 & 290.5 \\
\hline 39 & 59 & 1010 & 397.9 & 2.9 & 226.0 & 1.5 & 3.1 & 229.1 \\
\hline 39 & 65 & 1205 & 398.3 & 0.9 & 226.1 & 0.5 & 2.7 & 228.8 \\
\hline 39 & 72 & 1915 & 391.2 & 2.7 & 229.6 & 1.4 & 1.6 & 231.2 \\
\hline
\end{tabular}


Xenon Transient Erfect

The reactivities for each run were corrected for the decay of xenon during the time of the experiments. To accomplish this, the time dependent concentration of xenon was calculated. The reactivity effect was taken to be proportional to the concentration of xenon. The constant of proportionality was evaluated by minimizing the differences in the reactivities measured, after correcting for this xenon effect, for all repetitive runs during each day. In this manner the calculated xenon effect did not depend significantly upon the condition of the core.

The methods developed in Chapter 11 of reference (17) were used to determine the xenon concentration. At time, $t$, following shutdown, if the reactor had been operating at full power for a time, $T$, the concentration of xenon is:

$$
\begin{aligned}
& N_{x e}(t)=\left\{\frac{\left(\gamma_{x e}+\gamma_{I}\right)}{\lambda_{x e}+\sigma_{a}^{x e} \phi}\left(1-e^{-\left(\lambda_{x e}+\sigma_{a}^{x e} \phi\right) T}\right)\right. \\
& -\frac{\gamma_{I}}{\lambda_{I}-\lambda_{x e}-\sigma_{a}^{x e} \phi}\left(e^{-\left(\lambda_{x e}+\sigma_{a}^{x e} \phi\right) T}-e^{-\lambda_{I} T}\right) \\
+ & \left.\frac{\gamma_{I}}{\lambda_{I}-\lambda_{x e}}\left(1-e^{-\lambda_{I} T}\right)\left(-e^{-\left(\lambda_{I}-\lambda_{x e}\right) t}\right)\right\} \sum_{f} \phi e^{-\lambda_{x e} t}
\end{aligned}
$$

where: $\quad \gamma_{I}=$ yleld of 10d1ne-135 $=0.061$

$$
\begin{aligned}
& \gamma_{x e}=\text { direct yleld of xenon-135 }=0.003 \\
& \lambda_{I}=\text { decay constant for lodine-135 }=2.88 \times 10^{-5} \mathrm{sec}^{-1}
\end{aligned}
$$




$$
\begin{aligned}
& \lambda_{x e}=\text { decay constant for xenon-135 }=2.11 \times 10^{-5} \mathrm{sec}^{-1} \\
& \sigma_{e}^{x e}=2.85 \times 10^{6} \text { barns at } k T=0.0253 \mathrm{ev} .
\end{aligned}
$$

Values for the constants were obtained from reference (15). The equilibrium concentration of xenon during operation 18:

$$
N_{x e}(e q)=\frac{\left(\gamma_{x e}+\gamma_{I}\right) \sum_{f} \Phi}{\lambda_{x e}+\sigma_{q}^{x e} \varphi}
$$

Then, w1th an operating t1me of 16 hours at one megawatt and a 28 element core, inserting the values of parameters 11sted g1ves:

$$
\rho_{x e}(t)=\rho_{x e}(e q)\left(5.413 e^{-0.016 t}-4.820 e^{-0.1037 t}\right)(9.6 .4)
$$

for $t$ in hours. The constant in equation (3.6.4), Pxe (eq.), is the reactivity due to equilibrium xenon. Minimizing the measured reactivities of repeated runs for the same samples gave $-1.39 \% \Delta k / k$ for $P_{x e}\left(e_{0}\right)$. The values of $\rho_{x e}(t)$ were added to the reactivity for each run. These results are also given in table 9.2. After the second day's rung 1 t was noted that the gulde tube was pulled up from the assembly by about one-half inch. Th1s occurred between runs 51 and 52 when a new sample was inserted and stuck in the guide tube. The standard, sample 37 , was run after this change as well as sample $2 I$ which was run just before and after. A correction of $14 \mu \mathrm{k}$ was made for th1s change and $1 \mathrm{~s}$ included in table 9.2 for runs 52 through 55. 


\section{Thermal Cross Section for Gold}

The effective thermal absorption cross section for each sample w11l be expressed in terms of the thermal absorption cross section of gold. For this reason, cadmium rat10 measurements were nade for the gold folls at the sample location. These folls were gamma counted to total counts of about 300,000 for each of the cadmlum covered folls and to well over a million for each of the bare folls. The cadmlum rat1o, from the average of the f1ve bare and five covered folls, was 6.80. Assigning the same worth to the eplthermal and thermal absorptions in gold, the thermal effectiveness of the gold standard was taken to be 0.853 of its total effect.

The thermal absorption cross section of gold was taken to be the average value in a 0.0253 ev Maxwellian spectrum. A further correction was made for the spatial self-shielding in the foll: According to reference (18), the self-shielding factor for the gold foll (0.003 inch thick; 0.800 inch d1ameter) 1s 0.83 . Th1s gives an effective thermal absorption cross section of 72.1 barns. Effective Sample Cross Section

The reactivity effect can now be expressed in terms of the thermal absorptions in gold. This was done by averaging the corrected reactivity for each of the runs, subtracting 1 f from the average for dummy sample number one, and dividing by the lhurmal effectiveness of the gold standard. This was lone separately for each of the first two 
days. These values are glven in Table 9.3. Data from runs number 42 and 45 were discarded as belng in error. This was due to the sample's not having reached 1 ts bottom position in the test assembly. Th1s had been not1ced when the sample was changed following run number 45 , so an extra run was made for that sample. This explanation is inferred from the results of run number 42 .

The effective thermal absorption cross section of each sample was then obtained by correcting for the flux depression in the sample. References (19, 20, and 21) develop expressions for the self-shlelding factor for a dispersion of particles in a larger sample. Due to the low density of particles in these experiments, the method given in reference (19) was used. Accordingly, the total self-shlelding factor was taken as the product of the mlcroscopic selfshlelding factor for the Individual particle and the macroscoplc self-shlelding factor for the sample. The macroscoplc self-shlelding factor was computed with the particles homogenized throughout the sample with an effective cross section, $\sum$, equal to the product of their actual cross section and the microscopic self-shlelding factor. It is th1s microscoplc self-shlelding factor which is belng measured. Using reference (22), the macroscopic self-shlelding factor for the sample was taken to be $1 /(1+B K)$, where $B$ 18 a constant. The geometry dependence of $B 18$ not displayed since all samples have the same dimensions. The only significant difference in the nuclear effect of the 
samples belng measured and the dummy sample 18 due to the absorption cross section. Therefore, the measured reactivity was taken to be proportional to the product of the effective cross section and the macroscopic self-shlelding factor,

$$
P=\frac{A \varepsilon}{1+B \varepsilon}
$$

where A is a constant. Solving for $\sum$ gives:

$$
\Sigma=\frac{1}{A / \rho-B}
$$

The constants were evaluated using samples number 8 and 4 . Sample number 8 contains exactly 0.479 times as much gadolinia as sample number 4. The absorption cross sections for both samples were corrected for spectral hardening, as in Section 6 , by averaging the product of the cross section and selfshlelding factor over the Maxwellian distribution at $\mathrm{kT}=$ $0.0253 \mathrm{ev}$. These factors were 0.972 for sample 8 and 0.953 for sample 4. Th1s makes the effective cross section for sample elght equal to 0.488 times that of sample four. Then the ratio of equation $(9.6 .6)$ for samples 8 and 4 was taken using the measured reactivities. Normalizing to unity for standard sample number 37 gave: $A=1.267$ and $B=0.267$. Table 9.3 gives these corrected effective cross sections relative to that of sample 37 . 
With 13.315 granis of gold and the microscoplc value of 72.1 barns, sample 37 has an effective cross section of:

$$
(13.315)(0.602)(72.1) / 197.2=2.93 \mathrm{~cm}^{2}
$$

Th1s was used to obtain the effective thermal absorption cross section for each sample. These are given in the last column in Table 9.3. The second values for samples 4 and 8 are corrected for spectrum effects.

For the measurement of the resldue, done the third day, a gadolinium sample, contalning one per cent of the amount of gadolinlum Irradlated, was used as a reference. From table 9.2, the average worths of the 1rradiated sample (number 3) and the reference (number 11) were 41.8 and $21.7 \mu k$, respectively.

\section{TABLE 9.3}

ERFECTIVE THERMAL CROSS SECTIONS

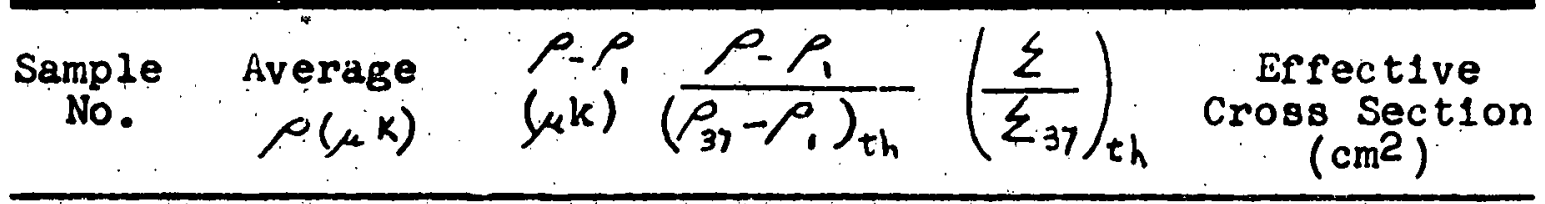

\section{P1rgt Day}

1

$1093.0 \quad \cdots$

$\begin{array}{llll}\text { 2 } & 1105.7 & -12.7\end{array}$

4

$310.5 \quad 782.5$

2.086

2.941

8.62 (9.05)

8

$600.6 \quad 492.4 \quad 1.313$

1.433

$4.20(4.32)$ 
Ti.3ieg.3 (Cont1nued)

\begin{tabular}{|c|c|c|c|c|c|}
\hline $\begin{array}{c}\text { Sanplo } \\
\text { No. }\end{array}$ & $\begin{array}{l}\text { Average } \\
P(\mu k)\end{array}$ & $\begin{array}{l}p-p \\
\text { (ukk) }\end{array}$ & $\frac{P-P_{1}}{\left(P_{1}-P_{1}\right)_{t h}}$ & $\left(\frac{\Sigma}{\varepsilon_{37}}\right)_{t h}$ & $\begin{array}{c}\text { Erfectlve } \\
\text { Cross section } \\
\left(\mathrm{cm}^{2}\right)\end{array}$ \\
\hline 10 & 987.1 & 105.9 & 0.282 & 0.237 & 0.70 \\
\hline 13 & 461.2 & 631.8 & 1.685 & 2.062 & 6.08 \\
\hline 14 & 454.4 & 638.6 & 1.704 & 2.096 & 6.18 \\
\hline 16 & 508.7 & 584.3 & 1.558 & 1.832 & 5.40 \\
\hline 17 & 379.2 & 713.8 & 1.904 & 2.51 & 7.36 \\
\hline 18 & 373.7 & 719.3 & 1.919 & 2.54 & 7.49 \\
\hline 23 & 416.6 & 676.4 & 1.802 & 2.29 & 6.76 \\
\hline 37 & 653.4 & 439.6 & 1.000 & 1.00 & 2.93 \\
\hline 38 & 915.5 & 177.5 & 0.404 & 0.349 & 1.03 \\
\hline
\end{tabular}

Second DaY

$\begin{array}{lllllll}1 & 1142.7 & \ldots & & & \\ 21 & 666.6 & 476.1 & 1.270 & 1.368 & 4.03 \\ 24 & 677.6 & 465.1 & 1.240 & 1.324 & 3.91 \\ 25 & 689.8 & 452.9 & 1.208 & 1.279 & 3.77 \\ 26 & 629.5 & 513.2 & 1.369 & 1.520 & 4.48 \\ 27 & 611.8 & 530.9 & 1.416 & 1.592 & 4.70 \\ 28 & 611.4 & 531.3 & 1.417 & 1.593 & 4.70 \\ 30 & 546.3 & 596.4 & 1.590 & 1.887 & 5.57 \\ 32 & 785.1 & 357.6 & 0.953 & 0.942 & 2.78 \\ 34 & 469.7 & 673.0 & 1.797 & 2.283 & 6.74 \\ 35 & 561.7 & 581.0 & 1.551 & 1.818 & 5.36 \\ 36 & 536.2 & 506.5 & 1.351 & 1.490 & 4.39 \\ 37 & 653.4 & 439.6 & 1.000 & 1.000 & 2.93 \\ 38 & 958.9 & 183.8 & 0.418 & 0.362 & 1.07\end{array}$


Measurement of Sample Irradiation

The aluminum-cobalt w1res; used to integrate the flux for the 1rradiated samples, were counted at the All1s Chalmers Greendale Laboratory. A cobalt foll, having a known disintegration rate, was used to calibrate the counting system. A sample of monttor wire and a foll 1dentical with the standard were Irradiated together in the CP-5 Reactor at Argonne. Th1s experiment was used to convert the monitor wire activ1ty into neutron 1rradiation.

Gamma spectra were measured for each of the samples. These were found to be 1dentical in the vicinity of the two cobalt-60 peaks ( 1.17 and $1.33 \mathrm{Mev})$ and showed no interferring activity. They were measured with a single channel pulse helght analyzer using a sodium lodide crystal detector. The actual counting was performed with the amplifler gain and analyzer baseline settings such that the $1.17 \mathrm{Mev}$ line was covered with a six volt window. This gave little drift. The samples were counted for short perlods w1th frequent repetitions in order to detect any drift. Data was taken for perlods of several hours w1th no more than 1.5 per cent change in counting rates for repeated samples. When more drift than this occurred during a counting series, the data were discarded and the set was repeated.

The monitor wires were cut into sections one-half inch long for counting. Th1s gave thirteen sections per wire. All sections of all twelve wires were counted relative to one specific section. Th1s one section was interspersed 
between samples of a single wire so that 1 t was counted at least flve times w1th each wire. Each sample was counted twice for one minute at counting rates of over 50,000 counts per minute. The counts for each sample were corrected for dead time and background. They were then welght normalized and referenced to the repeated section. The 1rradiation for each section of the four wires from sample number three 1s shown in figure 9.12. The values utilize the absolute result for the measurement of the repeated section which 18 described below. The flux corresponds to a Maxwellian distribution at $k T=0.0253 \mathrm{ev}$. An unperturbed curve is also shown. Th1s was formed by applying an integrated axial distribution for the sample's location from an earlier MTR cycle to the est1mated maximum unperturbed irradiation for the actual cycle. The axial distribution, estimated irradiation, and cadmlum ratio for a cobalt detector were supplied by PhIllips Petroleum Company. The consistency of the results, as seen in the r1gure, is very good.

The reference section, the standard foll, and the wire and foll irradlated together were then counted in the same geometry. Substantially different activity levels had to be accomodated. The monltor wire had an expected disintegration rate per half inch of about 100 times that of the standard f011. The reference foll contalned about 0.1 grams of cobalt while the monitor wire was specifled at only about $3 \times 10^{-6}$ grams per 1nch. A specimen of wire eight Inches long was spiraled to form a disk one layer th1ck and 
a little more than one-half inch in diameter. Th1s was cemented to the reference foll which had the same diameter. When Irradiated together they would have act1vity levels differing by a factor of about 4000 . The integrated flux was selected so that the activity range of these samples brackated that of the standard foll and monitor wire. Th1s limited the span of counting rates to the factor of 4000 determined above. When the samples were counted, it was found that the wire had a cobalt concentration nearly four times that specified. This reduced the range to about 1000 , although 1t made the monltor w1res somewhat "hotter" to handle than anticipated. A summary of these samples and measured counting rates is given in table 9.4. The count1ng rates were corrected for dead time and background. The minimum total counts for any sample exceeded 10,000.

The standard foll had a speclfied disintegration rate which, when corrected for decay to the date of counting, was $1.005 \times 10^{5} \mathrm{~d} 18 . / \mathrm{mln}$. The matched fo1l, irradiated in the CP-5, then had $(100,985 / 118.5)\left(1.005 \times 10^{5} / 60\right)=1.428 \times 10^{6}$. The number of cobalt atoms in this foll are $(0.1023 / 58.94)$ $\left(0.6023 \times 10^{24}\right)=1.045 \times 10^{21}$. Cobalt -60 has a half ilfo of 5.27 years which ylelds a decay constant of $0.417 \times 10^{-8}$ sec. $^{-1}$. Then, since the time between 1rradiation and countIng was negligibly short, the ratio of activated to inftial cobalt atoms was $\left(1.428 \times 10^{6} / 1.045 \times 10^{21}\right)\left(0.417 \times 10^{-8}\right)^{-1}$ $=3.277 \times 10^{-7}$. Attributing all activation to thermal neutrons, this equals $6 \phi t$. At room temperature, the capture 
TABLE 9.4

CALIBRATION OF FLUX MONITOR WIRE

\begin{tabular}{|c|c|c|c|c|c|}
\hline $\begin{array}{l}\text { Sample } \\
\text { No. }\end{array}$ & Description & Irradiation & $\begin{array}{l}\text { Welght } \\
(\mathrm{gm})\end{array}$ & $\frac{\text { Counting rat }}{\text { Geometry } 1}$ & $\frac{\operatorname{te}\left(\operatorname{mln},^{-1}\right)}{\text { Geometry }}$ \\
\hline 1 & $\begin{array}{l}\text { Standard Co } \\
\text { Fo11 }\end{array}$ & None & 0.1102 & 118.5 & 1259 \\
\hline 2 & $\begin{array}{l}\text { Co Foll } \\
\text { matched with } \\
\text { standard }\end{array}$ & $C P-5$ & 0.1023 & 100,985 & 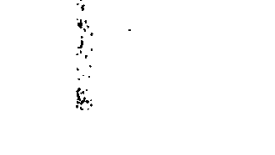 \\
\hline 3 & $\begin{array}{l}\text { Sample of } \\
\text { Co-Al mondtor } \\
\text { wire. }\end{array}$ & $\begin{array}{l}C P-5 \\
\left(\text { same } \varphi_{t}\right. \\
\text { as 2) }\end{array}$ & 0.2406 & & 936 \\
\hline 4 & $\begin{array}{l}\text { Repeated } \\
\text { section of } \\
\text { Co-Al monitor } \\
\text { wire }\end{array}$ & MTR & 0.0150 & 31,070 & \\
\hline
\end{tabular}

cross section of cobalt is $(\sqrt{\pi} / 2) 37=32.8$ barns. Thus the CP-5 1rradiation was $\left(3.277 \times 10^{-7}\right)\left(32.8 \times 10^{-24}\right)=10^{16}$. This $1 \mathrm{~s}$ also the 1rradiation for the monitor wire sample number 3. Since both the $C P-5$ and MTR 1rradiations were: performed in reflector locations and the cadmium ratio of cobalt at the MTR location was 30, it was assumed that the cadmium ratio was the same for both samples. Thus no ep1thermal component was calculated for elther case. The irradiation of the monltor wire sample number 4 then 13 $(31,070 / 118.5)(1259 / 936)(0.2406 / 0.0150) 10^{16}=5.65 \times 10^{19}$.

The Irradiation of all other wire sections was calculated by welght normalization of the observed counting rates to 
that of this repeated section.

The flux at the surface of each axlal section of the Irradiated sample was taken to be the average of the values measured for the four corresponding wire sections. The volume average flux in the sample was obtalned by multiplying this value by the sample self-shielding factor. For a scattering and absorbing material, the self-shielding factor, according to reference (14) 18 :

$$
f=\frac{f_{0}}{1-\left(1-f_{0}\right) P_{s}}
$$

where: fo is the self-shielding factor for pure absorption, and

$P_{s}$ is the ratio of scattering to total cross sections in the sample.

The self-shlelding factor fo was taken as the complement of the collision probability for infinite cylinders tabulated in reference ( 1 ).

The sample slze and absorption were selected so that this correction would not be large. The self-shielding factors for samples number 21 and 28 were calculated at the beginning and end of lrradiation by using the measured absorption cross sections for the identical (unirradiated) and actual sample, respectively. Due to the small difference obtalned, the average of these two values was used. Table 9.5 shows the calculation of the self-shlelding factors for samples number 21 and 28. The unlrradiated values correspond 
to samples number 23 and 30 . The measured sample absorption from table 9.3 was used with a sample volume of $45.34 \mathrm{~cm}^{2}$ to calculate the macroscopic absorption cross section.

TABLE 9.5

SELF-SHIELDING OF IRRADIATED SAMPLES

\begin{tabular}{ccccc}
\hline $\begin{array}{c}\text { Sample } \\
\text { No. }\end{array}$ & $\begin{array}{c}\sum_{a}^{\prime} \\
\left(\mathrm{cm}^{-1}\right)\end{array}$ & fo & $\mathrm{f}$ & Average $\mathbf{f}$ \\
\hline 23 & 0.149 & 0.684 & 0.831 & \\
21 & 0.0889 & 0.729 & 0.893 & 0.862 \\
30 & 0.123 & 0.702 & 0.857 & \\
28 & 0.104 & 0.716 & 0.877 & 0.867 \\
\hline \hline
\end{tabular}

Due to the rapid depletion of the unshielded gadolinium In sample number 3, the self-shlelding decreased rapldiy during the early stages of 1rradiation. A numerical integration was performed for the gadolinium burnup in each of the eleven sections of the sample, taking into account the change in the self-shielding facto: and spectral hardening in the sample. Table 9.6 gives th- …srage integrated flux on the surface and in the volume of the samples. The end sections of wirc are not incl... 
TABLE 2.6

SAMPLE IRRADIATION*

\begin{tabular}{cccccc}
\hline $\begin{array}{c}\text { Wire } \\
\text { No. }\end{array}$ & $\begin{array}{l}\text { Sample No: } \\
\text { Irradiation: }\end{array}$ & Surface $^{3}$ & Volume & $\begin{array}{c}21 \\
\text { Surface }\end{array}$ & $\begin{array}{c}28 \\
\text { Surface }\end{array}$ \\
\hline 1 & 5.650 & 5.425 & 6.930 & 5.320 \\
2 & 5.816 & 5.588 & 6.875 & 5.250 \\
3 & 6.070 & 5.842 & 7.009 & 5.295 \\
4 & 6.227 & 5.998 & 7.080 & 5.272 \\
5 & 6.440 & 6.208 & 7.140 & 5.427 \\
6 & 6.555 & 6.323 & 7.197 & 5.594 \\
7 & 6.605 & 6.372 & 7.159 & 5.815 \\
8 & 6.637 & 6.403 & 7.220 & 5.909 \\
9 & 6.768 & 6.533 & 7.306 & 6.002 \\
10 & 6.801 & 6.568 & 7.427 & 6.130 \\
11 & 6.796 & 6.562 & 7.790 & 6.409 \\
Surface Average & & & 7.194 & 5.675 \\
Volume Average & & 6.166 & 6.201 & 4.977 \\
\hline
\end{tabular}

* All entries are in units of $\phi t \times 10^{-19}$.

\subsection{Results}

\section{Gadolintum Cross Section}

Samples number 4 and 8 were used to obtaln a measurement of the gadolinium absorption cross section. Since these samples were used together for normalization, only 
one sample need be evaluated. The pertinent data for sample number 4 are listed below:

$$
\begin{array}{ll}
\text { welght of } \mathrm{Gd}_{2} \mathrm{O}_{3} \text { ('Table } 3.1 \text { ) } & 0.0848 \mathrm{gm} \cdot \\
\text { number of Gd atoms } & 2.82 \times 10^{20} \\
\begin{array}{l}
\text { effectlve thermal cross section } \\
\text { (Table 9.3) }
\end{array} & 9.05 \mathrm{~cm}^{2} \\
\begin{array}{l}
\text { microscop1c absorption cross } \\
\text { section for Gd }
\end{array} & 3.21 \times 10^{4} \text { barns }
\end{array}
$$

Th1s compares very well w1th the calculated value of 32,800 barns given in table 6.1 .

The major factors contributing to uncertainty in the experimental result are summarized below. The contribution from each is expressed as a percentage of the measured microscoplc absorption cross section of gadolinium. Contributions of less than 0.1 per cent are listed as negliglble. Although many of the uncertainties are estimated, they w1ll be taken to represent standard deviations.

Reactiv1ty Measurement of Samples: 19

The reactivity of sample number 4 depends upon the measurements of the dummy, sample number 1; the gold standard, sample number 37 ; and sample number 4 1tself. Since each result is subtracted from that of the dummy, any Inaccuracy in the dumny's result w111 only contribute as a second-order effect. Th1s w111 make a negligible contribution. For small values, the final uncertalnty w1ll be approximately proportional to those of samples number 4 and 37 . The factors contributing to this effect are: the reactivity of the 
reactor at the time of the individual measurement, including the position of control rods, the xenon content and temperature effects, the reproduction of sample position, the counting and timing uncertalnties of the measurement, the fitting of the measured values with a period, any difference between the measured and asymptotic periods, and conversion of period into reactivity. The efforts made to reduce these uncertaintles were alscussed under experiment design and data reduction. The standard deviations listed in table 9.2 only represent the departure in fitting the measured polnts with an exponential. This will represent a lower limit to the uncertalnty. For samples number 4 and 37, th1s represents less than 0.5 per cent. A composite of all of the above effects can be estimated by observing the reproduction of the measurements of repeated samples. This yields less than $\pm 3 \mu \mathrm{k}$ in the individual reactivity values and less than one per cent for the final reactivity determination of sample number 4. Cross Section of Gold Standard: $3 \%$ Since the $2200 \mathrm{~meter} / \mathrm{sec}$. cross section of gold is taken as a standard, no inaccuracy is assigned to 1t. The amount of gold in the sample and 1ts homogene1ty was measured before and after the experiments and found to contribute a negligible uncertainty. The cadmium ratio measurement for gold was estimated to 
be accurate to within five per cent for the epithermal component which is less than one per cent for the thermal component. The rlux depression into the gold foll was estimated to be accurate to within ten per cent which gives about two per cent uncertainty in the effective thermil cross sect1on. The sum of these effects is three per cent. Uncertainty in Sample Loading: 18

As discussed above, there was no signiflcant uncertalnty in the loading of the gold standard. The gadolinta loading for sample number 4 was weighed to about 0.1 per cent. Care was taken to load all of this material into the sample. Several hours mixing with the alumina was performed to insure homogeneity. The material was heuted to drive off any adsorbed water before welghing. A summary of the loading of all materlals was kept to provide a correction factor In the event of significant differences in the alumina or aluminum content. The differences were negligible for all measurements except the residue determination. Rerlecting the care taken in sample preparation, an uncertainty of one per cent is assigned to the effective gadolinium loading.

Macroscopic Self-Shlelding: 1\%

The correction for the flux depression into the sample is applied to all samples so that only differences are significunt. The uncertainty in this factor 
is reauced by the normalization to the results of simples number 4 and 8 . The effect is estimated to be less than one per cent.

Combining all of these effects lineurly, which is conservative, gives an uncertalnty of 6\%. This gives $3.21 \pm$ $0.19 \times 10^{4}$ for the measured absorption cross section of gadolinium.

Gadol1nium Resldue

Sample number 11 was loaded with exactly one per cent of the gadolinia of the 1rradiated sample, number 3 . The determination of the residue was made in terms of these two samples. The reactivity values of samples number 3 and 11 were 41.8 and $21.7 \mu \mathrm{k}$, respectively. The ratlo of samples 3 to 11 is 1.92. This was corrected to account for small differences in alumina and aluminum content to 1.81. Th1s ylelds a final microscopic cross section of 594 barns. The corresponding average lrradiation, from table 9.6 , is 6.17 $x 10^{19}$. This point is shown on figure 9.4 .

The amount of gadolinium-155 remaining in the 1rradiated sample was calculated for each of the eleven sections and averaged to obtain an effective cross section of 490 barns. Attributing all of the difference to gadolinium-156, now with an 1sotoplc abundance of 35 per cent, gives 297 barns for its cross section.

The estimated uncertainties, expressed as barns in the gadolinium-156 cross section, are given below. 
Reuctivity Meusurement of Gurmples: 242 burns

The reactivioy measurements are estinated to be within $\pm 10 \%$ for samples number 3 and 11 . These conbine to give $\pm 14 \%$ for the ratio of these results. Subtracting the facolinium $155^{\circ}$ content of sample number 3 , gives an uncertainty of 242 barns in the gadol1nịuri-156 cross section. Uncertainty in Surrole jouding: 87 barns

The smaller gadolinfa content of sample number 11 required that more than a single sample loading be welghed, mixed with alunina, and a proportionate part used for the sample. An uncertainty of $5 \%$ is assigned to the gadolinium loading in this sample. This ylelds 87 barns in the uncertainty of the gudolinium-156 cross section. Macroscoplc.Self-Shielding: Negligible

The difference in the thermal absorption cross sections of samples number 3 and 11, less than 0.001 $\mathrm{cm}^{-1}$, makes an insignificant contribution to selfshielding.

Sample Irradiation: $+154,-180$ barns

The major uncertalnty in the determination of the sample Irradiation 1 s the $3.2 \%$ limit on the disintegration rate of the standard cobalt foll. Adding the effects of uncertainties in the counting and cobult cross section gave an uncertianty of five per cent in the 
1rradiation. This is $6.17 \pm 0.31 \times 10^{19}$. In terms of the gadolinium-155 remaining, these limits give +154 and -180 barns as the uncertainty in the gadolinium156 cross section.

Combining all of these results gives a standard deviation for this measurement of about 300 barns. Thus the gadolinlum-156 cross section was determined to be $300 \pm 300$ barns. Effect1ve Cross Sections for Gadolintum D18ks

The number of gadolinium atoms, corresponding to the loading given in table 9.1, in each of the samples containIng gadolinium disks is given in table 9.7. The unshielded cross section, corresponding to a microscoplc value of 32,800 barns, 1s also shown. The measured effective cross section from table 9.318 given. The ratio of measured to unshielded cross sections is then the self-shlelding factor and given in the last column. These values were compared w1th calculations in table 7.4 .

The uncertainty in these values will be the same as that of the gadolinium cross section measurement, excluding the effect of uncertainty in the sample loading. Since the gadolinium was separated and weighed after the experiments, the exact amount used was determined. This leaves $\pm 5 \%$ ав the uncertainty in the measurement of the effective cross section and hence self-shlelding factor. 
TABLE 9.7

SELF-SHIELDING OF GADOLINIUM DISKS

\begin{tabular}{ccccc}
\hline $\begin{array}{c}\text { Sample } \\
\text { No. }\end{array}$ & $\begin{array}{c}\text { No. of } \\
\text { Gd atoms }\end{array}$ & $\begin{array}{c}\text { Unshielded } \\
\text { cross section }\end{array}$ & $\begin{array}{c}\text { Measured } \\
\text { cross section }\end{array}$ & f \\
\hline 24 & $0.6922 \times 10^{21}$ & $22.70 \mathrm{~cm}^{2}$ & $3.91 \mathrm{~cm}^{2}$ & 0.172 \\
25 & 0.6438 & 21.12 & 3.77 & 0.178 \\
26 & 1.204 & 39.49 & 4.48 & 0.113 \\
27 & 1.269 & 41.62 & 4.70 & 0.113 \\
30 & 3.161 & 103.7 & 5.57 & 0.0537 \\
32 & 1.623 & 53.30 & 2.78 & 0.0522 \\
34 & 4.561 & 149.6 & 6.74 & 0.0451 \\
35 & 4.280 & 140.4 & 5.36 & 0.0382 \\
36 & 2.538 & 83.25 & 4.39 & 0.0527 \\
\hline
\end{tabular}

Effective Cross Section of Irradiated D1sks

From table 9.3 the effective cross sections of the Irradiated disk sample, number 28, and the identical sample, number 30 , are 4.70 and 5.57 , respectively. The ratio is 0.844 . The 1rradiation of sample number 28 , from table 9.6 , $184.98 \times 10^{19}$. Th1s point is shown in figure 8.7 .

Since this result is the ratio of the measurement of two disk samples, the uncertainties due to the gold standard cancel out. Also, the reactivities are so nearly the same that the uncertalnty in the self-shlelding correction should be small. It is estimated that the rat1o 18 accurate 
to w1thin 1.5\%. The Irradiation w1ll again be accurate to w1thin five per cent.

Gadolinlad Particles

The lack of integrity of the gadolinia particles precluded any use of these measurements. Fortunately, they were not essential to the major conclusions. They were performed for the following reasonss

(1) to demonstrate method of fabrication of gadolinium containing bodies,

(2) to further substantiate the measured self-shlelding for gadolinium disks, and

(3) to show the rapid depletion characteristics of spheres.

Item (1) was emphat1cally not shown. Item (2) was unnecessary due to the very good results obtalned. Item (3) remalns unproved. 


\section{$-5-\infty-\infty-\infty-\infty-\infty-\infty-\infty-\infty$}

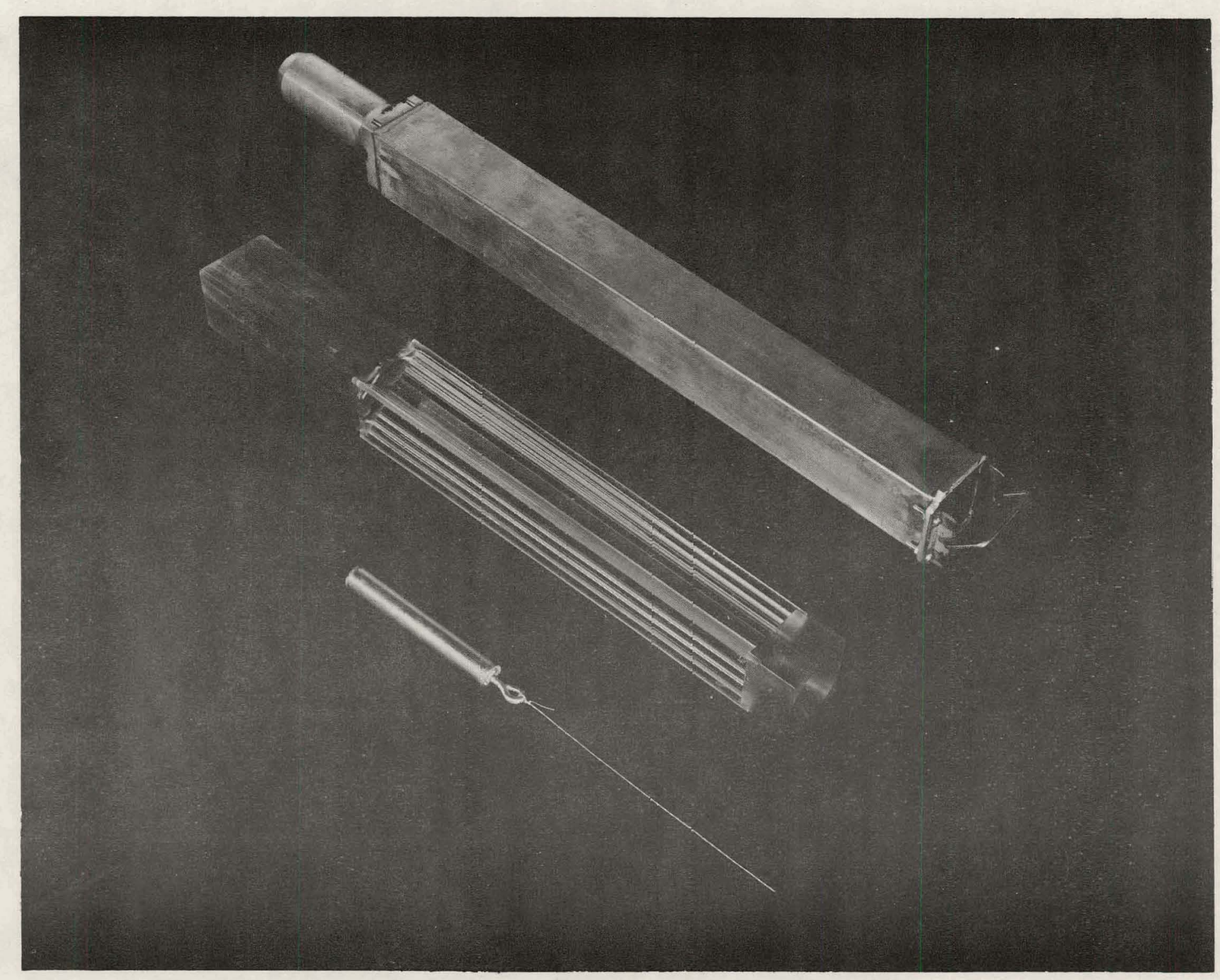

Figure 9.1 Test Assembly 


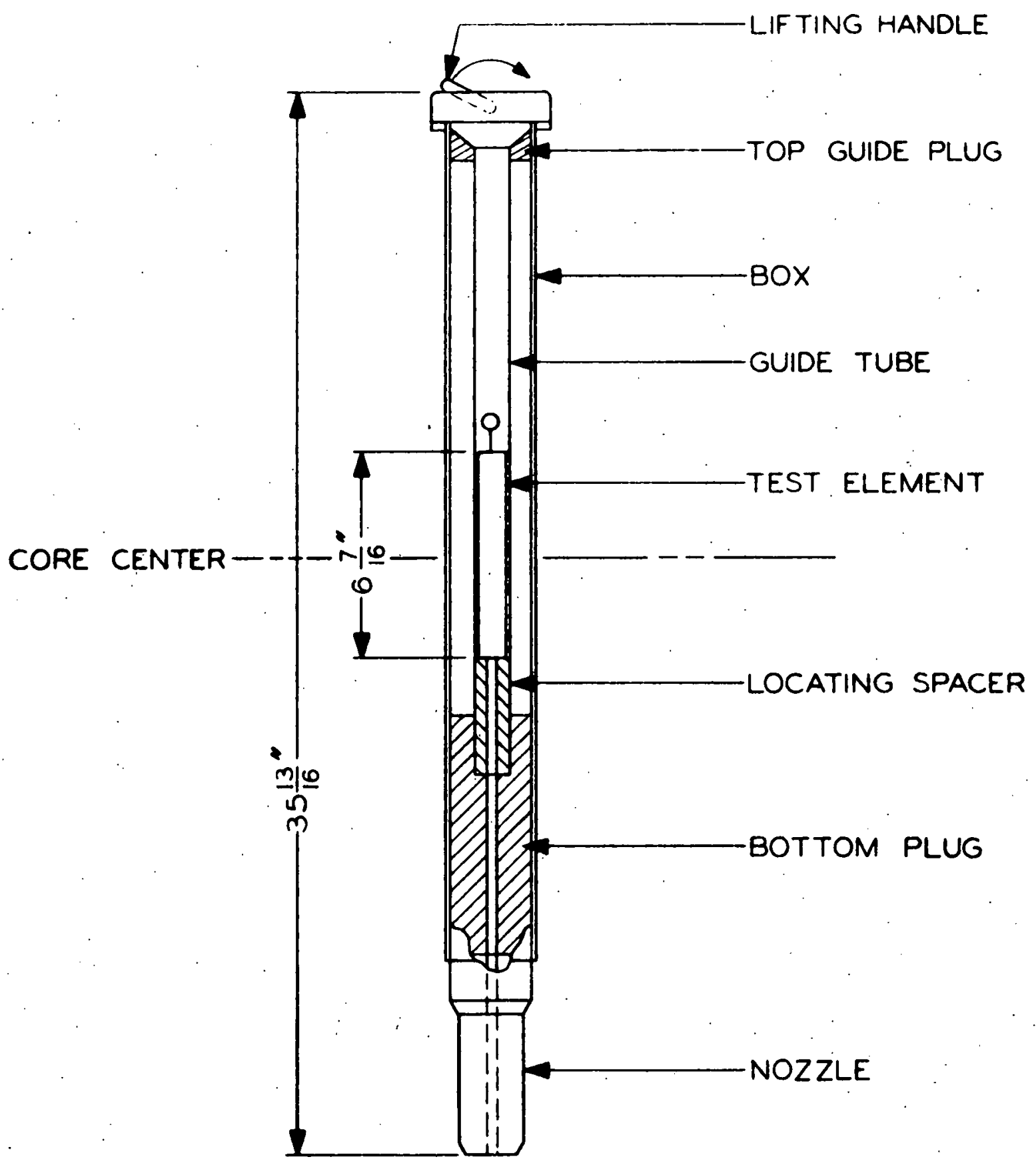

FIG. 9.2 TEST ASSEMBLY 


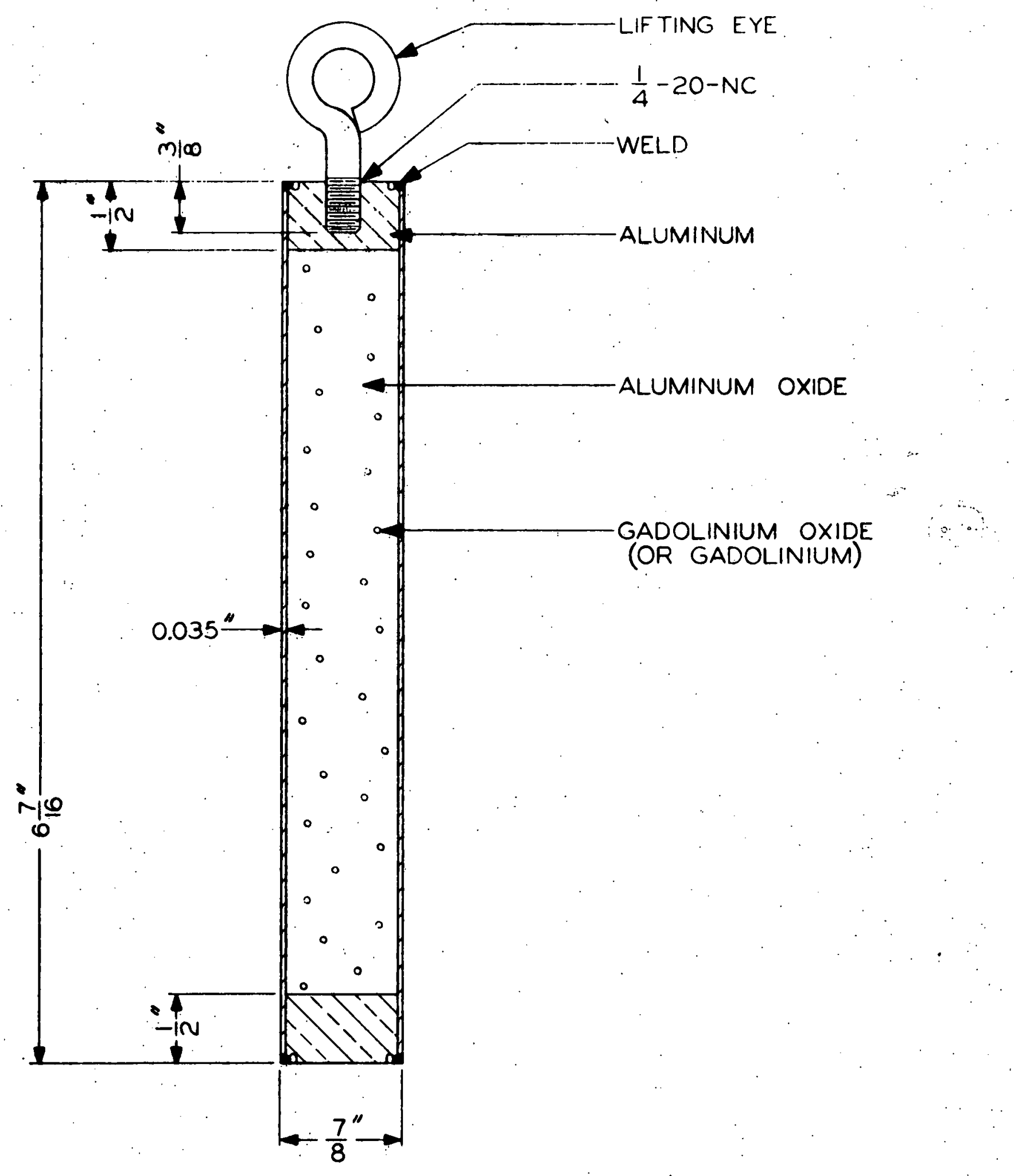

FIG. 9.3 TEST ELEMENT 


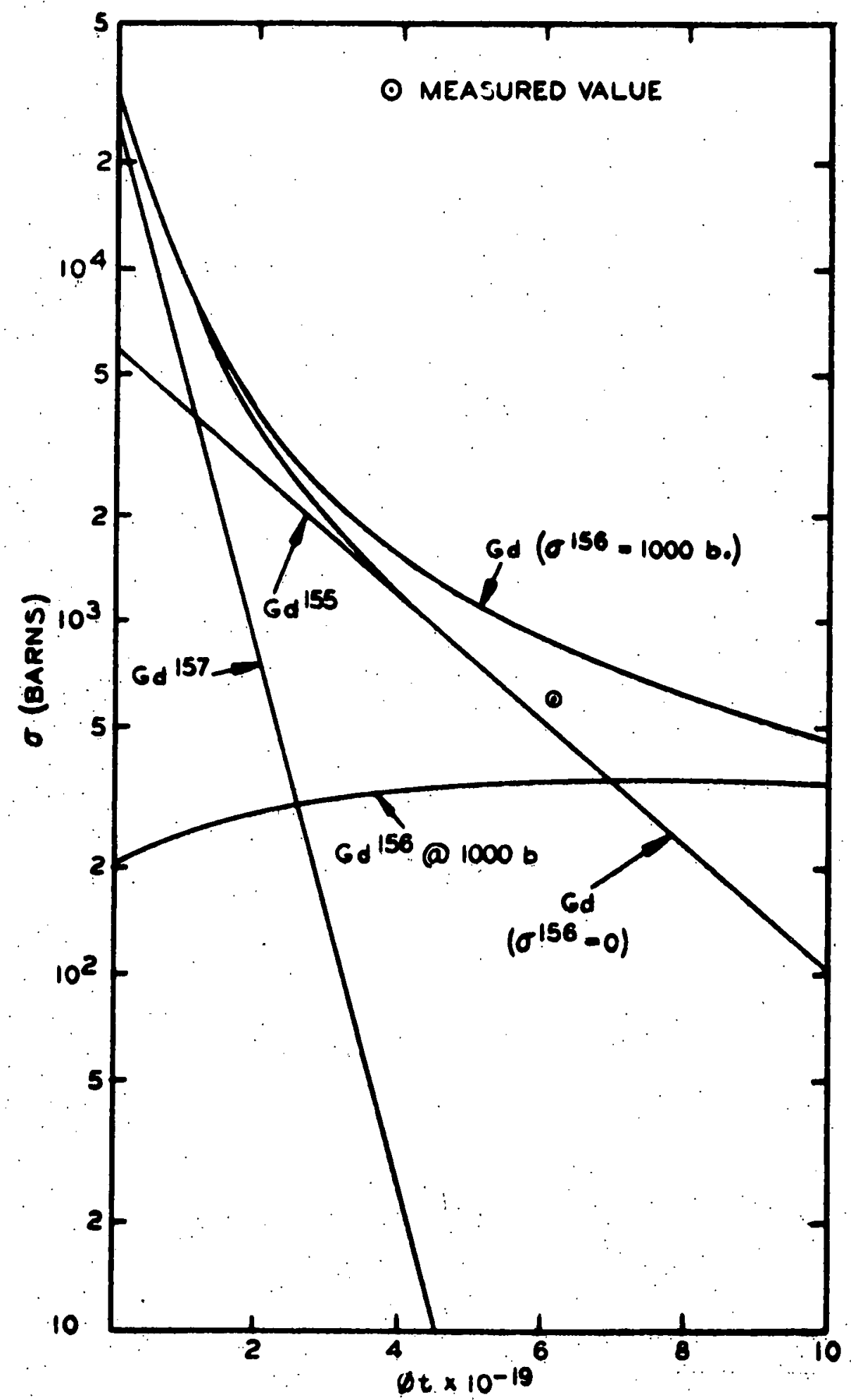

FIG 9.4 GADOLINIUM CROSS SECTIONS VS. IRRADIATION 


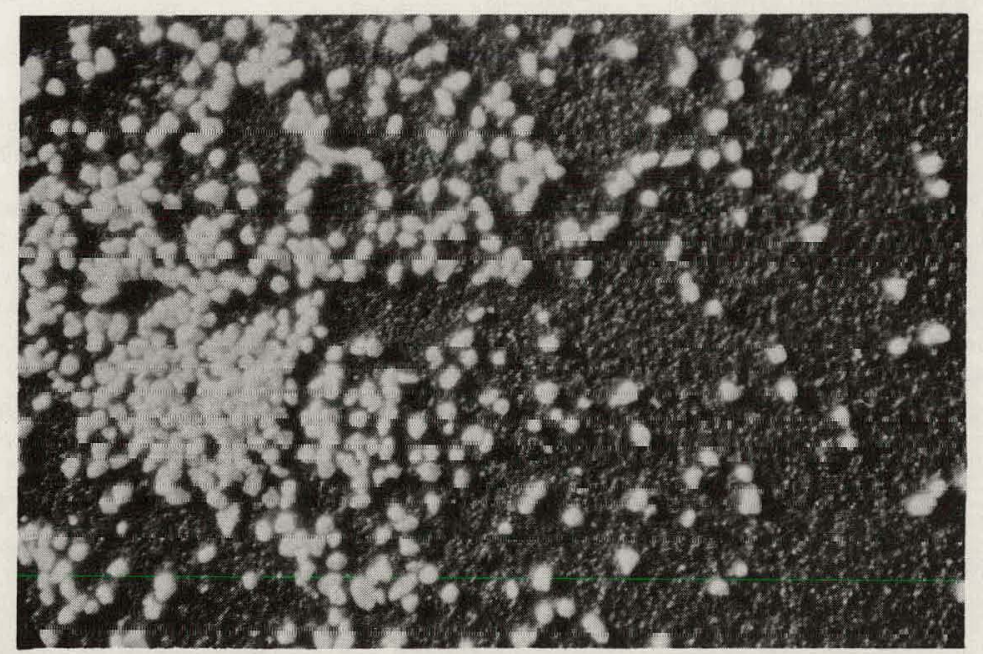

Size Range: 35 to 44 microns Magnification: 36 times

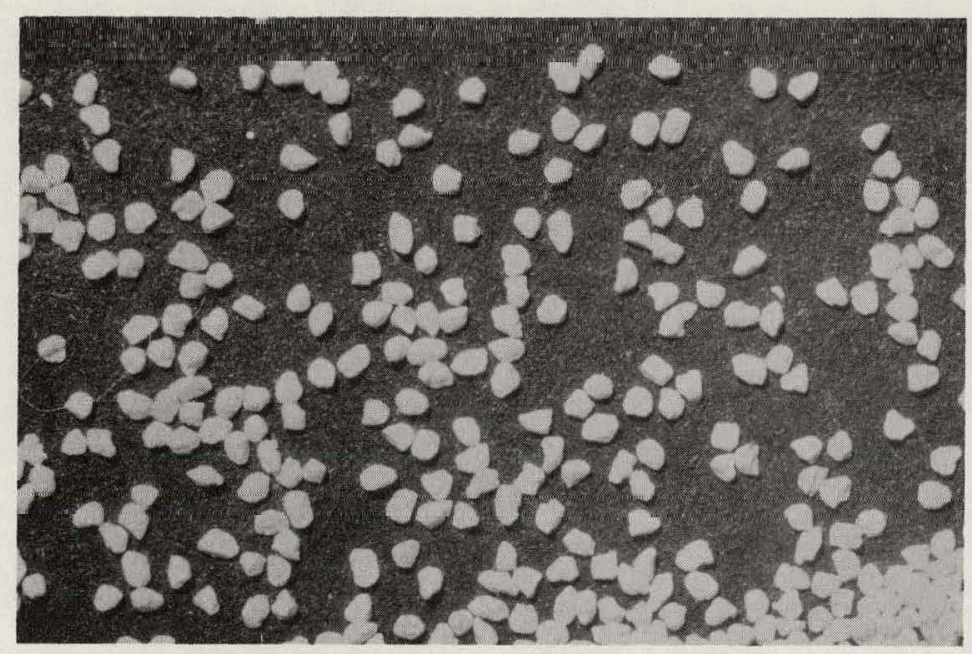

Size Range: 350 to 420 microns Magnification: 6.3 times 


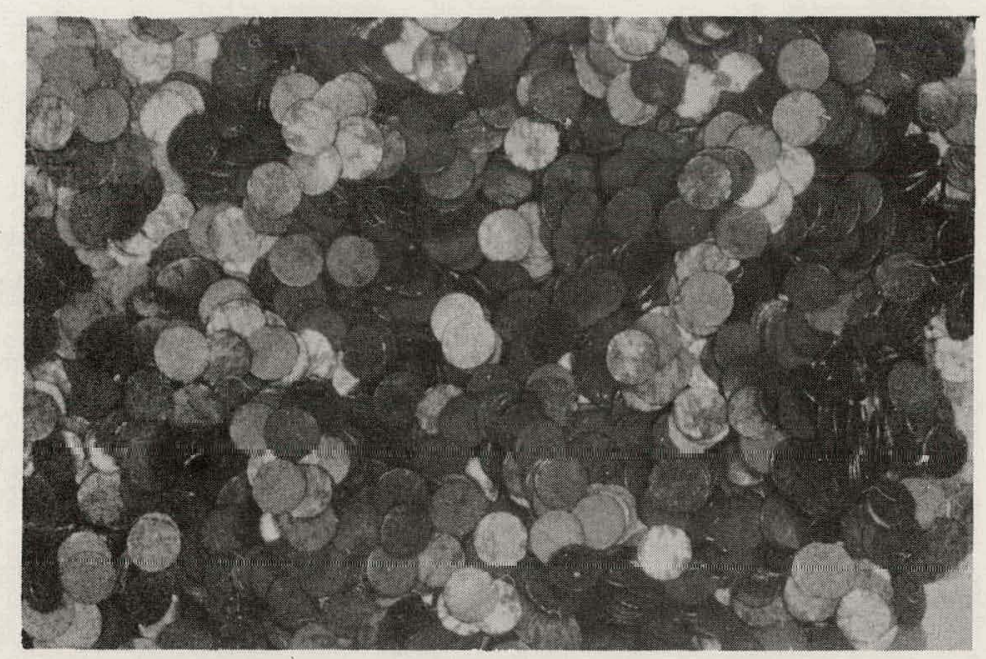

Nominal dimensions (inches):

diameter 0.025 , thickness 0.001

Magnification: 9.3 times

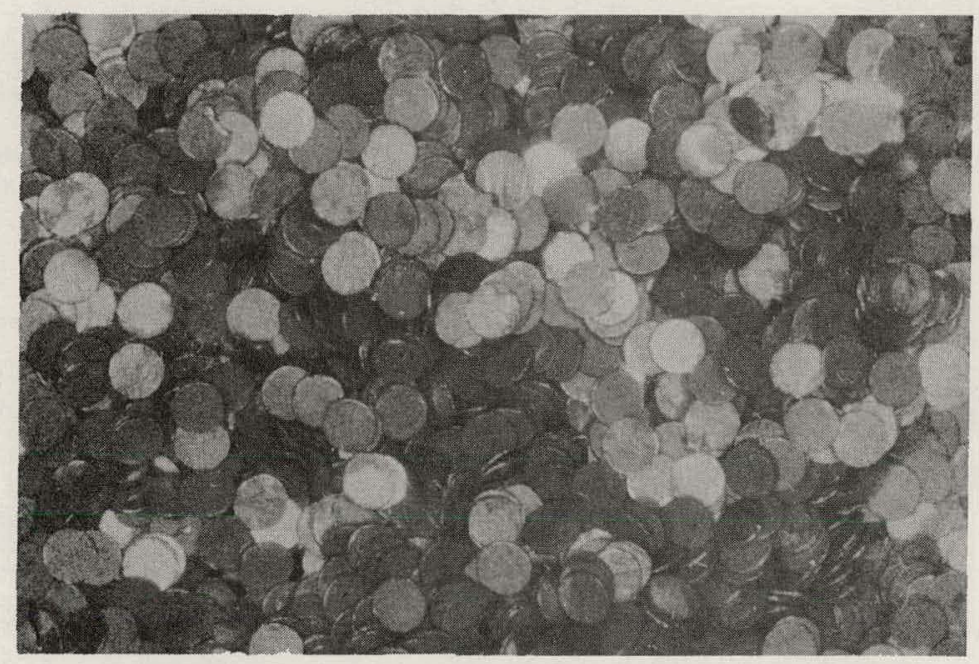

Nominal dimensions (inches):

diameter 0.025 , thickness 0.002

Magnification: 9.3 times

Fig. 9.6 Gadolinium Disks 


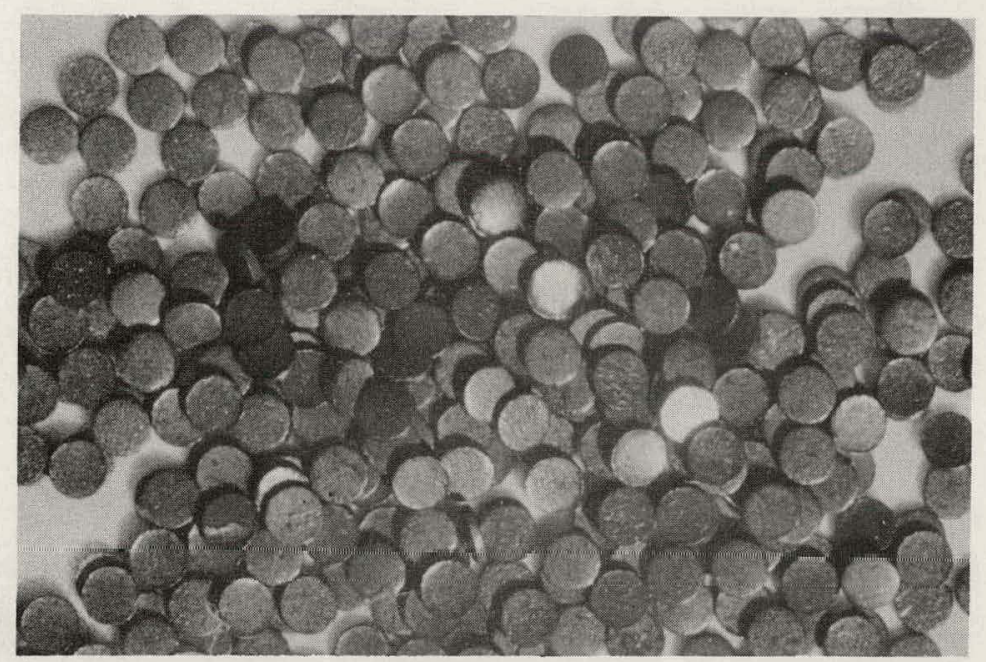

Nominal dimensions (inches):

diameter 0.025 , thickness 0.005

Magnification: 9.3 times

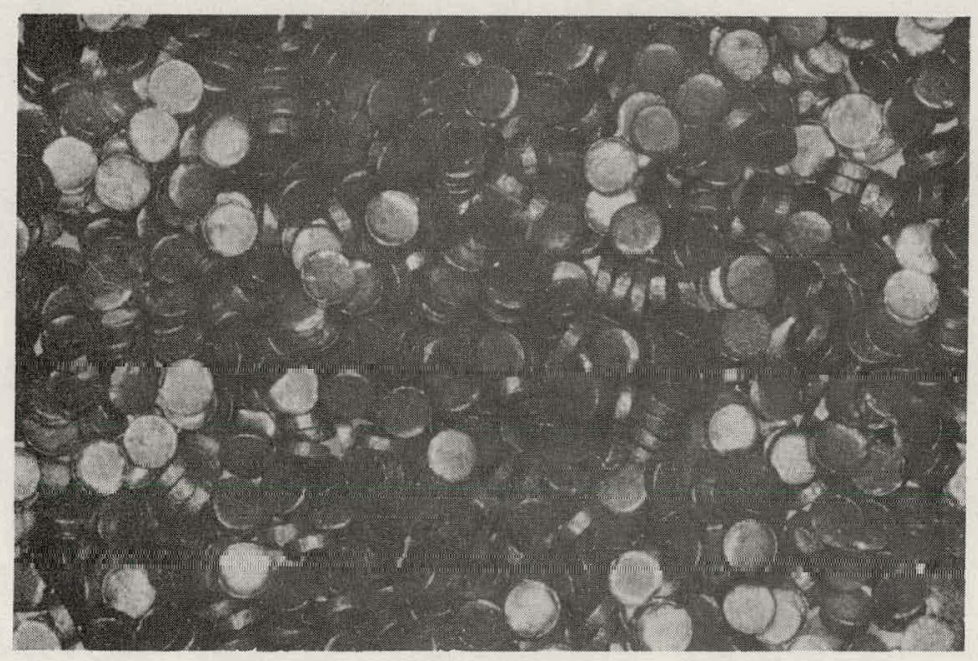

Nominal dimensions (inches):

diameter 0.025, thickness 0.007

Magnification: 9.3 times

Fig. 9.7 Gadolinium Disks 


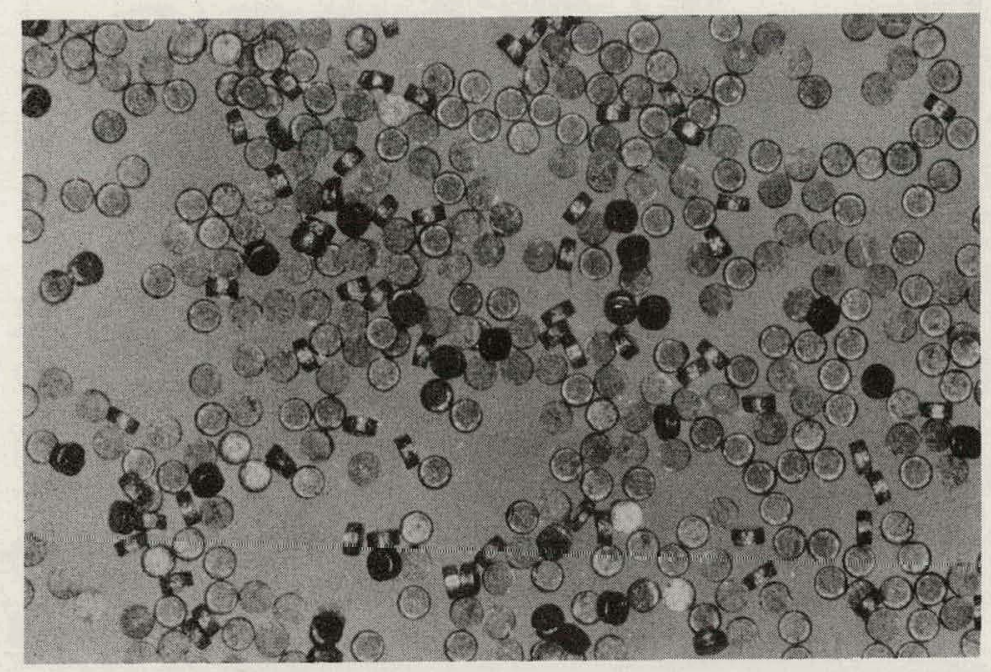

Nominal dimensions (inches):

diameter 0.015 , thickness 0.007

Magnification: 9.3 times

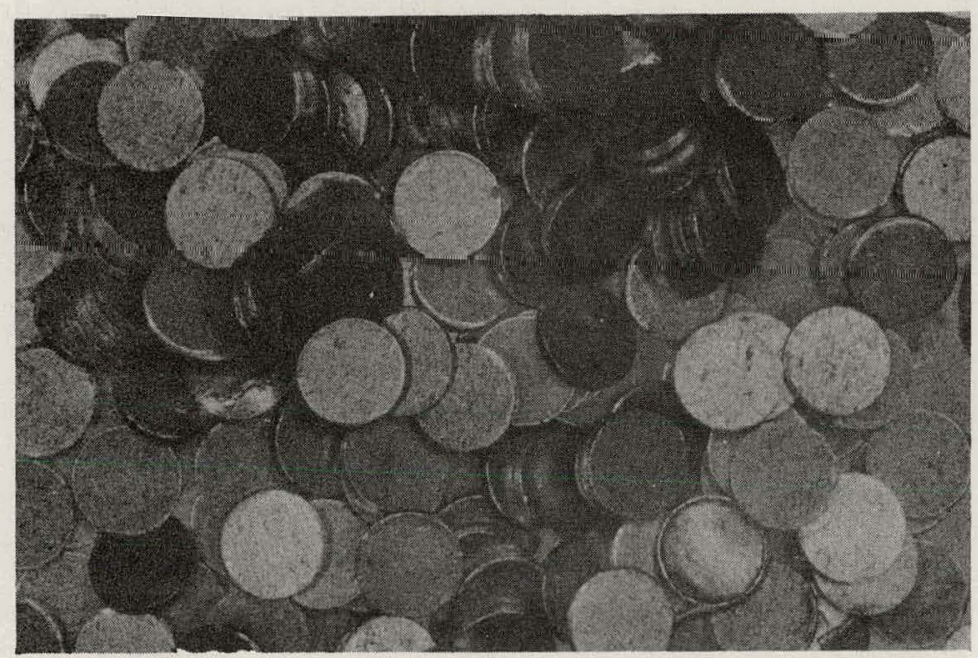

Nominal dimensions (inches):

diameter 0.050 , thickness 0.007

Magnification: 9.3 times

Fig. 9.8 Gadolinium Disks 


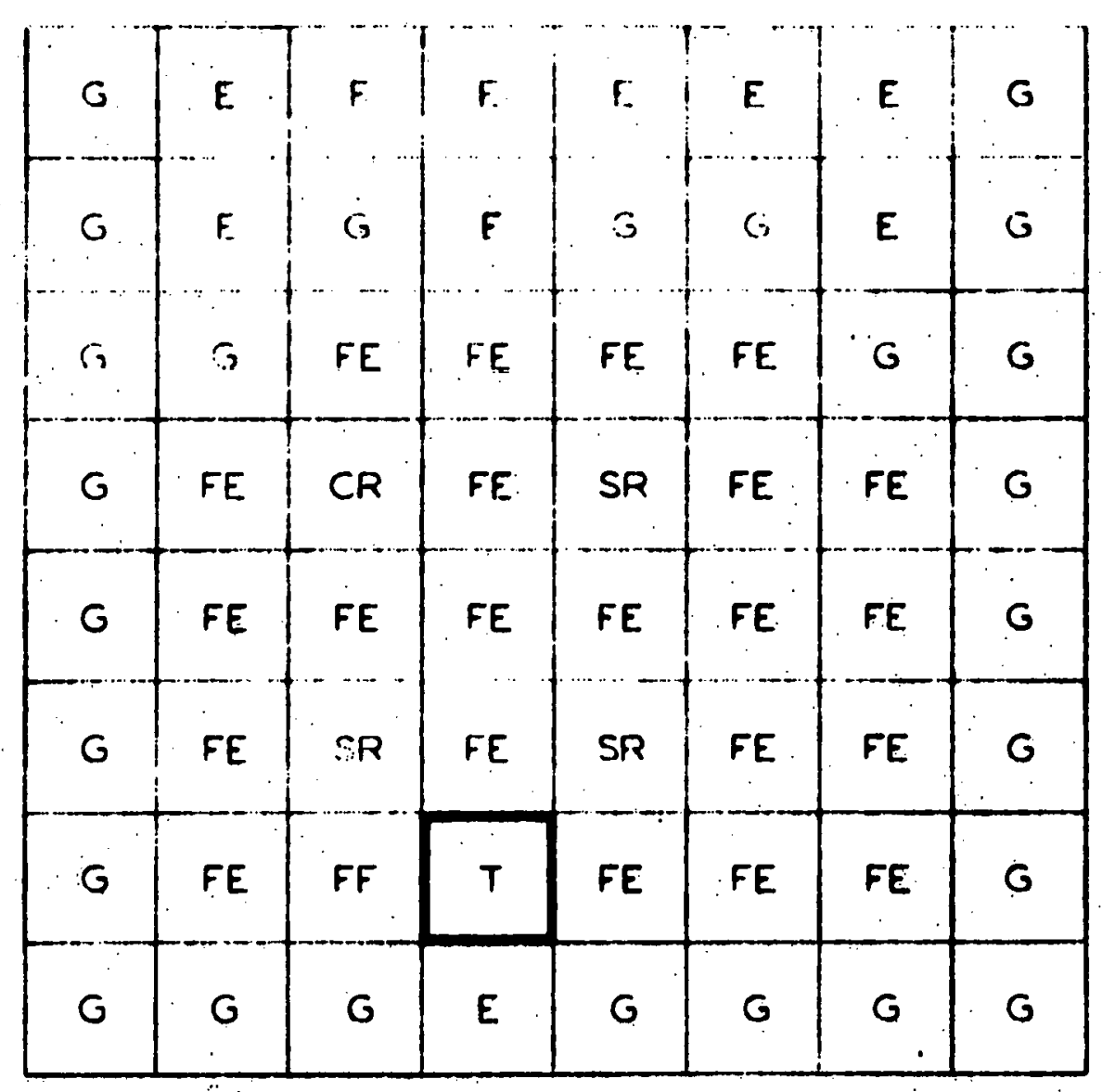

FE FUEL ELEMENT

SR SAFETY ROD

CR CONTROL ROD

$G$ GRAPHITE REFLECTOR

ELEMENT

E EMPTY LOCATION-WATER

$T$ TEST ASSEMBLY 


\begin{tabular}{|c|c|c|c|c|c|c|c|}
\hline$G$ & $E$ & $E$ & $E$ & $E$ & $E$ & $E$ & $G$ \\
\hline$G$ & $E$ & $G$ & $E$ & $G$ & $G$ & $E$ & $G$ \\
\hline$G$ & $G$ & $F E$ & $F E$ & $F E$ & $F E$ & $G$ & $G$ \\
\hline$G$ & $F E$ & $C R$ & $F F$ & $S R$ & $F E$ & $G$ & $G$ \\
\hline$G$ & $F E$ & $F E$ & $F E$ & $F E$ & $F E$ & $F E$ & $G$ \\
\hline$G$ & $F E$ & $F E$ & $T$ & $F E$ & $F E$ & $F E$ & $G$ \\
\hline$G$ & $G$ & $G$ & $F E$ & $G$ & $G$ & $G$ & $G$ \\
\hline
\end{tabular}

FE FUEL ELEMENT

SR SAFETY ROD

CR CONTROL ROD

$G$ GRAPHITE REFLECTOR

E. EMPTY LOCATION-WATER

$T$ TEST ASSEMBLY

FIG. 9.10 CORE CONFIGURATION-PHASE II 


\section{1}

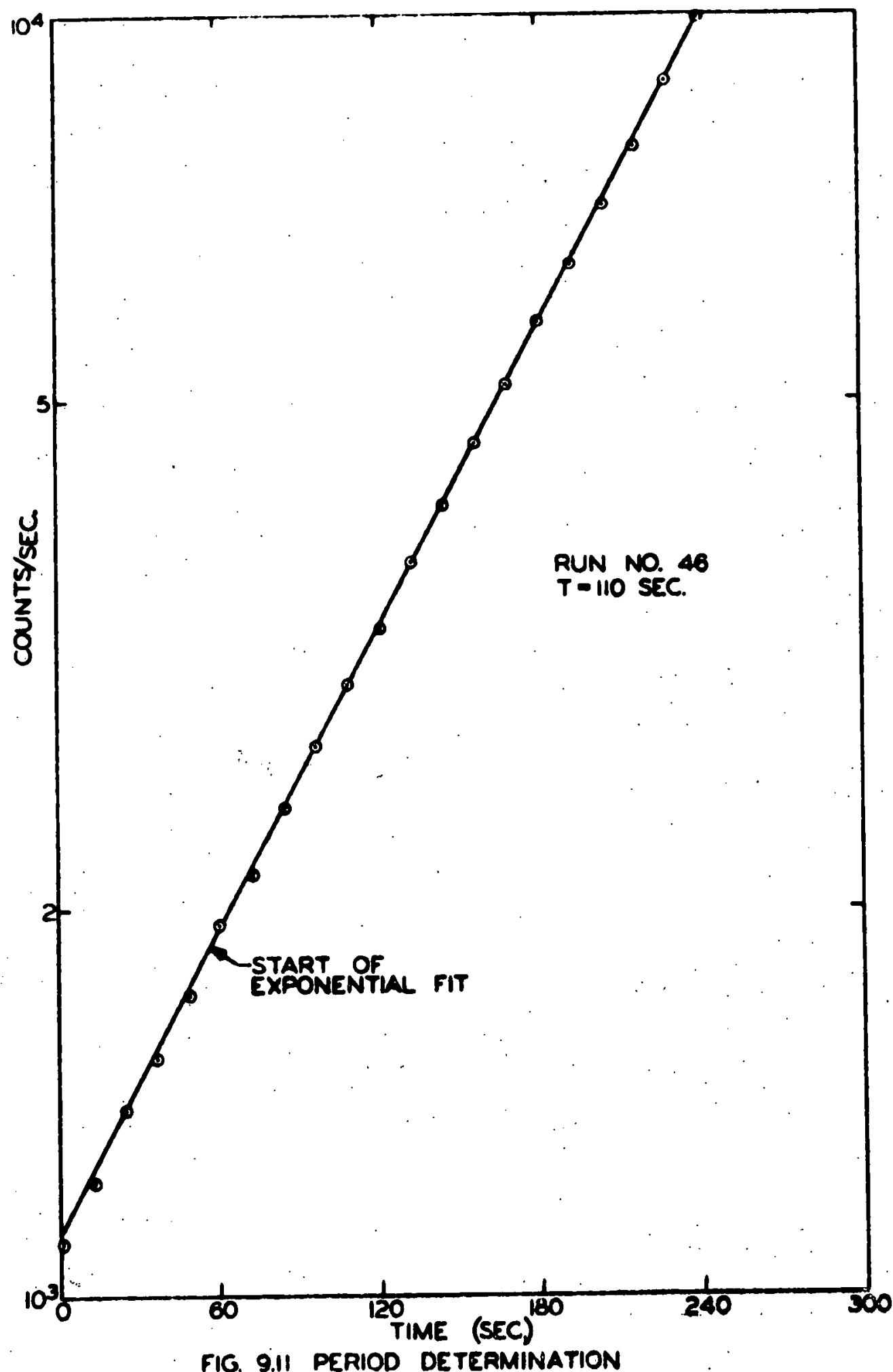




\section{CONCLUSIONS}

The general result of this study is that this new burnable polson concept should be useful for many thermal reactor designs. Specifically, the following generil conclusions can be made:

(1) The burnout behavior of highly self-shlelded, high cross section disks, as shown in figures 8.3 through 8.6 , cover a wide range of interest to reactor design. The single measurement, shown in figure 8.7 , is highly encouraging. However, additional experiments to substantiate the pred1cted burnout curves are recommended.

(2) The disk self-shlelding factor can be adequately calculated by the methods of Section 7 .

(3) The high oross section of gadolinium makes it an attractive material to use in this burnable po1son concept. The gadolinium residue, due to gadolinium-156, is sufflclently small so that this concept can be used in many applications. An additional experiment to limit the residue further is recommended.

(4) The temperature effects found in Section 6 11m1t the full matching of shim requirements with this 
burnable poison. However, the behavior of the temperature coefflclent might allow some compensation for the temperature defect. Th1s behavior itself might also be usefully exploited. 


\section{BIBLIOGRA PHY}

1. K. M. Case, F. DeHoffman, and G. Placzek, Introduction to the Theory of Neutron Diffusion, U.S. Government Printing Office, Washington, D.C. (1953).

2. C. H. Westcott, Effective Cross Section Values for Well-Moderated Thernal Reactor Spectra (3rd Ed. Corr.), CRRP-960, Chalk R1ver, Ontar1o (1960).

3. T. R. England and R. J. Eckert, A Generallzed Treatment of Fission Product Polsoning. Trans. Amer. Nuc. Soc. 4 , No. 2,321 (1961).

4. D. J. Hughes and R. B. Schwartz, Neutron Cross Sections, BNL-325, 2nd Ed1tion (July, 1958), and Supplement No. 1 (Jan., 1960).

5. V. B. Klimentov and V. M. Griazev, Some Neutron Resonance-Absorption Integrals, J. Nucl. Energy 2, 20 (1959).

6. R. L. MacKlin and H. S. Pomerance, Resonance Capture Integrals, Proc. Intern. Conf. Peaceful Uses Atom1c Energy, Geneva, 5, 96, New York (1955).

7. C. D. Hodgman, Handbook of Chem1stry and Phys1cs, 34 th Ed., Cleveland (1952).

8. F. H. Spedding and A. H. Danne, The Rare Earths, New York (1961). 
9. Rare Earths as Nuclear Po1sons, II, Lindsay Data Sheet (Aug., 1958).

10. H. B. Mфller, F. J. Shore, and V. L. Sallor, Low Energy Neutron Resonances in Erblum and Gadolinium, Nuclear Science and Eng. $\underline{8}, 183$ (1960).

11. J. L. Russe11, M. R. Carrothers, and W. V. Mosgovoy, Absorber Burnup Experiment Interim Report, GEAP-3617. (Jan., 1961).

12. L. Dressner, Comparison Theorems for the Estimation of Average Coll1sion Probab1lities, Nucl. Sc1. and Eng., 므, 63 (1959).

13. L. Dressner, Comparison Theorems for the Estimation of Averige Coll1sion Probabli1ties II, Nucl. Sc1. and Eng., 7, 260 (1960).

14. J. C. Stewart and P. F. Zwelfel, A Review of SelfShielding Effects in the Absorption of Neutrons, Proc. 2nd Intern. Conf. Peaceful Uses Atomic Energy, Geneva, P $631,16,650$ (1958).

15. Reactor Phys1cs Constants, ANL-5800, 485 (1958).

16. O. R. Keep1n, T. F. W1mett, and R. K. Z1egler, Delayed Neutrons from F18sionable Isotopes of Uranium, Plutonium, and Thorlum, Phys. Rev., 107, 1044 (1957).

17. S. Glasstine and M. C. Edlund, The Elements of Muclear Reactor Theory, Van Nostrand, New York (1952).

18. G. R. Dalton and R. K. Osborn, Flux Perturbations by Thermal Neutron Detectors, Nucl. Sc1. and Eng., 2, 198 (1961). 
19. H. Hurwitz, Jr., and P. F. Zweifel, Self-Shlelding of Luniped Po1son Mixtures, Nuc1. Sc1. and Eng., 1, 438 (1956).

20. W. R. Burrus, How Channeling between Chunks ra1ses Neutron Transmission through Boral, Nucleonics, 16, 91 (January, 1958).

21. W. B. Doub, Particle Self-Shlelding in Plates loaded W1th Spherical Po1son Particles, Nucl. Sc1. and Eng., 10, 299 (1961).

22. A. Radkowsky, Theory and Application of Burnable Po1sons, Proc. 2nd Intern. Conf. Peacerul Uses Atom1c Energy, Geneva, P/1900, 13 (1958).

23. a. C. Hanna, The Depression of Thermal Neutron Flux and Density by Absorb1ng Fo11s, Mucl. Sc1. and Eng., 11, 338 (1961).

24. R. H. Ritchie and H. B. Eldridge, Thermal Neutron Flux Depression by Absorb1ng Fo1ls, Nucl. Sc1. and Eng., 8 , 300 (1960).

25. J. R. Stehn, ed., Naval Reactors Physics Handbook, Vol. III, U.S. Gov. Printing Office, Washington, D.C.

26. A. M. Weinberg and E. P. Wigner, The Physical Theory of Neutron Chain Reactors, University of Ch1cago Press, Chicago (1958). 